\title{
PREACHING AND PRACTISING: \\ A RETROSPECTIVE EXPLORATION OF \\ GOALS AND INNOVATIVE DEVELOPMENTS \\ IN THE ADMINISTRATION OF \\ INTELLECTUAL PROPERTY RIGHTS
}

by

Ama Vivian Momoh

A thesis submitted to Victoria University of Wellington in fulfilment of the requirements for the degree of

Master of Commerce and Administration in Management

Victoria University of Wellington

2012 



\section{ACKNOWLEDGEMENTS}

'Not by might nor by power, but by My Spirit,' says the sovereign LoRD.

\section{-Zechariah 4:6}

My life and this thesis experience is evidence that the above statement is true. Jesus Christ is the reason I stayed committed throughout the prolonged process, and I thank the Lord God for loving me unconditionally and giving me the perfect eternity -with Him.

For Francess Rutland (mum) whose pressure and persuasion caused me to begin the Master's Thesis program, and whose continuous love and support has made a world of difference in ALL my endeavours.

In loving memory of Peter Rutland (dad), who is still my role model and the inspiration behind my determination to do things with excellence.

For Vicky Mabin in appreciation for her professional and personal contribution to this report, because of her on-point advice that elusive focus was maintained, and her decision NOT to micro-manage was ironically a very successful application of goal setting theory for complex tasks. Her friendship helped preserve my sanity.

For the managers and staff of the Intellectual Property Office of New Zealand, without whose vital participation and support, this study would not have been possible.

For my best friends, family, church family at Porirua Christian Life Centre and friends at the Faculty of Commerce and Administration, all your patience and encouragement was like water to the life of this work.

THANK YOU!!! 


\section{ABSTRACT}

The management of innovation is a common phrase in many conversations about modern business management. However, management innovation has comparatively less recognition despite claims that it is one of the key components to organisational development in the $21^{\text {st }}$ Century (Hamel, 2006). This study explores the generation and adoption of management innovation, within an organisation that administers legal rights for the commercialisation of innovation in New Zealand. The exploration focuses on the implementation of changes within Intellectual Property Office of New Zealand (IPONZ), seeking evidence of innovative changes in management. Identified management innovations are examined to uncover their functions and effects within the context of IPONZ's purpose, articulated through goal setting.

The study utilises case study methodology, borrowing from phenomenological methods to carry out an in-depth analysis of unfolding events at the organisation. Perceptions within the organisation and historical information were used to establish the occurrence of events. The organisation was examined holistically, with exploration including all areas of operation. Both primary and secondary data informs the research analysis and conclusions, guided by developments in previous innovation studies and literature on the use of goals. The prescribed Goal Setting Theory of Locke and Latham (1979) was examined to consider the effects goal setting has on performance.

It was found that at IPONZ, changes implemented were a direct result of the goals that were set. In a period of holistic transformation, some goals were set as the successful implementation of change initiatives. Findings point to implications that the manner in which goals are set affects the amount and nature of changes that are implemented. The highest number of changes and management innovations were introduced in periods where changes were part of official performance expectations. All management innovations found were contextually novel, and were closely linked to the introduction of a holistic transformation project. 


\section{LIST OF CONTENTS}

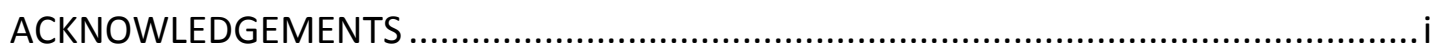

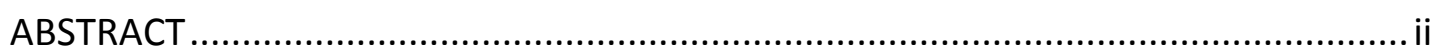

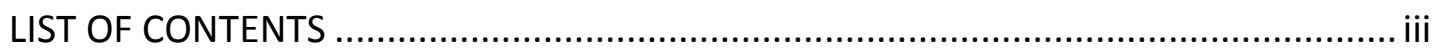

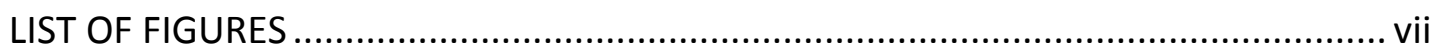

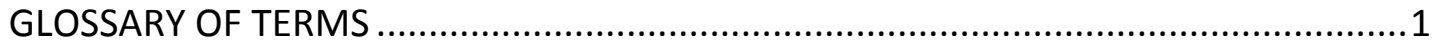

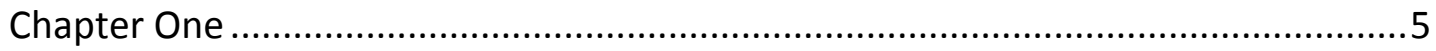

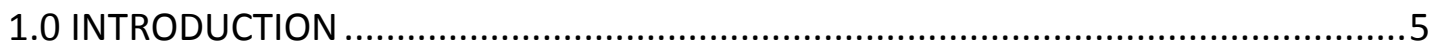

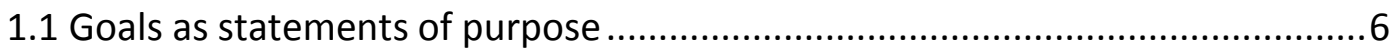

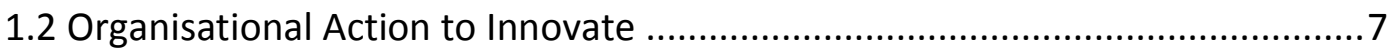

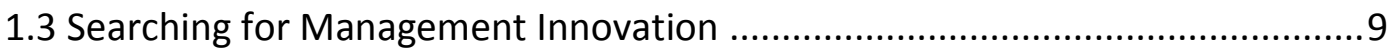

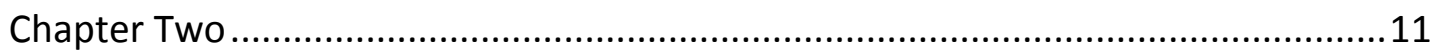

2.0 THE CASE: Intellectual Property Office of New Zealand ...................................11

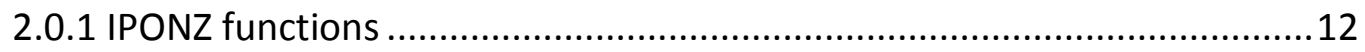

2.1 History of the Intellectual Property Office of New Zealand.............................13

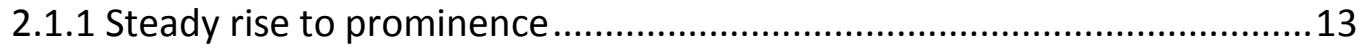

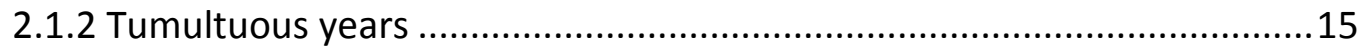

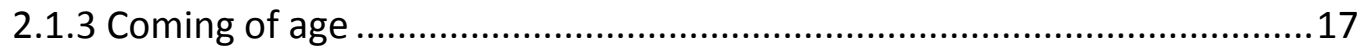

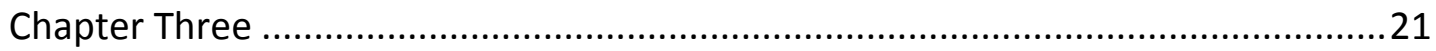

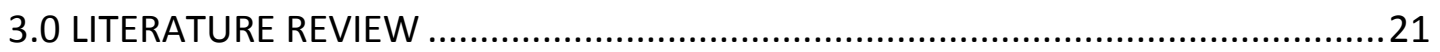

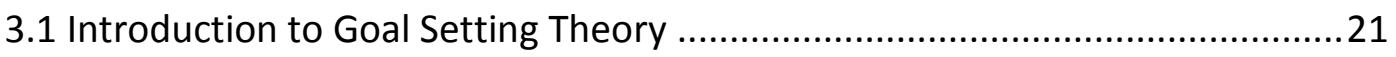

3.2 Exploring the connection between goal setting and goal achievement..........24

3.2.1 Mapping goal setting and task performance......................................25

3.3 Organisational Innovation and Organisational Goals ..................................29 


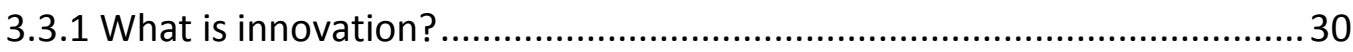

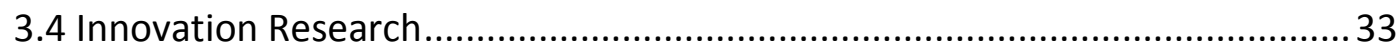

3.5 Defining innovation as a change process in organisations .............................37

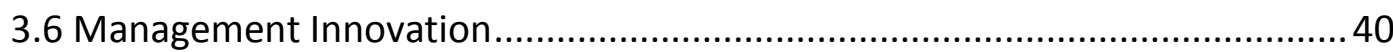

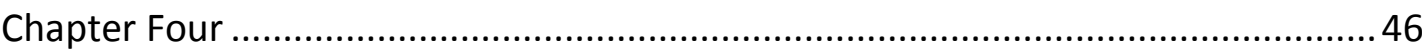

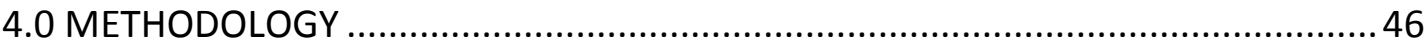

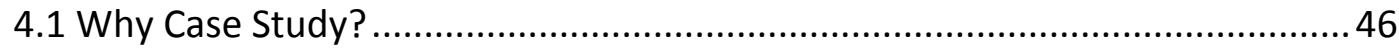

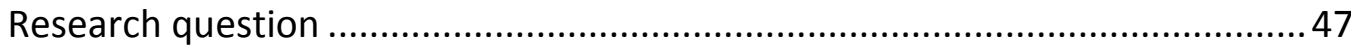

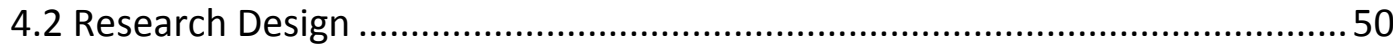

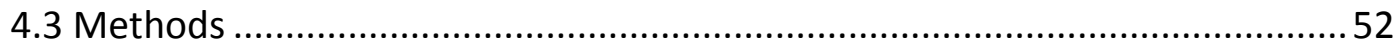

4.3.1 Constructs from Current Theory ........................................................... 52

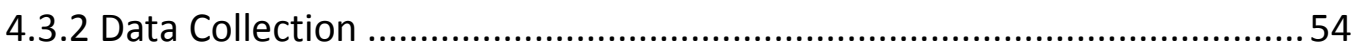

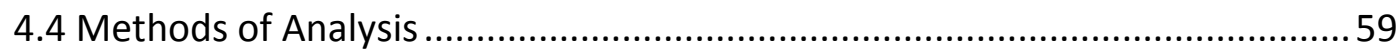

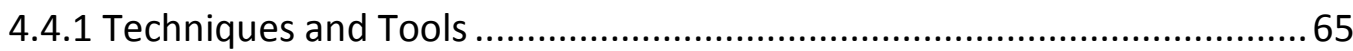

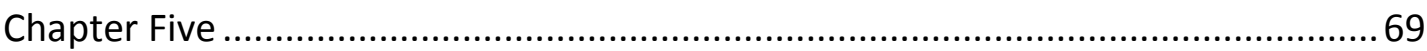

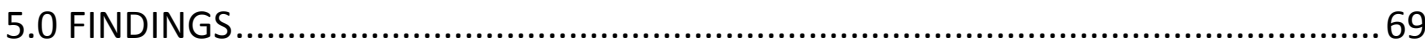

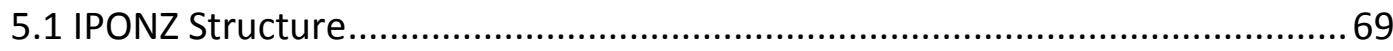

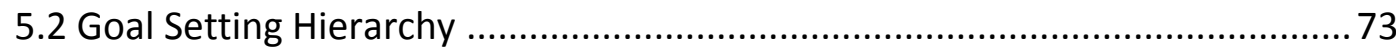

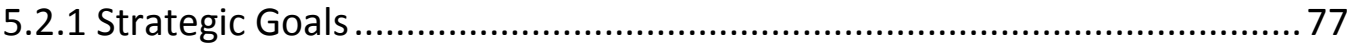

5.2.2 Objective and Operational Goals......................................................... 79

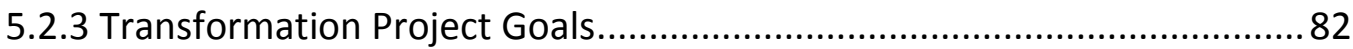

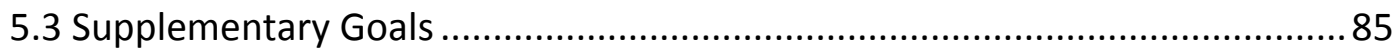

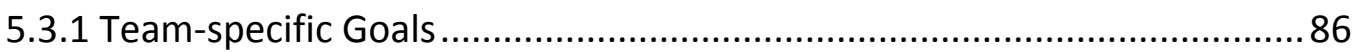

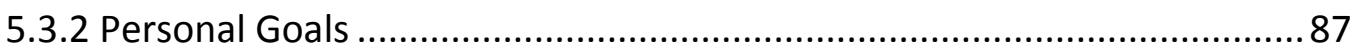

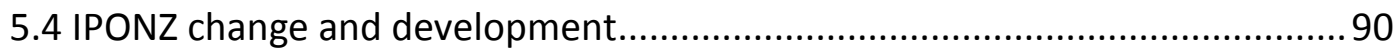

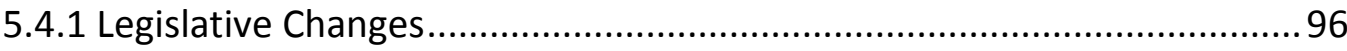




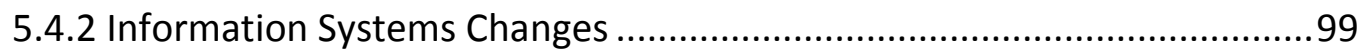

5.4.3 Innovative Changes in Management ......................................................103

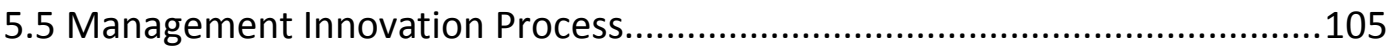

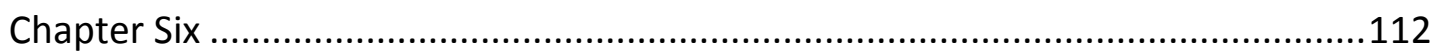

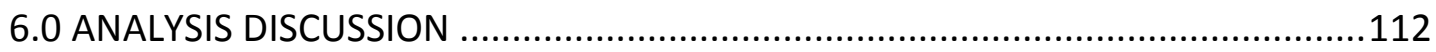

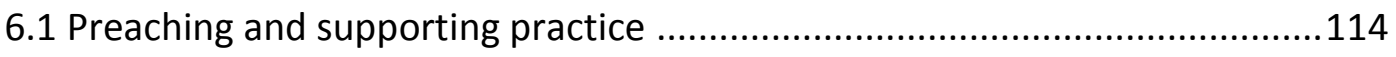

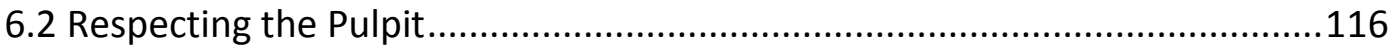

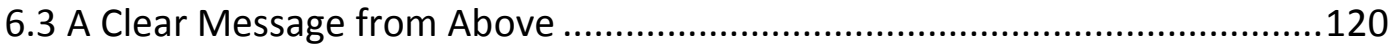

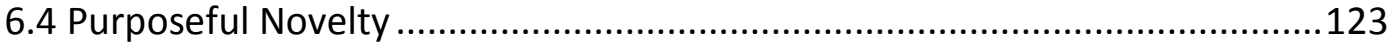

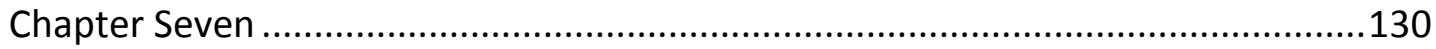

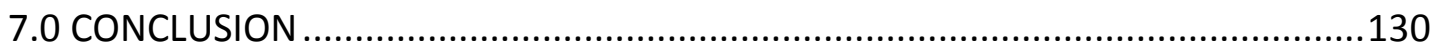

7.1 Preaching Goals and Practising Innovations ............................................131

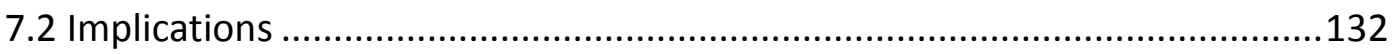

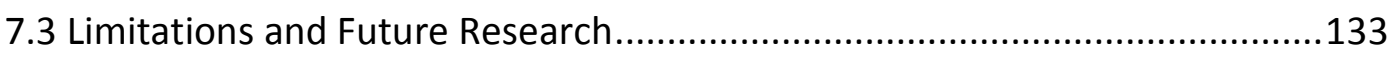

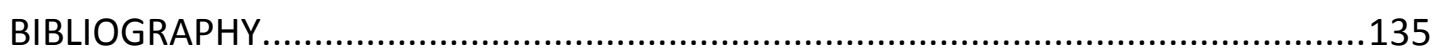

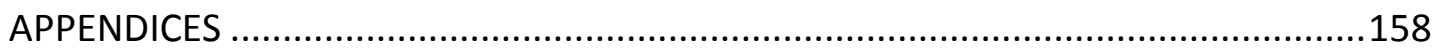

1.0 IPONZ Output Volumes 1950-2008 (WIPO Statistics Database, 2010) .........159

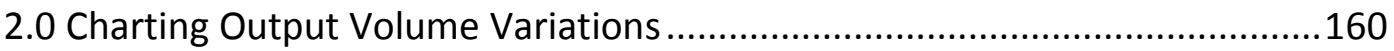

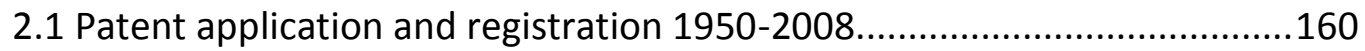

2.2 Trade Marks application and registration 1950-2008 ..............................161

2.3 Design application and registration $1950-2008$.......................................162

2.4 Plant Variety Rights (PVR) application and registration 1975-2008...........163

2.5 Combined IP application and registration 1950-2008.............................164

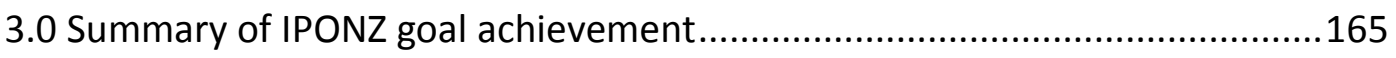

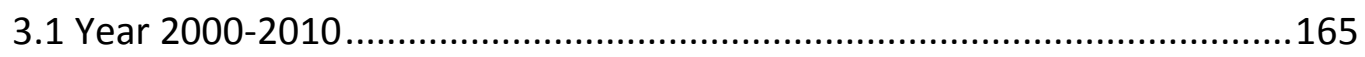

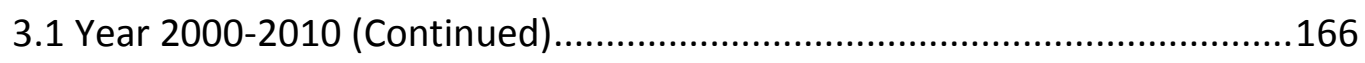


3.3 IPONZ Business Plan goal achievement 2009-2010 ..................................168

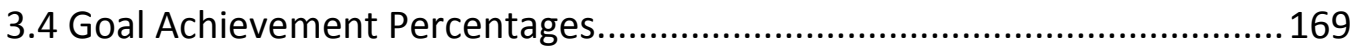

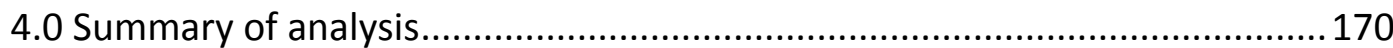

4.1 Ranking of data within categories ..................................................... 170

4.2 Overall ranking of data by number of sources ....................................... 171

4.3 Overall ranking of data by number of units coded...................................172

5.0 Summarizing IPONZ processes of management innovation ....................... 173

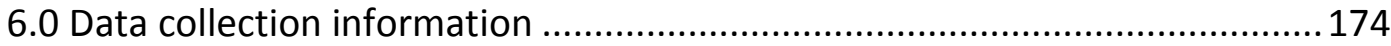

6.1 IPONZ letter of request to participate in research .................................174

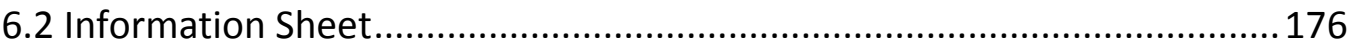

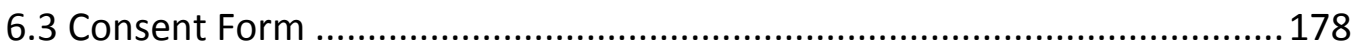

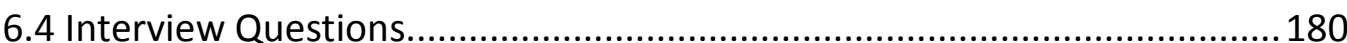




\section{LIST OF FIGURES}

Figure 3.2 Goal Setting and Task Performance Mechanism

Figure 3.3 Understanding the process of generating and adopting innovations ......33

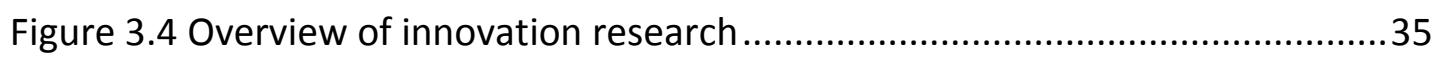

Figure 3.5 Illustration of four process theories underlying explanations of

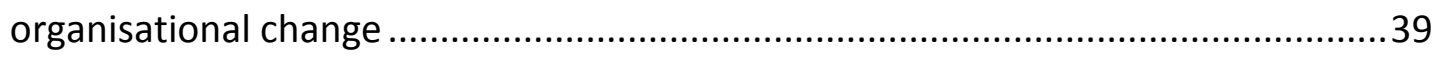

Figure 3.6a Typology of Management Innovation Perspectives ............................ 43

Figure $3.6 \mathrm{~b}$ Interactions to generate and adopt management innovation ...............45

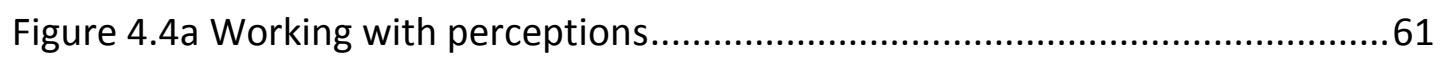

Figure 4.4b Conceptual Framework for analysing the innovation process ..............65

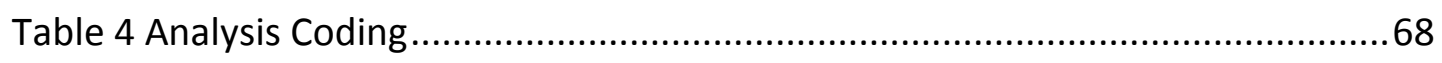

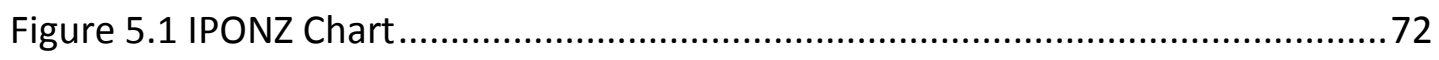

Table 5a References classified into goal themes in the Goal Focus category ............77

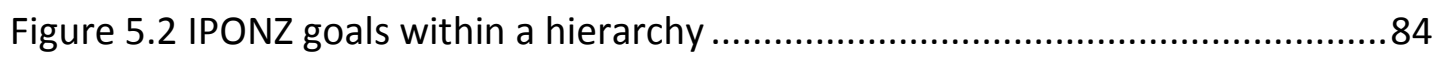

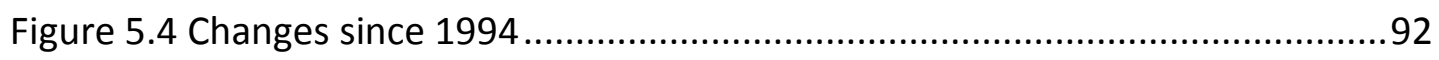

Table 5b Change descriptions referring to aspects of the organisation, and

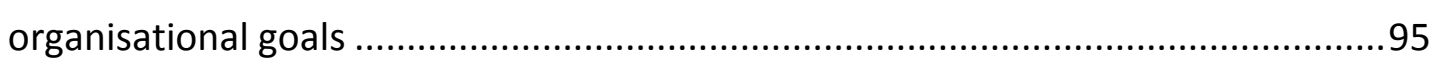

Table 5c Identifying Management Innovation...................................................104

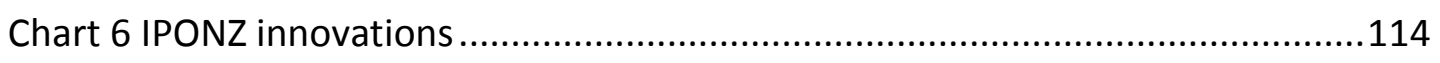

Figure 6.1 Percentage of goals achieved each year ...........................................116

Table 6a Goal achievement 2009-2010 ...........................................................118

Table 6b Innovative Goals .......................................................................... 122

Figure 6.4 Management Innovation to achieve goals ........................................125 



\section{GLOSSARY OF TERMS}

Adoption: Acceptance, implementation and evaluation of an idea proposed for organisations (Becker and Whisler, 1967; Sapolsky, 1967)

Change: A deviation from the norm that is physically manifested and identifiable in organisational settings (Van de Ven and Poole, 1995)

Change Initiatives: Changes introduced into the operations, management practices and systems of the organisation

Client: Used here interchangeably with "customer", to refer to users and consumers of a product or service (IPONZ, 2010)

Conflict/Contradiction: Seemingly mutually exclusive requirements (Goldratt, 1984; Mann, 2004)

Core Functions: The primary activities designated to organisation members; used interchangeably with core operations.

Development: A series of change processes that define an entity over time (Van de Ven and Poole, 1995)

Feedback: The transfer of evaluative information that characterises a specific activity (Locke and Latham, 2002; Birkinshaw, Hamel and Mol, 2008)

Event: Defined here for analysis purposes to mean individual or group activities that are implemented to achieve goal or objective (Van de Ven and Poole, 1990)

Evolution: Theories of variation, selection, retention and adaptation processes of entities (Van de Ven and Poole, 1995)

Generation: Discovery/construction and presentation of an idea proposed for organisations (Becker and Whisler, 1967; Sapolsky, 1967)

Goal: Explicitly expressed desire to reach an objective or aim, either specifically measured or unmeasured (Locke, Latham, Saari and Shaw, 1981) 
Goal Achievement: Complete performance of the tasks related to set goals, reaching or exceeding the level of proficiency specified in the goal (Locke, Latham, Saari and Shaw, 1981)

Goal Orientation: The level of understanding about the aim of the goal or the task related to the goal, and the effort required for achieving the goal (Locke, Latham, Saari and Shaw, 1981)

Goal Setting Theory (GST): The prescription that specific difficult goals lead to higher performance outcomes than vague goals or no goals at all (Locke and Latham, 2006b)

Ideal Final Result (IFR): The ultimate goal of an organisation which represents the achievement of a perfect condition for the organisation and its stakeholders (Mann, 2004)

Innovation: The implementation of a change that is universally or contextually novel to its host (Becker and Whisler, 1967; Damanpour, 1991; Birkinshaw, Hamel and Mol, 2008)

Management: The coordination and arrangement of people, tasks and resources; a field of study about the coordination and arrangement of people, tasks and resources (Terziovski, Samson and Dow, 1997; Hamel, 2006)

Management Innovation (MI): The introduction of novel changes to processes and practices related to the coordination and arrangement of people, tasks and resources (Hamel, 2006; Birkinshaw, Hamel and Mol, 2008)

Management team: A set of people appointed to jointly perform the functions of coordinating and arranging people, tasks and resources

Manager: A person who is given the responsibility of overseeing the coordination and arrangement of people, tasks and resources (Terziovski, Samson and Dow, 1997)

Objectives: The object or subject of desire, which efforts are made to achieve and accomplish (Locke and Latham, 1979) 
Operations: Refers to the performance of tasks assigned to organisation members, ranging from strategic to routine activities (Terziovski, Samson and Dow, 1997)

Organisation: A social grouping of people, brought together to perform functions that contribute to the same purpose (Van de Ven and Poole, 1995)

Organisation Member: Used interchangeably with "employee" to mean any member of the organisation that is appointed for and on behalf of the organisation. This also includes higher level managers (Terziovski, Samson and Dow, 1997)

Problem: A situation that is undesirable; a notable difference between an organisation's current performance and its desired performance (Goldratt, 1992; Mann, 2004; Dettmer, 2007; Hamel, 2006)

Process: A series of events (Van de Ven and Poole, 1995)

Purpose: A socially defined desire that is intended to elicit an intrinsic sense of obligation in members of a group (Locke and Latham, 2004; Locke and Latham, 2006b; Locke, Latham, Saari and Shaw, 1981)

Significant Changes: Changes requiring multiple members to participate in implementation, and that affect current performance of operations in more than one area of the organisation.

System: Not restricted to its use for Information Technology, but more generally for any cohesive collection of numerous parts individually serving diverse functions, but combined to fulfil a unified purpose (Terziovski, Samson and Dow, 1997; IPONZ publications, 2010)

Transformation: Development that produces new forms; a series of change processes that produces a new entity from the components of an old entity, with changes that cause variations to a majority of the norms of the old entity (Van de Ven and Poole, 1995) 
Vision: Explicitly expressed desire to reach a long-term objective or aim that is set through the leadership unit of the organisation (Van de Ven and Poole, 1995; Locke and Latham, 2006) 


\section{Chapter One}

\subsection{INTRODUCTION}

The Intellectual Property Office of New Zealand (IPONZ), also referred to as "the Office", is a small public organisation taking big steps forward. With a plethora of changes implemented in the organisation in recent years, IPONZ still forges on processing comparatively large volumes of legal, administrative and technical work, refusing to settle for quality that is not satisfactory to clients. Upon winning the 2009 Vero Excellence Award in Business Support, IPONZ Group Manager expressed interest in being "....as innovative as those IP owners we support...." This implies that there is a significance placed on organisational innovativeness, echoing the industries they serve and a desire to practice what they preach.

Innovation has become a widely sought after organisational practice. It is advocated for success in the manufacture of goods and delivery of services. It is also a well sought after, but sometimes elusive, capability for organisations seeking to grow in their development. In New Zealand, innovation is widely preached, particularly for the development of the economy (van Melle, 2010). Intellectual Property (IP) encapsulates the value of innovation by providing the legal basis for defining its value. IPONZ enforces this value by providing exclusive rights to the use of innovations represented by patents, trade marks, designs and plant varieties.

Innovation can be in a technical form such as the iPad produced by Apple Inc, or non-technical form such as the elimination of stocking warehouses in the distribution of Dell computers. While technical innovation is well recognised, the non-technical form is still gaining awareness. It is also considered necessary, for harvesting the technical form (Govindarajan and Trimble, 2005b; Hamel, 2006). This research study explores the existence and use of a non-technical type of innovation - management innovation, and its implementation at IPONZ. 
Innovation studies have been expanding since the introduction of the concept through Joseph Schumpeter's (1934) economic theories. Although as yet there is no one cohesive theory of innovation (Wolfe, 1994; Damanpour, 1991; Van de Ven and Poole, 1990), there have been several attempts to compile theories that address innovation as a phenomenon in organisations. Most emerging studies appear mainly focused on particular perspectives, possibly in attempts to remain theoretically consistent. The lack of a cohesive theory of innovation may be attributed to the extensive breadth of the topic which spans many fields of study from business to technology to biology and physics.

In spite of a lack of cohesion, an understanding of innovation can be developed that transcends theoretical boundaries, using concepts that apply to innovation in every area of application. This case study of IPONZ attempts to establish the innovation experiences of the organisation, using the concept of change as the universal innovation construct. As a change, innovation is explored within the context of its role in the achievement of organisational purposes, which are represented by explicitly stated goals. Using this contextual frame for understanding innovation, past events within IPONZ are dissected in time to uncover connections between the organisation's purposes and the innovations implemented.

To understand how organisational goals relate to the use of innovation, this research seeks to address the question:

\section{Is there a relationship between goal setting and the development of innovation in managing the administrative function of an organisation?}

\subsection{Goals as statements of purpose}

When considering the functions and purpose of the organisation, intentions are sometimes formally captured in the form of vision statements and expressed objectives and targets. Understanding innovation in the context of organisational 
purpose can be achieved by placing their implementation within the explicit expression of such purposes and imperatives. Countless organisations use goal setting in general to communicate expectations and drive the performance of their members. IPONZ is one such organisation, formally setting goals to give members direction, and including them in their performance agreements.

A prescribed view of goal setting was slowly brought to the fore in the 1970's through studies conducted by Edwin A. Locke and Gary P. Latham, and has been extensively researched since its recognition. Their theory proposes that specific difficult goals lead to a better outcome than non-specific goals or no goals at all. Although Locke and Latham have developed this theory of goal setting for performance and motivation, and it has been tested by numerous other scholars and practitioners (these are listed by Locke and Latham, 2009), goal setting extends beyond their theory. Scholars have proposed the development of a meta-theory or overarching theory of work motivation, and attempts have been made and are still progressing (Locke and Latham, 2006b).

The majority of empirical studies that have tested the theory's propositions have been carried out in the United States of America, and most of the field studies are in privately operated organisations in America. IPONZ utilises goals on all levels of organisational activity. This study applies some of the propositions of the prescribed theory to a New Zealand public sector organisation.

\subsection{Organisational Action to Innovate}

Breaking down innovative action requires a unified construct that suitably addresses the issues involved in performing tasks for the implementation of innovation. This construct would have to be versatile and generic enough to be able to be applied to all the different kinds of innovations, and all the different aspects of organisational activities. This is particularly useful in this study because here innovation is considered in combination with goal setting for performance management. Using change to define innovation activities allows it to be broken 
down and connected to performance management activities, which can also be defined by change. Similarly defining innovation as a type of change presents a holistic understanding of the implementation of different types of innovation in the organisation (applied in Sapolsky, 1967). In this study, the impact of all types of innovations are broken down and dissected to separate the technical from the nontechnical, specific attention is attributed to management innovation. Using change to dissect all types of innovation helps provide a comprehensive understanding for identifying management innovation. It also contributes to a valid understanding of the implementation processes.

Some theories of innovation suggest that technical and non-technical innovation are distinct from one another and are implemented separately and often incongruent to one another (Daft, 1978). This view has been somewhat accepted as is discussed by Damanpour and Gopalakrishnan (1998), and can be applied to structures that are decidedly mechanistic or organic, strictly hierarchical or decentralised, having a clear division between technical and administrative functions. However in the modern public sector, organisations are adopting complex business arrangements such as multi-disciplinary units, flatter hierarchies, and mixtures of all types of arrangements. Under such conditions, this theory of separate technical and non-technical innovating may not be applicable.

Furthermore, recent studies have examined different complementarities in various areas of organisations (Milgrom and Roberts, 1995; Pettigrew, Woodman and Cameron, 2001; Lonti and Verma, 2003), and found evidence that the implementation of certain changes are linked to and supported by the implementation of other changes. This indicates that technical and non-technical innovation are sometimes intertwined and embedded within each other in organisations. Therefore the actions involved in incorporating innovations into an organisation will not be understood fully unless they are explored collectively. The holistic collection of innovations will be used to examine specifically for management innovations, and to explore how they were generated and adopted over time. 
Identifying innovations at IPONZ will require a study of IPONZ history, to understand the events surrounding change implementations. Information about changes that took place at IPONZ can be derived from details of the events in the history of the Office. In addition, discovering historic functions of the organisation make it possible to establish the precedence that led to the current functions, and projections of future functions. As the backdrop of organisational innovation is the organisation's purpose, it is important to understand if and how IPONZ purpose has changed, through past official statements.

\subsection{Searching for Management Innovation}

This research takes a special note of Management Innovation (MI). Gary Hamel (2006), an educator, researcher and consultant on management strategy, ranked the world's most influential business thinker by Wall Street Journal (White, 2008), described MI as a fundamental reason for organisation success. He also suggested that using $\mathrm{MI}$, organisations can sustainably improve the way that they conduct business, through fundamental changes in the way that people, tasks and other resources are organised. Citing organisations that have successfully implemented MI such as General Electric, Visa and Linux, Hamel suggests that the more unconventional the innovation, the more difficult it is for competitors to imitate, and "in some cases the head scratching can go on for decades".

The re-organisation of work processes was a significant contributor to the success and competitive advantage Henry Ford enjoyed in Ford Motor Company, with sales of its Model T vehicle. Such novel changes to the manner in which people, resources and tasks were arranged and coordinated can be considered $\mathrm{MI}$. However, very few attributed this success to $\mathrm{MI}$ when Ford became recognised for his moving assembly line production design in 1913 (Binder and Rae, 2011). The Management of Innovation has become a popular concept in organisation theory; however Management Innovation has comparatively little recognition. Few articles were found that described research dedicated to understanding MI. Two authors 
discuss management innovation in a process perspective (Birkinshaw, Hamel and Mol, 2008), and in a prescriptive perspective (Hamel, 2006).

Determining appropriate action for adopting $\mathrm{MI}$ requires an increase in understanding of implementation processes. This research study attempts to uncover insights into the implementation of $\mathrm{MI}$ for public sector organisations. Innovation is considered a novel change generated and adopted by the organisation. Through a filtering process, change implementations are used to identify novel changes that can be considered MI. Identified $\mathrm{MI}$ will also be examined to understand their impact on the achievement of explicit organisational goals.

The next chapter narrates past history of the Office, piecing together changes in the progression of development over the years, since its formation. Chapter 3 presents an understanding of goal setting and innovation in organisations, based on previous studies. The effects of goal setting are examined from studies conducted for the prescribed theory by Locke and Latham (1979). Organisational innovation studies are summarised and the process approach for studying innovation is explained. Chapter 4 outlines the details of the methodology, and the approaches used to collect and analyse the data from which conclusions are drawn. Findings are presented in Chapter 5 and discussed in Chapter 6. Implications for Goal Setting Theory and innovations studies are stated in the concluding chapter, along with practical implications for public sector organisations. 


\section{Chapter Two}

\subsection{THE CASE: Intellectual Property Office of New Zealand}

Intellectual property (IP) is an important indicator of the economic conditions for trade and innovation (OECD, 2011). It is the means by which inventors can protect their functional ideas, and make use of their inventions for commercial and noncommercial benefits without the threat of unfair infringement (Probine, 1987; James and Wells, 2007). It provides a framework for disseminating the knowledge essential in generating and developing innovation (OECD, 2011). The approach by which IP protection is delivered is a socio-economic exchange. The inventors register their idea (trade mark, patent, design or plant variety) with the national or state IP agency, and in exchange for a period of legal protection, they agree to allow their idea to be published for public access (James and Wells, 2007). The publication of the idea promotes the development of the idea by either its inventor or other members of the public, for the generation of future inventions. The IP exchange fosters innovation by allowing the owner a term of exclusive use to commercialise their idea.

Intellectual Property Rights (IPR) refers to the legal protection that the owner of a functional idea is entitled to, provided that its novelty has been established (Probine, 1987). First mover theory (Lieberman and Montgomery 1988) examines the advantages of organisations or groups that introduce newly designed products and services into their respective markets, and how this pioneer advantage has the potential to place that organisation or group "ahead of the game" in terms of market share and profits. IPR legitimises this opportunity, to encourage innovative developments and creativity within firms. Legal protection is provided for organisations that first register the IP, and it is protection against unauthorised use 
by other organisations in the same legal jurisdiction. This legal protection for exploiting pioneer advantage is restricted in time to allow subsequent development of the registered IP by others.

In New Zealand IPR was introduced in 1860, twenty years after the signing if the Treaty of Waitangi (IPONZ, 2008). The registration of IP is currently the responsibility of a Government appointed agency in New Zealand -The Intellectual Property Office of New Zealand (IPONZ). IP is embedded into the commercial regulatory framework of most developed countries and increasingly in developing countries, to cultivate an economic environment that fosters growth.

\subsubsection{IPONZ functions}

There have been changes made to the functions of the Office since its conception that appear monumental. These changes have remained in line with its original mandate for the registration of intellectual property and the administration of intellectual property rights. The functions of IPONZ today (IPONZ, 2011) can be categorised as follows:

- Examine Patents, Trade Marks, Designs and Plant Variety Rights for registration

- Maintain registered IP

- Administer quasi-judicial proceedings for oppositions and disputes on registered IP

- Contribute to the development of legislation for the registration and administration of IPR

- Provide a publicly accessible database of information related to registered IP

- Promote IP awareness in New Zealand

- Aligning New Zealand IP system with international IP legislative and administrative infrastructure

- Maintain a register of certified Patent Attorneys.

The functions of IPONZ are carried out by maintaining a system to receive and process IP applications, register and update IP records, manage and provide public 
access to IP records. In addition as IPONZ is a Government agency, it is required to abide by the regulatory framework of the State Services Act 1988, which is used as an accountability mechanism or a mechanism of control for Government offices.

\subsection{History of the Intellectual Property Office of New Zealand ${ }^{1}$}

Since the first patent was registered in 1861, New Zealand IP System has seen numerous major changes in its structure. The most notable changes have been in the last decade, where significant technological, legislative and operational changes have occurred. These changes induced major developments to the methods and means through which the registration and maintenance of IPR is carried out in New Zealand.

\subsubsection{Steady rise to prominence}

IPONZ began as a supplementary function of the Colonial Secretary's Office in 1860. In that year IP registration was basic in New Zealand with only 21 patents filed through the Colonial Secretary's Office, under the Patent Act 1860. After the passing of the UK Merchandise Marks Act in 1862, the New Zealand Trade Marks Act was passed in 1866 . Shortly following in 1870, New Zealand legislation made provision for a Patent Officer to be appointed under the Colonial Secretary's Office. The Patent Officer made up the first Patent Office of New Zealand and primarily dealt with the registration of patent records without examining them.

In 1882 significant changes to the way applications were received was made by the setting up of filing facilities in court offices throughout New Zealand. This change was likely implemented as a response to the continued increase in patent applications filed. Filing facilities provided multiple locations where applicants could more conveniently submit records in their geographic areas. Although this would

\footnotetext{
${ }^{1}$ Records retrieved from Archives New Zealand 2008 and the IPONZ website.
} 
likely have increased average timeframes for processing applications, it increased the accessibility of the patent system to New Zealanders in many locations.

In 1883 , the Patent Office began performing examinations for patent applications before they were registered, which represented a significant shift in the process of registering patents. The New Zealand Government of the time also elevated IP registration to an operation requiring a separate unit, functioning under the Ministry of Justice. The Patent Office also took over the registration of Copyrights from the Colonial Secretary's Office in 1886, and took over the registration of Trade Marks in 1889. A new Patent, Designs and Trade Marks Act 1889 was passed which was adopted from the 1883 British Patent Act (Hawke's Bay Herald, 1889), with the three forms of IP included in one piece of legislation, all to be administered by the Patent Office. Changes under the 1889 legislation included an increase in the price of applying for patent registration, to reflect the internal costs of quality examinations (Hawke's Bay Herald, 1889).

In the 30 years between 1861 and 1891 the New Zealand Patent Office went from a one-man show to a geographically co-ordinated organisation-orchestra. During that period, the Patent Office started publishing its very own supplement in the New Zealand Gazette to make patent specifications accessible through public media, having registered almost 800 items of IP in 1890. The Office also released its first Annual Report to the Government in 1890 , now establishing its credibility through formal methods of accountability to both the public and the Government.

In the early 1900s, the operations of the Patent Office became increasingly comprehensive for its service provisions. This happened in accordance with changes in legislation that resulted in the subject matter of patent applications being examined more in-depth, to consider the novelty of the items for registration. Novelty was established by comparing proposed IP to previously registered IP in both New Zealand and Britain. By 1912, IP applications had reached a volume that warranted a separate publication to release the details of 1425 registered Patents, Trade Marks and Designs (WIPO Statistics Database, 2010). This marked the introduction of the IPONZ Journal which would from then on be produced by the 
Office. The Patent Office also became the centre for examining and registering patent attorneys in New Zealand, increasing further the scope of IPONZ services.

\subsubsection{Tumultuous years}

Until the First World War in 1914, the Patent Office saw a relatively steady progression in the development of its operations, making incremental changes to its services and how they were delivered. Changes were made as a response to steadily growing demand and changes in legislation and government administration. During the war from 1914 to 1918, the Patent Office was faced with significant changes to its core functions, which define the primary activities of organisation members. The number of IP applications significantly reduced and the renewal of many already registered foreign IP was suspended due to political war-time tensions. Resources were reassigned to the direct regulation of trade, to prevent the sale of fraudulent products. The registration of IP from owners that were members of opposing countries was also barred by the Office. Similarly this was the case during the Second World War between 1939 and 1945.

After the First World War, in addition to the backlog of applications and renewals that the Patent Office had to tackle, the increase in the number of patents filed annually was accelerating. The examination of patents prior to accepting registration also became more rigorous and the Office was allowed to reject applications to register unacceptable IP. With the surfacing of the Great Depression in 1930, New Zealand economy went into decline and so did the number of patent applications, although the development of new technologies during that period offset this somewhat.

Such fluctuations were the nature of changes that the Patent Office had to respond to during the years between the beginning of the First World War and the end of the Second World War. Following the Second World War the Patent Office started providing even more technical examination of the content of patents. The first technically-qualified examiners were employed in 1946. This illustrates that significant emphasis was then shifted to the qualitative character of patent content. In 1952 the Patent Office closed the branch that administered copyrights records, 
and the Government abolished the registration of copyrights in favour of automatic protection. Maintenance of the legislation to protect copyrights was still within the functions of the Patent Office.

The most significant shift in the legislative developments of New Zealand's IP history took place in 1953, as a result of growing public concerns about the relevance and practicality of IP legislation enacted in 1908 and 1921-22. This resulted in the appointment of the first Commission to inquire into and report upon the Laws of Patents, Trade Marks and Designs in 1948. Chaired by the SolicitorGeneral, and including among others a prominent patent attorney and the Secretary of Industry and Trade (Currently Ministry of Economic Development), this inquiry resulted in the enactment of a new IP legislation in 1953 that give each form of IP a distinct legislation, but all were still administered by the Patent Office. But this meant that the registration of each type of IP would now become differentiated, and the structure of the Office would eventually be changed to reflect this differentiation.

The 1953 legislation addressed issues relating to the abuse of monopoly rights, which would have caused numerous legal proceedings that required administrative coordination by the Patent Office. Curtailing the costs of these legal proceedings in the implementation of the current law was also another issue that the new legislation addressed. The recommendations of the Commission was to employ IP legislation similar to that currently in force in Britain -the British Patent and Designs Act 1949. The Commission indicated that in their opinion the issues that the act had addressed in the United Kingdom were similar to the issues that needed to be addressed at that time (New Zealand Commission to Inquire into and report upon the Law of Patents, 1950).

By 1967 the Patent Office had a high number of patent applications pending examination, creating large backlogs that were exacerbated by a shortage of staff. Application volumes had reached up to 3,665 in the previous year with completed registrations for the same year at only 2,824 (WIPO Statistics Database, 2010). In response to the growing backlog, the Office increased staff numbers and initiated a 
graduate recruitment program which eventually helped to significantly reduce the backlog by the early 1970 s.

\subsubsection{Coming of age}

The capacity of the Patent Office was expanded in many areas during $1980-2000$, to keep up with the changing demands of the New Zealand economic environment. Concerted efforts were made to make it more conducive for economic expansion and the related commercial progress. In the midst of widespread public sector reform beginning in 1984 (Evans, Grimes, Wilkinson and Teece, 1996), reformation led to the separation of policy management and administrative management (Scott, 1996, pp. 14). This meant that the establishment of policy and legislation would not be included in the core functions of the Office, thought they were required to make contributions.

The 1953 legislation also underwent frequent changes triggered by changes in international legislation and stakeholder concerns in New Zealand. Although the Patent Office started making preparations to join the Patent Cooperation Treaty (PCT) in 1984, the Patent Office only officially became party to the Treaty in 1992. Part of the purpose for NZ becoming a PCT party was to make provisions for reducing compliance costs, in the application and grant of international patents. PCT allows the transfer of "convention priority" rights from one party country to another.

The Office experienced expanding backlogs of work, not uncommon to IP Offices in other Jurisdictions (WIPO Statistics Database, 2010). Between 1975 and 1985 the average annual number of applications filed was approximately 9,600, while the average annual number of completed registrations was much lower at approximately 5,180 (WIPO Statistics Database, 2010). These numbers show that for applications to register IP, an average of almost twice as much work was coming

\footnotetext{
${ }^{2}$ The right to have the same priority date for a new application as its counterpart which has already been filed in other jurisdictions party to the convention, with the condition that the new application is filed within the specified time afforded by legislation. References: IPONZ website, 2009; Frankel and Mclay, 2002, s. 2.1.4.
} 
in compared to the work that was going out. This difference peaked in 1988 with incoming applications at approximately 17,500 and outgoing registrations at 5,600 making a difference of almost 12,000 pending applications for processing. Dealing with these volumes and other changes would likely have increased recognition of the need to increase efficiency.

In 1989, emerging technological development in relation to data storage and information management was adopted by the Office, starting with the electronic recording of physical documents. In 1994 some records of IP were electronically stored and accessed through a database that adopted existing technology for the uses of IPONZ. This marked the beginning of a shift from manual processing to electronic processing. This may have contributed to the efficiency of operations aiding the elimination of backlogs.

In the twilight of radical public sector reformation in 1995 (Evans, Grimes, Wilkinson and Teece, 1996), the Office was transferred from the governance of the Ministry of Justice to that of Ministry of Commerce, now known as the Ministry of Economic Development. This may be indicative of the growing emphasis in the importance of IP to commerce at that time. Two years later the Patent Office was renamed the Intellectual Property Office of New Zealand (IPONZ). Under the Ministry of Commerce, the operations of IPONZ initiated fixed time frames for delivering services to clients incorporating a greater customer focus. This would have encouraged credibility for the Office under the "user-pays" system of public service provision. In addition, a database of some IP records were made accessible 24 hours a day through online facilities by the year 2000 , providing automated selfservice to clients, and further increasing efficiency.

Over the last 10 years IPONZ has introduced new service delivery methods and initiatives to develop efficiency and reduce office error including the development of an online application and correspondence system. A similar facility specifically targeting businesses that deal frequently with IPONZ is now provided, directly connecting government-to-business (G2B) through online media. Where IPONZ previously dealt with clients through face-to-face interactions due to the need to 
physically access IP records, IPONZ now provides these records via the internet, and has maintained a toll free customer service line for clients all over New Zealand since 2001. Following from the use of online processes, is an organisation-wide effort to minimize physical paper in both internal and external communication.

In 2002 the Trade Mark legislation of 1953 received an overhaul. IP issues regarding legal rights to traditional knowledge, the extent of protection for trade mark owners, cost effective IP registration processes and copyright enforcement measures were addressed in the new Act. As a result significant changes were made to the trade marks registration and maintenance processes, including provision of specialized information for the examination and registration of trade marks relating to Maori traditional knowledge.

In 2004, IPONZ was expanded to include the Plant Varieties Rights (PVR) office which administered testing and recording of plant varieties. NZ was made an official party to the Union of New Varieties of Plants (UPOV) convention in 1981, and PVR legislation is aligned with the 1978 UPOV Convention Act. Also in 2004, efforts began to reform the Patent Act of 1953 as a draft Patents Bill was released for public consultation. The Bill was submitted to the New Zealand Parliament for review in 2008. Having been reviewed by the House in 2009, it was referred to the Select Committee for Commerce who reported back to Parliament in March 2010.

The Select Committee has recommended that changes be made to the Bill and it is currently pending changes and another review by Parliament. IPONZ is involved in working through the issues relating to the bill, and contributing to a re-drafted bill for submission to the House of Representatives. The changes proposed to reform the Patent Act would bring about a significant difference to the process of application, examination and registration. One such difference is the consideration of the inventive value of the patent and its use, in addition to international examination for novelty. This will mean that the procedure for examination of patent will include more considerations than currently is made.

Facing future possibilities of internal inefficiencies and client dissatisfaction, IPONZ management took measures for its operations to be evaluated and a report of the 
review was published in 2009. This report validated the importance of carrying out planned changes to its internal operations, which will contribute to its ability to respond effectively to legislative changes and changing environmental factors. As a result of the release of that report, IPONZ was able to reinforce efforts to implement initiatives such as the complete replacement of their electronic database, documentation of their processes, achievement of ISO accreditation, upgrade of their computer facilities and several changes to the structure of teams within IPONZ. Though many of these changes are technological, some are also procedural and practice changes that are contextually novel to IPONZ. 


\section{Chapter Three}

\subsection{LITERATURE REVIEW}

\subsection{Introduction to Goal Setting Theory}

"Goal theories suggest that goals are cognitive representations of what individuals are trying to attain and that these goals can guide and direct achievement behaviour".

(Linnenbrink and Pintrich, 2000)

Goal Setting Theory (GST) developed by Locke and Latham (1979), presents a number of ways in which goals can be used effectively within organisational settings. Their proposals, which have been extensively tested and applied empirically, are that specifically set difficult goals produce more effective motivation mechanisms than vaguely set, easy goals or no goals at all. Backed by an estimated 400 field and empirical studies (Locke and Latham, 2006b), goal effects on performance outcomes are examined for different levels of goal difficulty, and comparisons are made between specifically set goals versus vague goals such as "do your best". The majority of the findings they discovered point to conclusions that higher performance is related to more specificity than to ambiguity, and to higher difficulty than to no difficulty (Locke, Latham, Saari and Shaw, 1981).

Goal setting is a technique for using motivation to direct performance, in that goals are set specifically to heighten awareness of a discrepancy in the level of current activity and the level of desired activity (Locke and Latham 1990). This discrepancy is then used to promote activities that eliminate the discrepancy, by fostering individuals' intentions to engage in discrepancy eliminating behaviour. Beyond the outward observation of specifically setting goals and the performance related to those goals, the connection between the motivation provided by expressed goals and action occurs in a complex manner (Locke and Latham, 2002). 
There are many criticisms of GST, and Locke and Latham (2006a) outlined 10 possible disadvantages in applying GST in organisations. The most notable of the critical perspectives on GST is perhaps given by Ordonez, Schweitzer, Galinsky and Bazerman (2009a). They suggest that its use can lead to serious negative consequences if it is used without careful consideration and precaution. They identify some dangers of over-prescribing Goal Setting without regard for caution. They discuss how this may lead to circumstances of unethical behaviour, intra-team competition, detrimental risk taking, hindrance to learning, and intrinsic motivation atrophy.

Ordonez, Schweitzer, Galinsky and Bazerman (2009a) draw attention to systematic side effects of goal setting, where employees engage in unethical behaviour to achieve goals, especially when achievement is tied to monetary compensation. An example is the manipulation of reporting systems to give the appearance of meeting specific targets without actually performing the tasks required. Another side effect has to do with group cooperation, which is often necessary to achieve a whole team's goals, and the detrimental effects of goals that lead to intra-team competitiveness. When using specific and difficult goals for individual performance within a group, individual goal commitment may lead to team members competing with and working against each other, more so when there is a perception of limited resources and rewards (Locke and Latham, 2006a).

Detrimental risk taking is another suggested point, when there is blind commitment to unrealistic goals, set without careful consideration of implications. Another danger is that hindrance to learning can occur in cases where performance goals are applied for complex tasks requiring new knowledge (Locke and Latham, 2002; Locke and Latham, 2006a; Locke and Latham; 2006b). Due to lack of knowledge, unnecessary effort will be exerted to perform inappropriate tasks, where effort could have been directed towards learning what was required to reach the goal.

The final negative consequence raised by Ordonez, Schweitzer, Galinsky and Bazerman's (2009a) criticisms is intrinsic motivation atrophy. The circumstance where because of excessive extrinsic motivation such as goal setting, punishment 
and rewards, the effects of intrinsic motivation are diminished when it would otherwise have sufficiently motivated employee performance. Intrinsic motivation is defined as an individual's desire to perform a task for its own sake (Benabou and Tirole, 2003), without the use of incentives. Examples of intrinsic motivation could be a personal desire to meet or exceed a manager's expectations, or personal affiliations with an organisation that provokes exceptional performance, as in the case of some non-profit organisations.

Ordonez, Schweitzer, Galinsky and Bazerman's (2009a) critical review provides a necessary grounding for the application of GST in organisational settings, to improve the effectiveness of its use and curtail possible negative consequences. They suggest that although it is a seemingly simple motivation technique, GST requires in depth examination of the expectations for performance and the manner in which the goals are perceived by employees. That notwithstanding, it is not appropriate to limit every use of goals to the difficult and specifically set variant prescribed in the theory. Locke and Latham (2006a; 2009) addressed these issues raised, with the exception of intrinsic motivation atrophy. They propose certain methods for "overcoming" the "pitfalls" (Locke and Latham, 2006a). They also contest the claims of Ordonez, Schweitzer, Galinsky and Bazerman (2009a), questioning their use of a few case studies to challenge evidence from hundreds of empirical and field studies (Locke and Latham, 2009). Locke and Latham (2009), in their response, point out that GST is an "open-ended" theory that requires continuous development, and should not be viewed as complete, but rather used in light of making progress in knowledge and practice. In turn, in their own response to Locke and Latham (2009), Ordonez, Schweitzer, Galinsky and Bazerman (2009b) argue that Locke and Latham's convictions are preventing a comprehensive consideration of the full implications of GST.

However, the criticisms pointed out by Ordonez, Schweitzer, Galinsky and Bazerman (2009a) do not give any indication that high specific goals are inherently ineffective. Rather they draw attention to its effectiveness by pointing out the negative consequences of its motivational power. The dangers identified are related more to the manner in which goals are specified and used. For example 
behaving unethically to achieve goals, does not prove that such behaviour is the only course of action available.

In this study, goal setting is used as a framework for developing an understanding of goal and their effects on behaviour. Goal setting will be explored beyond the prescriptions of Locke and Latham, considering the variant suggested by the theory, but also including other variants of goals such as broader and non-specifically measured goals. The definition of goals here will also include group, multi-group and entire organisational goals. This will involve the exploration of goals in different areas of application, and will help to define the context within which innovations were generated and adopted. To do this, the researcher makes use of physical manifestations of activities in combination with organisation members' perceptions.

\subsection{Exploring the connection between goal setting and goal achievement}

GST maps some cognitive and physical processes between specific types of goals and performance of the tasks they relate to. "Goals" in GST refer to the proficiency with which a specified task is performed, as opposed to the mere completion of the task (Locke, Latham, Saari and Shaw, 1981). In other words, goals do not consider whether or not one performs a specific task, but rather and more specifically how well one performs a task compared to a set performance level that is defined using discrete measures.

Goals are effective provided whoever is attempting to achieve the goal commits to achieving it, and has the knowledge and skill required to achieve the goal with the exertion of effort (Locke, Latham, Saari and Shaw, 1981). Locke, Latham, Saari and Shaw (1981) differentiate two categories of goals, namely performance goals and learning goals. Learning goals are intention triggers that are set for the purpose of obtaining knowledge to accomplish tasks necessary for achieving performance goals. 
Although GST initially applied psychological theories of cognitive processes, it is claimed to have revolutionized the predominant organisational motivation studies in the late 1970s (Locke and Latham, 2002, pp705). The theory brought together cognitive processes and the physical effects they had on behavioural action in organisational performance. Its main conceptual focus is not the cognitive processes in themselves, but rather the behaviours that are presented as a result of those processes. This makes GST more functionally applicable to current management theories because specifically set goals and the related performances are explicitly manifested. Organisational action and phenomena are examined in terms of their outward manifestations, which can be independently measured and are easier to manipulate. The extent to which these actions should be manipulated is open for debate. Nevertheless, purposeful organisation action requires the directed behaviour of organisation members. GST allows for the examination of those directives by requiring that they be made explicit.

\subsubsection{Mapping goal setting and task performance}

In GST, the relationship between the goal and performance involves necessary conditions and moderators that affect how the goal-setting mechanism works. It is likely that these relationships are more appropriately viewed as interdependencies, than discretely dependent and independent categories. The different factors involved in the relationship can be categorized into variables that are influenced by other factors (dependent), variables that influence others either positively or negatively (independent), variables that affect the relationship between other variables (moderators), and variables that establish a relationship between two other variables (Cavana, Delahaye and Sekaran, 2001).

Experimental research and field studies were carried out and summarized in Locke, Latham, Saari and Shaw's (1981) “Goal Setting and Task Performance 1969 - 1980”. These studies identified a number of factors and conditions involved in the relationships between goal setting and task performance. The factors identified are not exhaustive but are the result of the studies done on the effects of goal-setting 
under different circumstances. These factors include set goals, task performance, goal orientation, goal commitment, task complexity and feedback.

Goal setting was found to positively affect task performance, when goals were specific and difficult. Task performance is used to refer to the achievement of the goals aims, through the performance of goal related tasks. Task performance can also be used interchangeably with goal achievement and goal attainment. In the case of specifically set goals, mere performance of tasks may not lead to achievement of the goal, as goals specify a desired level of proficiency with which the task is performed (Locke, Latham, Saari and Shaw, 1981).

A necessary condition is goal commitment, where the individual must make a psychological connection between the set goal and a desire to perform. The propositions of GST only apply when the individual makes a decision to contribute efforts to performance that will help achieve the goal. Locke, Latham and Erez (1988) discuss the determinants of goal commitment, and some of the ways that it has been measured in previous studies. A practical measure, which they point to (applied by Leifer and McGannon, 1986), is the expressed emotions a person attaches to the goal, whether they feel positively or negatively about achieving the goal.

Goal orientation is also a necessary condition for goal setting to affect task performance, because set goals are as effective as the extent to which they are understood. Goal orientation refers to an understanding of the effort required to perform the tasks, and a disposition towards the task which the goal is set to achieve (Locke, Latham, Saari and Shaw, 1981). Locke and Latham (2006a) distinguish between an orientation towards learning and an orientation towards performance. Goal orientation was formally incorporated into GST by Seijts, Tasa and Latham (2004), when they experimentally tested it in complex business tasks through the use of simulation. They found that the effect of goal orientation increased with complex tasks involving specific difficult learning goals, and not performance goals. This is because complex tasks require a high level of learning activities. In these cases, goal orientation was connected with higher performance 
when learning goals were specific, and performance goals were vague. When considering well known tasks, goal orientation is more likely to have a significant effect when related to performance and not learning.

A moderating factor between goal setting and goal achievement is task complexity. Task complexity can be understood as the variety of tasks or ambiguity about tasks that have to be performed in order to achieve the goal. An example of a very complex task involves different combinations of skills, such as the combination of mental reasoning skills, with physical dexterity and information retention required to perform a surgical operation. Findings from Seijts, Tasa and Latham (2004) point to conclusions that the higher the complexity of the tasks the lower the effectiveness of specific performance goals, which is contrary to GST propositions. Locke and Latham (2002) explain this outcome by making a distinction between using specific performance goals and using specific learning goals.

GST can be applied to performing complex tasks with the use of learning goals in the place of performance goals. Performance goals relate to the proficiency of performing the task, whereas learning goals relate to the increase in knowledge about the requirements of achieving the goals. Performance goals are effective in cases where there is low task complexity, whereas learning goals are effective in cases where the tasks required to achieve the goal are unknown and require further learning to be understood.

Another moderating factor is feedback, a highly popular concept in organisation theory, and specifically management theory. It is often presented as the multipurpose effectiveness boost for any organisational activity involving the coordination of effort. In GST, feedback is considered to be a positive moderator between the establishment of goals and its effects on performance. This signifies that giving feedback information about the performance of goal-related tasks increases the influence set goals have on performance. Locke and Latham (2002) put it this way -"the combination of goals plus feedback is more effective than goals alone". 
The following Figure 3.2 attempts to portray the factors involved in the goal setting and task performance mechanism. As previously discussed, Goal setting affects performance on the condition that there is individual or group commitment to the goal. In order for goals to have effect, there also needs to be orientation around what is required to achieve the goal. These conditions provide essential factors for the goal setting and performance mechanism. Feedback positively moderates the relationship between goals and task performance, while task complexity positively moderates learning goals and negatively moderates performance goals.

\section{Goal Setting Factors}

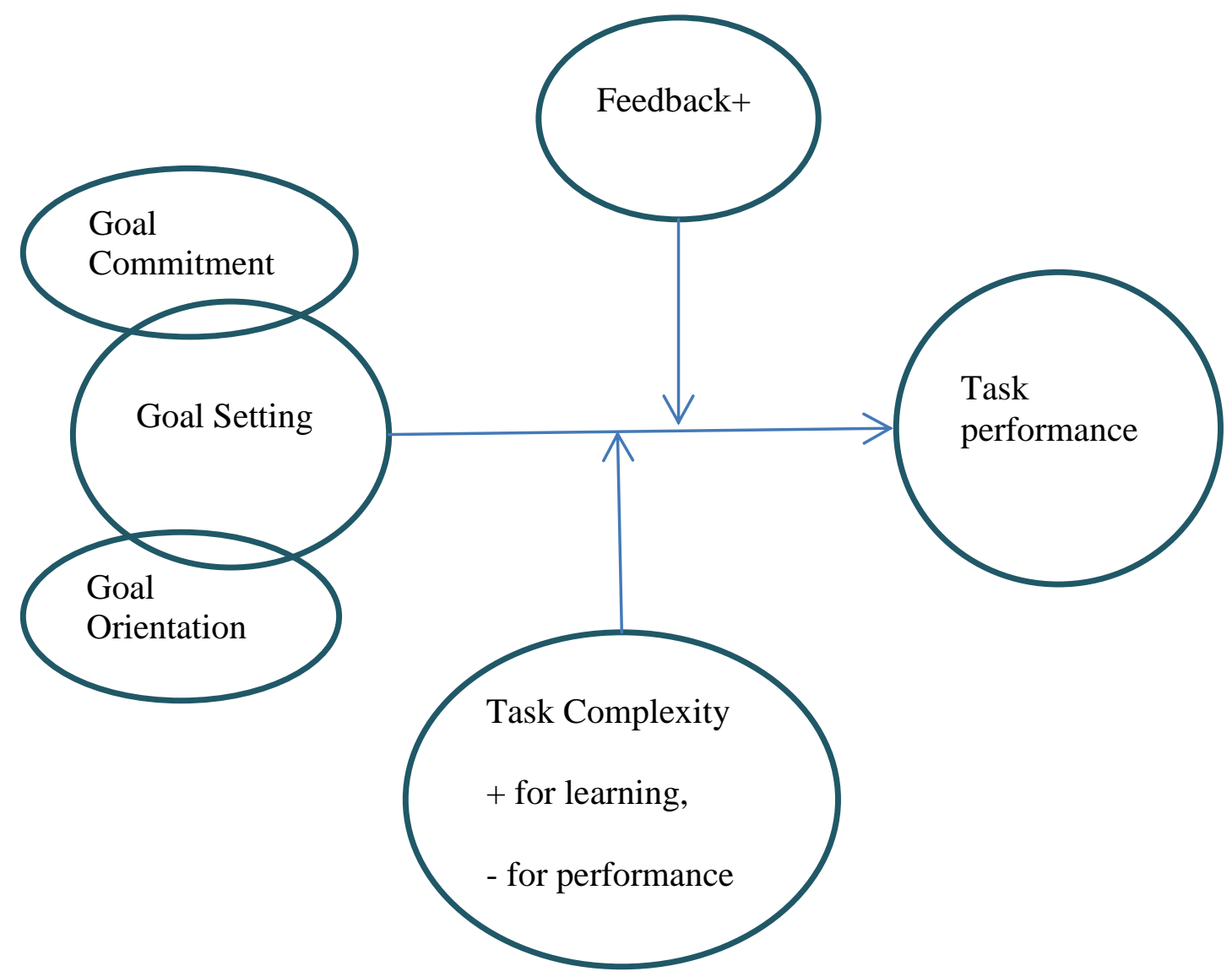

Figure 3.2 Goal Setting and Task Performance Mechanism 


\subsection{Organisational Innovation and Organisational Goals}

While a study focusing on the relationship between organisational innovation and organisational goals was not found in previous research, a number of studies appear to make an assumption that the two are connected. Hamel and Mol (2008), Mann (2004), Van de Ven and Poole (1990), and Sapolsky (1967) based their descriptions of innovation processes on the assumption that intended outcomes and future expectations guide present action. Innovation studies show that in the innovation process, there is complexity in "how" innovation occurs (Slappendel, 1996; Wolfe, 1994; Van de Ven and Poole, 1990). This research study proposes to use purposeful intentions as a context for the development of innovation, which helps to untangle some of the complexities in innovation processes.

Organisations generally have a reason for coming together. Even when the organisation is solely for purposes of a trivial nature, gatherings of people working together usually have a shared intention which induces them to form a gathering. Whatever the shared intentions are that a group of people hold, in theories of organising, these intentions can be referred to as goals (Locke and Latham, 2006b), though not necessarily the specific kind of goals prescribed in Locke and Latham's (1981) theory of goal setting and task performance. These expressed intentions are essentially goals in the sense that they capture overtly the achievement desires of the organisation.

Understanding the purpose of an organisation requires an understanding of the strategic direction of the organisation. In modern management, strategic management is the attempt to manage an organisation's operations and resources to successfully achieve its purpose and functions now and in the future. Angwin, Cummings and Smith (2011) describe an organisation's strategy as the influence/control that gives an organisation direction and feeds its existence (pg. $x v i)$. Knowing where you want to go as an organisation and progressively learning what it will take to get you there is essential in strategic management. Goals as 
statements of desired outcome capture where an organisation wants to go and how it plans to get there.

Goals are a way to clarify an organisation's purpose and functions at different levels: top management levels, middle management supervision levels and staff level production and delivery. Goals can be vague or specific, can have a well-defined scope or may be boundless in areas of application, whatever the extent of the goal, it exists without value until some effort is put into achieving it. Innovation is one means of putting effort into achieving organisation goals. According to Birkinshaw, Hamel and Mol (2008) MI "is intended to further organisational goals". The manner in which innovations are implemented and the outcome of their Implementation will affect the level of achievement that the organisation attains. This research will explore what is involved in implementing innovation in the context of an organisation's purpose and functions, referring to innovation as an agent for the organisation's ends.

\subsubsection{What is innovation?}

Innovation starts with invention and discovery (Van de Ven and Poole, 1990; Becker and Whisler, 1967). Inventions are introduced to society by individuals and groups (Burns and Stalker, 1961). Some have empirically established strong connections between adopting inventions and innovativeness (Becker and Whisler, 1967; Damanpour, 1991; Gopalakrishnan, Kessler, \& Scillitoe, 2010), though not all inventions become successful innovations. The Merriam Webster online dictionary presents a definition of innovation as "the introduction of something new", and "a new idea, method or device".

Organisational innovation can be viewed as the process through which organisation actors implement novel changes in their organisational setting (Damanpour 1991; Birkinshaw, Hamel and Mol, 2008). Innovation has also been considered the motivation behind organisational change, where members strive to make novel changes in an attempt to gain competitive advantage (Greve \& Taylor, 2000); or an adaptation mechanism in a rapidly changing environment (Damanpour 1991; Gopalakrishnan, Kessler, \& Scillitoe, 2010). 
Innovation is novel, but how novel is its novelty? Becker and Whisler (1967) suggest that novelty is defined within the scope of a specific organisation, inside a specific market which the organisation serves, as in "one of a set of organisations with similar goals". Another understanding of innovation novelty is that it is new to the operations of an organisation (Damanpour, 1991). This novelty considers any new introductions to the organisational system, including introductions that have already been made to other organisations within the same market. These definitions of innovation are contextually novel, as it includes novelty that may have already been introduced to other organisations in other markets.

Birkinshaw, Hamel and Mol (2008) refer to novelty as "without known precedent". Others propose that innovation can either be "generated" internally or "adopted" from the outside (Sapolsky, 1967; Mann, 2004; Hargrave and Van de Ven, 2006; Birkinshaw, Hamel and Mol, 2008; Gopalakrishnan, Kessler, \& Scillitoe, 2010). In other words both contextual novelty that is new to the organisation but not to its environment, and the state of the art or universal novelty, are appreciated as novel. Innovation includes novelty introduced to organisational processes, products, practices, and administrative structures (Damanpour, 1991).

Birkinshaw, Hamel and Mol (2008) also suggest that with universal novelty there is no prior information to draw from so the level of ambiguity is highest and uncertainty and insecurity of consequences follows. With contextual innovation actors can draw on prior implementation to support their case, though it is important to note that every organisation is different, even organisations offering the same products and services. Organisations being made up of different groups of people working in unique relationships makes each organisation different from the next, therefore any contextual implementation of innovation will eventually require a unique application of the innovation, tailored to the specifics of the host organisation (Mann, 2004). Johannessen, Olsen and Lumpkin (2001) address the question of novelty by operationalizing "newness" as the degree of variance and the speed with which it is implemented, either radically or incrementally. 
Weick and Quinn (1999) considered the degree of variance from normal organisational activities, which can be used to define implementation of change. They defined two variances of change as episodic and continuous change. In the case of innovative change, episodic is more in line with radical innovation, where continuous is more in line with incremental innovation. In the case of radical innovative changes, episodic or periodic revolutionary changes are introduced into the system, and this throws off the balance of the entire organisation, causing members to make changes to adapt and respond to the consequences of the sweeping change. At the end of the period the organisation is returned to relatively stable activities that become the new norm. These conceptualizations are in line with Romanelli and Tushman's (1994) punctuated equilibrium theories. Radical changes can lead to creation of new business models, procedures and technological capabilities (Andriani and Hall, 2002; Hamel, 2006).

Becker and Whisler (1967) suggest a simplified conception of how innovation occurs in organisations. Using a process model they made a theoretical representation for the organisational implications of the presence of innovation. They propose that innovation occurs in a four stage processes of stimulation, conception, proposal and adoption. Their framework is discussed here because Becker and Whisler's (1967) descriptions are the most generic conceptualizations of the innovation phenomenon found, and present a usefully simplified skeletal understanding on which further research and more richly detailed conceptualizations of innovation can be built.

Although this simple generic "stage model" (term by Wolfe, 1994) can be found useful, Van de Ven and Poole (1990) discuss the importance of not restricting all innovation studies to a single model. This is not representative of the complexities of innovation processes, and can also lead to "self-fulfilling prophecies" (Van de Ven and Poole, 1990). In this research, the most generic model is considered to enhance the openness with which innovations are viewed in light of their unique characteristics. 
Birkinshaw, Hamel and Mol (2008) apply a variation of Becker and Whisler's (1967) stage model. In their model, they use the word "invention" to represent the conception stage. This is consistent with their definition of innovation as a change involving universal novelty. They include "theorizing and labelling", which represents information to both evaluate the innovation and legitimize its presence in the organisation. This information can also be referred to as feedback as it is used to inform change agents about the possible implications of changing in the future. They also combine proposal and adoption and refer to those two stages as implementation. Figure 3.3 presents a combination of both models, to provide a framework for understanding the process of innovation at IPONZ. Unlike the models from Becker and Whisler (1967), and Birkinshaw, Hamel and Mol (2008), this combined model is presented as a cycle, with a feedback loop from the end back to the beginning of the process.

\section{Innovation Process}

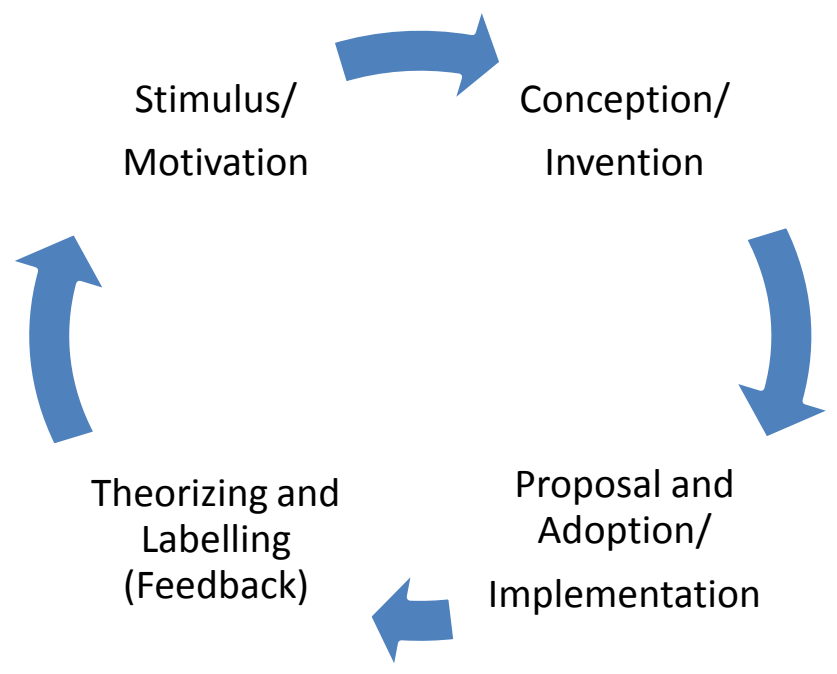

Figure 3.3 Understanding the process of generating and adopting innovations

\subsection{Innovation Research}

Different approaches have been taken to study the phenomenon of innovation and how it occurs in organisations. Wolfe (1994) asserts innovation studies are not 
comprehensive, with different approaches appearing independently re-invented, and are not cumulative. In his overview of the organisational innovation literature, he pointed out that as researchers were not fully aware of the broad range of other studies done on organisational innovation, many studies are disjointed from one another. A cumulative approach is proposed in order to progress the development of innovation studies. This research attempts to bring compatible theories of innovation and apply them in a cumulative way to IPONZ data, thereby building on pre-existing studies.

All the different aspects of innovating are complex and multi-faceted, more so than a simple structural representation can hope to describe (Van de Ven and Poole, 1990, p. 318). However an approach that examines several aspects of the phenomena in a way that reveals how they are interrelated is likely to lead to a richer understanding. Wolfe (1994) describes three streams of innovation research that categorize different aspects of innovation studied previously: Diffusion of Innovation studies, Organisational Innovativeness studies and Process Theory studies. Figure 3.4 illustrates Wolfe's (1994) identified perspectives of literature within the area of organisational innovation studies. This simple conceptualization of the bird's eye view of innovation studies helps to piece together the complex events and relationships involved in organisational innovation. His framework also offers a constructive way to understand what each perspective contributes to learning about innovation.

Diffusion of Innovation studies examines the transfer of innovation from organisation to organisation in a way that changes the collective development of a group of interrelated organisations. Organisational Innovativeness studies tries to establish a method for measuring how innovative an organisation is, and all the factors that influence that innovativeness. Process Theory studies attempts to unravel what happens when innovations are introduced into organisations, and how innovations are incorporated into organisations. The examination of $\mathrm{Ml}$ in this research will employ process theory approaches to study the development of innovation over time. 


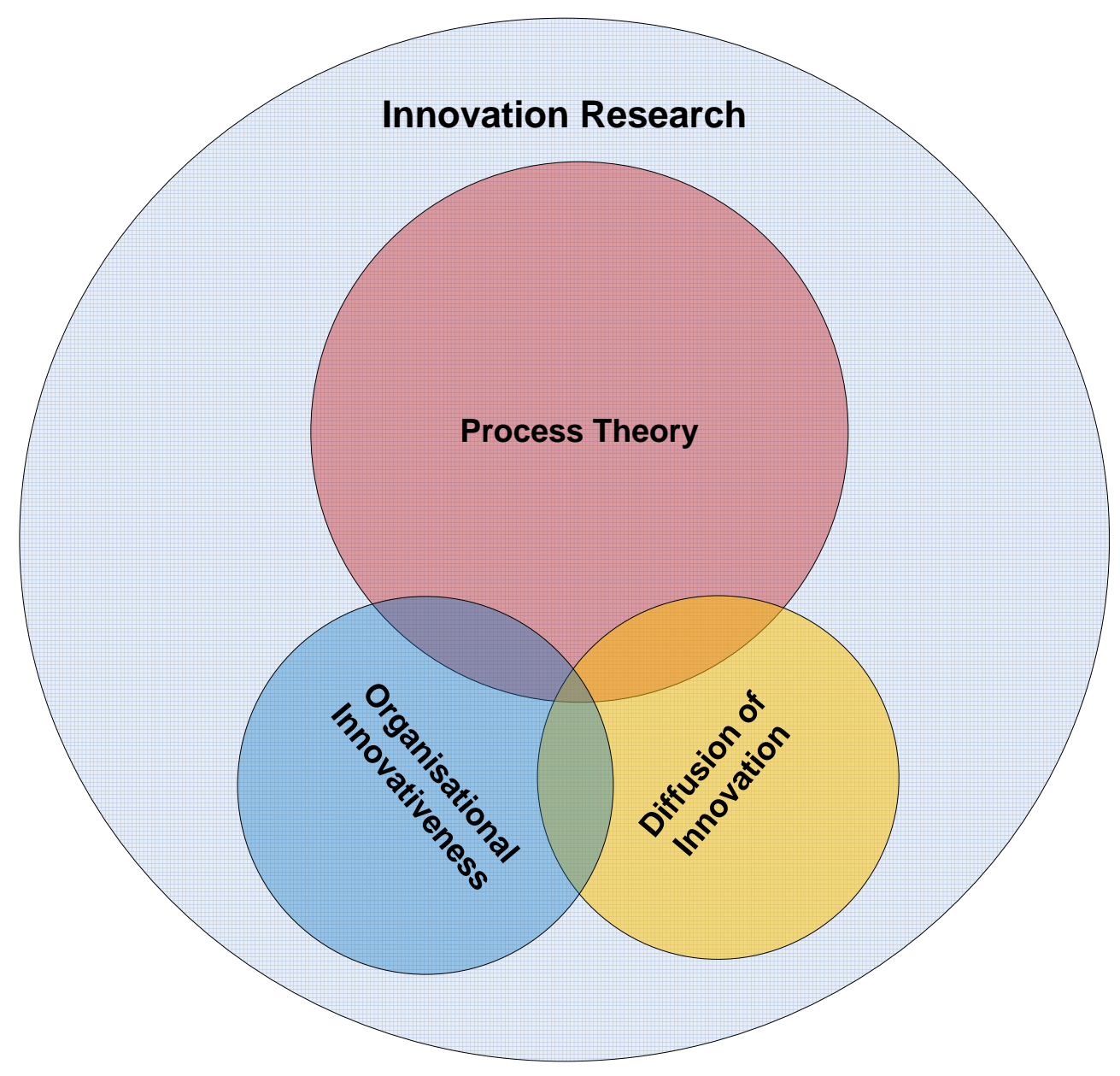

Figure 3.4 Overview of innovation research

Wolfe (1994) points out that although differentiation of the three streams is essential for recognizing the perspectives of different studies and evaluating their application to organisations, previous studies appear to mix up the three perspectives. They may be, because the different approaches look at different aspects of organisational innovation in ways that are not necessarily mutually exclusive. Therefore, a richer presentation of organisational innovation is likely to include more than one perspective of innovation, and without pre-conceived conclusions the same data set will inevitably uncover aspects of more than one stream. This research will focus mainly on identifying aspects of the data that reflect the process perspective, without necessarily excluding other perspectives.

Ideally, these three approaches should be distinguished for better focus and consistency. In reality however, because of the complexity of the phenomena, it is 
less likely to make a clear cut distinction among the 3 perspectives. Therefore, aspects of other approaches to studying innovation will likely be included in discussions of findings from IPONZ. Figure 3.4 represents this by overlapping and intersecting the 3 streams, with the biggest circle representing the main approach adopted. My focus on the Process Theory approach will help develop innovation studies by cumulatively contributing to existing process theories of organisational innovation.

Slappendel (1996) points to a progression from innovation as a static and finite occurrence to innovation as a continuing process (Edwards, 2000). A static finite occurrence implies that innovation is separable from other organisational phenomena, and quantitatively measurable. A continuous process implies greater complexity (Slappendel, 1996) and requires more in-depth examination to understand. Referring to Wolfe's (1994) and Slappendel's (1996) reviews, Edwards (2000) suggests that innovation studies will provide better exploration if they were examined as a process. Trends identified by Edwards (2000) indicate that processes are complex not static, and in order to understand them organisational actions and the organisational structures within which the actions occur need to be considered together, and not separately.

A separation of action from its contextual structures can be likened to the separation of milk from its cup of tea. In other words implications of the innovation on the organisation will not likely be manifest to a significant extent. Adopting the process perspective of innovation allows the incorporation of both actions within IPONZ, and the contextual circumstances surrounding those actions. This is because innovativeness studies and diffusion of innovation studies only focus on identifying the innovations themselves, their qualities, quantities and distribution. Alternatively, process perspectives allow for the examination of both the innovation themselves and the progression of conditions changing around them. 


\subsection{Defining innovation as a change process in organisations}

Innovation involves change, but more specifically novel change, and this research explores innovation using change as the core concept of analysis. Van de Ven and Poole (1995, pg. 512) define change as difference in an entity that can be observed over time (see also Van de Ven and Rogers, 1988). Weick and Quinn (1999) advocate that change as a process cannot be appropriately understood in isolation from its temporal nature and outside its context. Van de Ven and Rogers (1988) derived their requirements for analysing processes from the definition of change. Identifications of change in this research's study will combine both the actors who implement the changes and the structures in which the changes occur.

Change as a construct has been used to understand organisational development, and used so extensively that "change management" has become a practice and management field in its own right. Conceptions of organisational innovation align with conceptions of organisational change (Becker \& Whisler, 1967), because for an innovation to have any observable effect on its host organisation, the necessary changes have to be made for the organisation to adopt the innovation. Change is one of the necessities of organisational sustainability, as people need to respond to changes both inside and outside the organisation. Organisations also implement both planned and muddled changes according to what is considered expedient for their sustainability (Burgelman, 1991; Weick and Quinn, 1999; Van de Ven and Poole, 2005; Birkinshaw, Hamel and Mol, 2008).

Several different theories for identifying change co-exist in organisational studies. In spite of the differences, common threads of philosophical assumptions have been identified and used to categorize the different theory propositions. These philosophical assumptions give rise to internal consistencies that different theories share, presenting harmonized views of organisational change. Van de Ven and Poole (1995) examined change as a fundamental construct in social theory by presenting four ideal type theories of change and development -life cycle, evolution, dialectic and teleology. 
These four theoretical conceptions of social change show different philosophical assumptions about organisational existence. They are ideal type theories (Van de Ven and Poole, 1995), which implies that they are the purest form of that typology of change. Each category paints a clear picture of the assumptions that define them, and can be used to categorize existing theories of social change and organisational development (Van de Ven and Hargrave, 2006; Van de Ven and Poole, 1995). Figure 3.5 is an excerpt from Van de Ven and Poole's (1995) "Explaining Development and Change in Organisations", which illustrates the four ideal type theories and their proposed patterns for understanding change and development.

The life cycle theory can be used to categorize theories of social change where development is characterized by the biological processes between birth and death, with the view of organisations as semi-autonomous entities shaped by the conditions in their environment. The key assumption in life cycle theories is that organisations develop in an isomorphic manner, which means that they conform or change to fit into the pre-existing conditions of their environment. This also implies that their pattern of development will be the result of them implementing changes that comply with conditions in their environment (Hargrave and Van de Ven, 2006). It also implies that organisations die when their changes are no longer compatible with their environment. It is this isomorphism assumption that provides a justification for the validity of the life-cycle theory. 
Process Theories of Organizational Development and Change ${ }^{\alpha}$

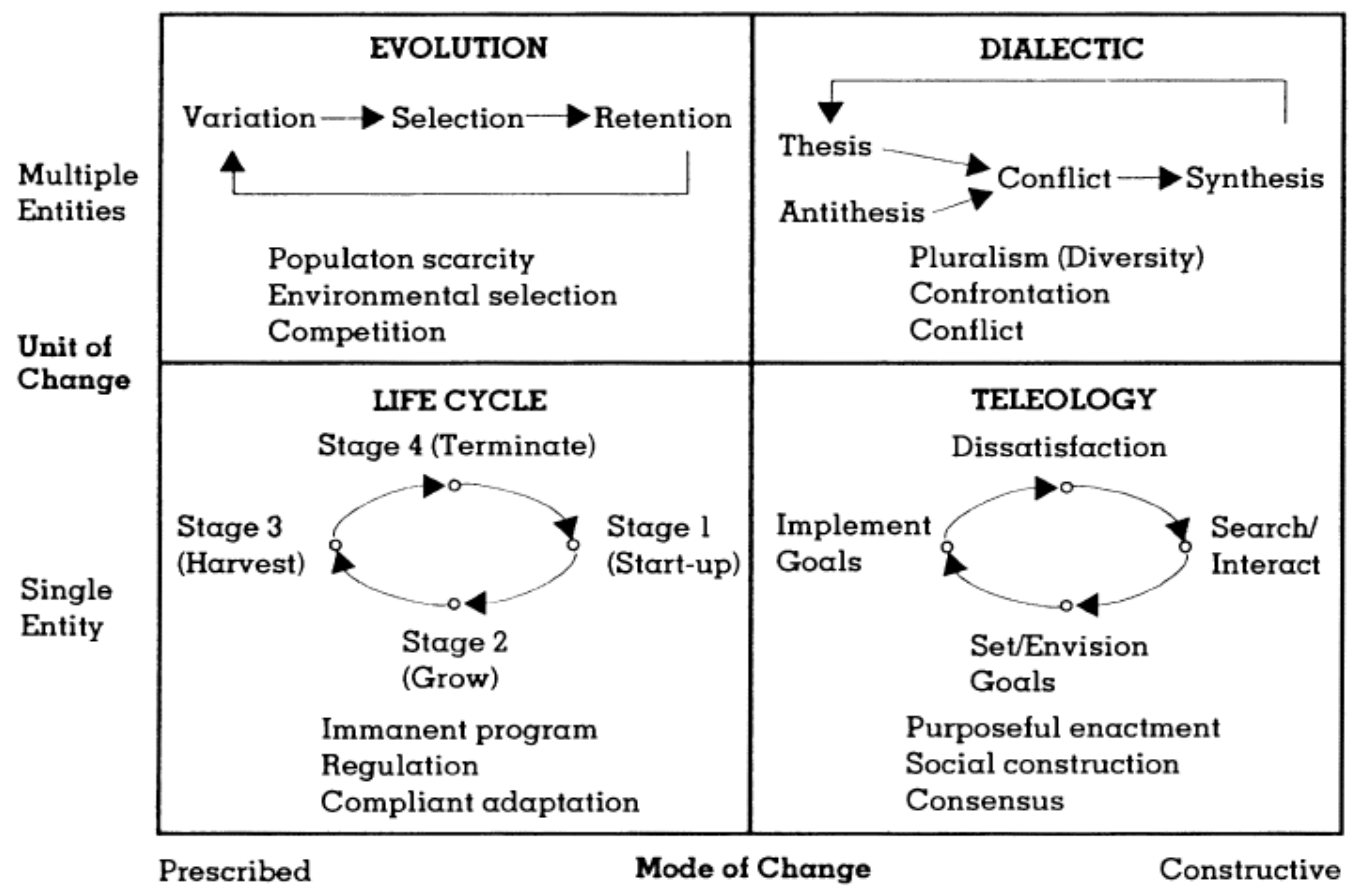

${ }^{a}$ Arrows on lines represent likely sequences among events, not causation between events.

Figure 3.5 Illustration of four process theories underlying explanations of organisational change (Van de Ven and Poole, 1995)

Other theories of social change can be categorized into the evolution theory of development, in cases where only some variations from change are selected and retained for future development. The evolution theory is also isomorphic, assuming continuous organisational conformity, but evolution theory uncovers change patterns different from the life-cycle theory (Hargrave and Van de Ven, 2006). Studies in this category establish that social change occurs through selection and retention of change events to increase the likelihood of gaining scarce resources for survival.

The dialectic theory, which is the third typology, emphasise relationships as the driving force for social change, particularly relationships of opposition. These theories assert that change emerges from the resolution of conflicts between opposing entities (Hargrave and Van de Ven, 2006), be they events, processes, people or values. The outcome of change in dialectic theories is either a cooperation of both sides or a domination of one side over the other. A key 
assumption for this theory is that conditions in the organisation are determined by the winners of the power struggle.

The fourth and final theory offered by Van de Ven and Poole (1995) is the teleological categorization of social change theories. Teleology represents theories of organisational purpose and pursuit. The assumptions are that organisations exist to fulfil specified purposes, and that the operations of the organisation serve as a means through which those purposes can be fulfilled. An analogy that describes the concept of changing in this category is that of running a race for a prize. They search for the best route to get to the finish line, and they take steps on that route. Out of all four typologies of change, teleology theory focuses on the aspects of change that are relevant to the application of goal-setting and innovation for IPONZ. In the teleological perspective change occurs as a means to reach a desired state. Therefore, this perspective provides the basis for understanding innovation as a means of progressing towards organisational goals. Accordingly teleology perspective of organisational change will be used to define innovative changes at IPONZ. The teleological typology considers how an organisations present or past state is related to its future state. Consequently historical information about the past changes that took place at IPONZ will be the background for understanding the impact of recent changes.

\subsection{Management Innovation}

"Over the past century, breakthroughs such as brand management and the divisionalized organization structure have created more sustained competitive advantage than anything that came out of a lab or focus group."

(Gary Hamel, 2006)

Management Innovation (MI) is a non-technical innovation that can be described as a novel formation or re-reformation of activities to organise and co-coordinate 
people, tasks and resources. It is considered non-technical innovation, because it cannot be quantitatively measured or physically represented. It requires a significant novel change to management practices (Teece, 1980, pg. 464), and leads to changes in process designs, policies and organisational forms (Van de Ven and Poole, 1990, p. 316). MI can be used interchangeably with administrative innovation (Teece, 1980). While a single novel non-technical change implementation can be considered innovative, it is not considered MI until it affects a significant practice in the management of the organisation. $\mathrm{MI}$ can be included in the implementation of strategic innovation (see Govindarajan and Trimble, 2005a). Strategic innovation is the orchestrated combination of multiple innovations, both technical and non-technical, in an organisation.

A classic example of MI is Henry Ford's moving assembly lines, which introduced interchangeable parts and led to standardised manufacturing processes. A recent example of $\mathrm{Ml}$ is the $\mathrm{m}$-form structure of organisations where multiple differentiated products and services are offered by different semi-autonomous units in the same organisation, to diversify business risk and build capability (Birkinshaw, Hamel and Mol, 2008). Another example is the personnel principle of Toyota Corporation that affords every member of the organisation opportunities to contribute to the development of manufacturing systems, and provides the facilities for them to express and explore their ideas (Hamel, 2006).

In comparison to studies of other non-technical innovation such as service innovation and production process innovation, research on $\mathrm{Ml}$ is limited. This is in spite of its emerging reputation as one of the defining attributes of organisational sustainability (Stata, 1994; Hamel, 2006; Birkinshaw, Hamel and Mol, 2008). Implications of generating and implementing $\mathrm{Ml}$ are under-researched, though general theories of technical and non-technical innovation have been applied to MI (Sapolsky, 1967; Teece, 1980; Van de Ven and Poole, 1990). Other studies and discussions also acknowledge deficiency in the studies that are focused of understanding MI (Hamel, 2006; Birkinshaw, Hamel and Mol, 2008). 
Exploring how and when $\mathrm{Ml}$ emerges will require an understanding of the change processes that led to its generation and implementation. This research focuses on MI by examining the change processes surrounding the existence of innovation at IPONZ. The process perspective is important to extensively uncover the implications of those changes processes that led to MI. Other studies have examined the existence and development of $\mathrm{MI}$ in organisations. However, no prior work was found that uncovers the situations from which $\mathrm{Ml}$ emerges, nor were any studies found that carried out in-depth analysis of the implications of having such innovation in the organisation.

Birkinshaw, Hamel and Mol's (2008) provide different conceptualizations of MI. They identify studies of $\mathrm{Ml}$ examined through an institutional perspective, a fashion perspective, a cultural perspective and a rational perspective. Their typology is shown in Figure 3.6a, where they attempt to offer an understanding of the different views of $\mathrm{MI}$, and to describe the elements that drive its implementation. They describe $\mathrm{Ml}$ as a change that is "new to the state of the art", referring to only examples of universally novel management change. In this study of $\mathrm{MI}$, both universal novelty and contextual novelty will be examined.

Each category in Figure 3.6a offers varied areas of understanding of the inputs, processes and outputs of MI. The industrial perspective uses concepts that focus on inter-organisational tendencies and the outworking of change at a macro multimarket industrial level. The fashion perspective uses the temporary popularity analogy of fashion trends to explain how new management concepts are created, spread and decline in industries, across markets and among groups of organisations operating through connected networks. The cultural perspective provides an intraorganisational perspective, where changing interactions between organisational players give rise to new types of management activities. The rational perspective also has an intra-organisation focus, however it incorporates the interrelationship dynamics between the organisation and its environment, and how changes in one creates a need for changes in the other. Though this typology focuses mainly on $\mathrm{MI}$, it assimilates to Van de Ven and Poole's (1995) theories of organisational change and development. 
Key Features of Four Perspectives on Management Innovation

\begin{tabular}{|c|c|c|c|c|}
\hline Fectures & $\begin{array}{l}\text { Institutional } \\
\text { Perspective }\end{array}$ & Fashion Perspective & Cultural Perspective & Rational Perspective \\
\hline $\begin{array}{l}\text { Representative } \\
\text { papers }\end{array}$ & $\begin{array}{l}\text { Barley \& Kunda } \\
\text { (1992). Bendix } \\
\text { (1956). Cole (1985). } \\
\text { Guillén (1994). } \\
\text { Kossek (1987). } \\
\text { Strang \& Kim } \\
\text { (2005). Weitz \& } \\
\text { Shenhav (2000) }\end{array}$ & $\begin{array}{l}\text { Abrahamson (1991. } \\
\text { 1996). Abrahamson } \\
\text { \& Fairchild (1999). } \\
\text { Clark (2004). } \\
\text { Huczynski (1993). } \\
\text { Kieser (1997). Mazza } \\
\text { \& Alvarez (2000). } \\
\text { Staw \& Epstein } \\
\text { (2000) }\end{array}$ & $\begin{array}{l}\text { Gill \& Whittle (1992), } \\
\text { Knights \& McCabe } \\
\text { (2000). Knights \& } \\
\text { Murray (1994). McCabe } \\
\text { (2002). Stjernberg \& } \\
\text { Philips (1993). Zbaracki } \\
\text { (1998) }\end{array}$ & $\begin{array}{l}\text { Alänge, Jacobsson, \& } \\
\text { Jarnehammar (1998). } \\
\text { Chandler (1962). } \\
\text { Damanpour (1987). } \\
\text { Kaplan (1998). } \\
\text { Kimberley \& } \\
\text { Evanisko (1981). } \\
\text { Tichy \& Sandstrom } \\
\text { (1974). Yorks \& } \\
\text { Whitsett (1985) }\end{array}$ \\
\hline Core question & $\begin{array}{l}\text { What institutional } \\
\text { conditions give } \\
\text { rise to the } \\
\text { emergence and } \\
\text { diffusion of } \\
\text { management } \\
\text { innovations? }\end{array}$ & $\begin{array}{l}\text { How do aspects of the } \\
\text { supply of and } \\
\text { demand for new } \\
\text { management ideas } \\
\text { affect their } \\
\text { propagation? }\end{array}$ & $\begin{array}{l}\text { How do management } \\
\text { innovations shape. } \\
\text { and get shaped by. } \\
\text { cultural conditions } \\
\text { inside an } \\
\text { organization? }\end{array}$ & $\begin{array}{l}\text { What is the role of } \\
\text { managers in } \\
\text { inventing and } \\
\text { implementing new } \\
\text { management } \\
\text { practices? }\end{array}$ \\
\hline $\begin{array}{l}\text { Key factors } \\
\text { influencing } \\
\text { the } \\
\text { innovation } \\
\text { process }\end{array}$ & $\begin{array}{l}\text { Institutional } \\
\text { conditions and } \\
\text { attitudes of major } \\
\text { groups of } \\
\text { influencers }\end{array}$ & $\begin{array}{l}\text { Suppliers of new } \\
\text { ideas and the } \\
\text { legitimacy of their } \\
\text { proposals }\end{array}$ & $\begin{array}{l}\text { Culture of the } \\
\text { organization in which } \\
\text { the innovation is } \\
\text { introduced }\end{array}$ & $\begin{array}{l}\text { Actions of key } \\
\text { individuals driving } \\
\text { the process inside } \\
\text { or outside the } \\
\text { organization }\end{array}$ \\
\hline $\begin{array}{l}\text { Role of human } \\
\text { agency in } \\
\text { driving the } \\
\text { process }\end{array}$ & Rarely discussed & Rarely discussed & $\begin{array}{l}\text { Agents are important but } \\
\text { constrained by power } \\
\text { relations and } \\
\text { traditions }\end{array}$ & $\begin{array}{l}\text { Agents initiate and } \\
\text { drive the process } \\
\text { within an organiza- } \\
\text { tional context }\end{array}$ \\
\hline $\begin{array}{l}\text { Level of } \\
\text { analysis }\end{array}$ & $\begin{array}{l}\text { Firm plus industry/ } \\
\text { country }\end{array}$ & $\begin{array}{l}\text { Firm plus market for } \\
\text { new ideas }\end{array}$ & Firm plus individual & Individual plus firm \\
\hline $\begin{array}{l}\text { Process of } \\
\text { change and } \\
\text { outcome of } \\
\text { innovation }\end{array}$ & $\begin{array}{l}\text { Progressive changes } \\
\text { in management } \\
\text { ideology and/or } \\
\text { practice. } \\
\text { sometimes toward } \\
\text { more effective } \\
\text { ways of working }\end{array}$ & $\begin{array}{l}\text { Cyclical process of } \\
\text { hype then } \\
\text { disillusionment; no } \\
\text { evidence that } \\
\text { innovation leads to } \\
\text { long-term benefits }\end{array}$ & $\begin{array}{l}\text { Socially constructed } \\
\text { change process: } \\
\text { usually very little } \\
\text { change in way of } \\
\text { working and } \\
\text { perpetuation of } \\
\text { existing power } \\
\text { relations }\end{array}$ & $\begin{array}{l}\text { Progressive changes } \\
\text { in management } \\
\text { practice toward } \\
\text { more effective ways } \\
\text { of working: success } \\
\text { not guaranteed }\end{array}$ \\
\hline
\end{tabular}

Figure 3.6a Typology of Management Innovation Perspectives 
Birkinshaw, Hamel and Mol's (2008) typology of MI perspectives does not only offer a conceptualization of the generation and adoption of $\mathrm{Ml}$, but also offers a conceptualization of the interactions involved in an organisation and in its environment. This organisation-environment conceptualization offers a framework for understanding the actions involved in generating and adopting innovation within the organisation, across markets and across an industries. They focus on organisational actors as the principals of innovation. Their conceptions of MI place emphasis on different combinations of the external macro, the external micro, the internal macro and the internal micro activities shaping an organisation. That is to say that $\mathrm{MI}$ can be seen as the result of novel change events taking place in the interactions between actors in the market and the industry. Alternatively, MI could be the result of individual and group action within an organisation's internal environment.

This research focuses on the rational perspective of $\mathrm{MI}$, as it is relevant to the rationalization philosophy that exists in New Zealand Government agencies. The diagram following (Figure 3.6b) illustrates the bi-directional influences in the organisation and its environment and the emphasis that different perspectives place on innovation action. In the rational perspective, $\mathrm{MI}$ is a result of the purposeful actions by individuals or groups operating within an organisation, who also interact with actors in the environment to generate and adopt innovations. This perspective offers conceptualizations of management innovation within the context of environmental influences, which will be applied to IPONZ. 


\section{Management Innovation Interactions}

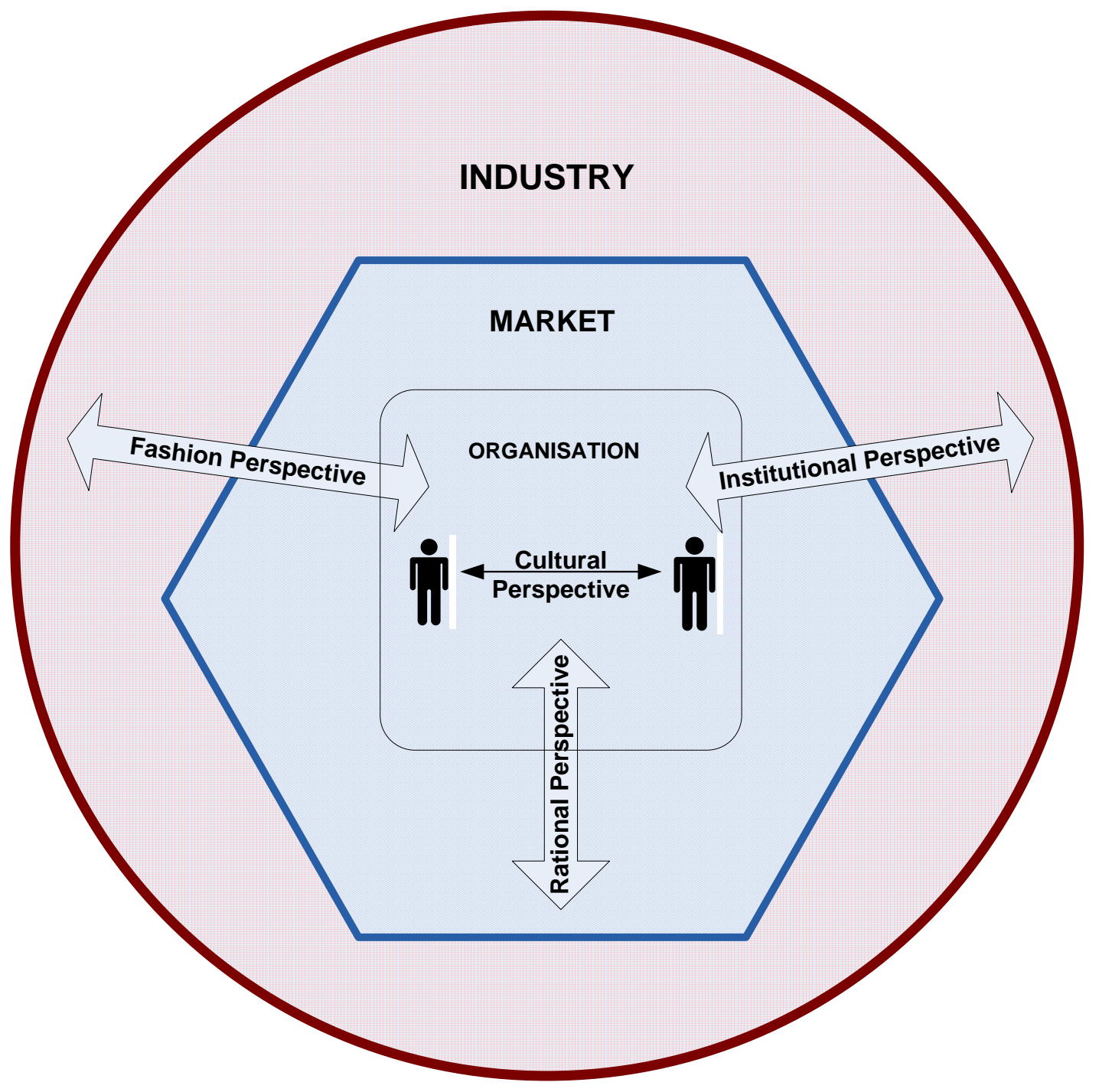

Actions: Ideas, Tasks and Relationships

$\longrightarrow$ Transaction within internal system: incentives and resources

Transaction with external environment: incentives and resources

Figure 3.6b Interactions to generate and adopt management innovation 


\section{Chapter Four}

\subsection{METHODOLOGY}

\subsection{Why Case Study?}

I was employed at IPONZ from 2009 to 2010, at a time when the organisation was settling into some major changes that had been introduced into the organisational system. Preparations were also being made to undergo some more changes. Being in the midst of such dynamic change in a relatively small organisation gave me an employee's perspective of the processes and implications of organisational change. However the duration of my stay and my role did not permit me to experience firsthand the full extent and scope of the changes being made. On the completion of my extended employment term, I took up the opportunity instead to explore the organisation from the outside, as a researcher.

Change is inevitable, but what organisations seek to do is to influence or direct change for their benefit, anticipating the requirements of future survival and success and acting in accordance with that, not unlike a lot of individuals. What seems to be emerging as arguably one of the most valuable kinds of change in organisational existence is innovative change (Gopalakrishnan, Kessler and Scillitoe, 2010). The view that organisations seek to pursue their progressive development or at least to maintain their existence can have various differing interpretations, in terms of what an organisation actually does to achieve that.

This research study takes the perspective that organisations are semi-autonomous entities existing under uncontrollable circumstances, but can be capable of pursuing their progressive development, and can possibly obtain the knowledge that informs them of adequate means to achieve their pursuits. Therefore in this view, change, and particularly innovative change is implemented to ultimately achieve an organisation's pursuits. This view of organisations can be considered a teleological perspective (Van de Ven and Poole, 1995). In the words of Van de Ven and Poole (1995): 
"In this theory, there is no prefigured rule, logically necessary direction, or set sequence of stages in a teleological process. Instead, proponents of this theory focus on the prerequisites for attaining the goal or end state: the functions that must be fulfilled, the accomplishments that must be achieved, or the components that must be built or obtained for the end state to be realised. These prerequisites can be used to assess if an entity is developing; that is, it is growing more complex or more integrated, or it is filling a necessary set of functions. We are able to make this assessment because teleological theory posits an envisioned end state for an entity, and we are able to observe movement toward the end state vis-a-vis this standard."

Understanding how an organisation has emerged through the progressions and regressions (Van de Ven and Poole, 1995, pp. 512), provides a constructive background to knowing the implications of decisions and actions. The importance of understanding how things have worked in the past was put succinctly by Cummings and Daellenbach (2009) when they recalled that "those who forget history are destined to repeat it", suggesting that in order to understand the nature and impact of something, and its potential for the future, its past has to be deciphered as a worthy part of the foundations of future development.

In order to explore innovative changes at the organisation, with the view that changes were directed to achieve organisational pursuits; changes had to be reconciled with organisational pursuits. IPONZ is a suitable case for this exploration, as an organisation with ample sample of changes to explore and as an organisation that explicitly expresses or formally represents organisational pursuits. The aim of this study was to address the following main question by answering the four subquestions below it:

\section{Research question}

Is there a relationship between goal setting and the development of innovation in managing the administrative function of an organisation? 
1. Do changes implemented at IPONZ contribute to the achievement of goals set at the Intellectual Property Office of New Zealand?

2. Are there changes implemented at IPONZ that can be considered "innovative"?

3. Have there been organisational goals at IPONZ, which were set for the development of innovation within the organisation?

4. Are there clearly identifiable management innovation changes that have been implemented at IPONZ that contributed to the achievement of set goals?

John Gerring (2007) defines case study research as the study of a phenomenon defined as an observable "unit" in time. Case studies can be based on one or several subjects of observation and testing, but the objective is insight into a unitary phenomenon, identifiable and distinguishable from other phenomena (Gerring, 2007). The advantage of distinguishing a unitary phenomenon from others is that it affords a richer understanding of the phenomenon, taking note of specifics that would otherwise be lost in the study of multiple phenomena or multiple cases. In some cases, the discovery of certain details may prove to be the defining attribute of the phenomenon, for example in motivation, monetary compensation which is not the only factor that motivates, in a lot of cases produces the most stimulation for action (Pessiglione et al, 2007). In social sciences the value of case study research is sometimes based on the assumption that what happens in one could also happen in many (Gerring, 2007), though research findings are not usually generalised beyond that particular case.

One recognised use for case study research is the clarification of causal relationships and correlations in quantitative research (Gerring, 2007). Multi-case and survey research are often used to establish the relationship and correlation of two or more elements in organisation studies. However, the acceptance of these relationships is questionable without consideration of the causal mechanisms that define those relationships. Causal mechanisms define what actually makes the 
relationship work. For example there might be an identified correlation between cases of alcohol addiction and cases of absenteeism, but this correlation holds little information value for reality until discovery is made of HOW alcohol addiction is related to absenteeism. Without knowledge of the causal mechanisms defining relationships, the "HOW" question is not easily answered. There can be other options, but case study research provides clarifications of related organisational elements and the causal mechanisms linking them.

The main question posed in this research relates to discovering and understanding any relatedness between multiple elements of organisational activities, while the objective of this study is exploration. Relationship modelling is typically considered "variance studies" which are pre-supposed to require quantitative cross-case surveys (2005). However, cross-case surveys are relevant to topics where indications of a relationship have already been previously established, and the validity of these indications can be tested using a hypothesis. In the case of this study, no previous indications were found in the literature that directly connected goal-setting measures and innovation. Therefore the objective of this study is directed towards identifying indications that there can be such a connection, exploring an organisation that shows the use of both elements and discovering the various possibilities of that connection within that specific organisation.

In this study of innovative changes, case study research is especially useful for identifying $\mathrm{MI}$ because unlike technical innovation which can be physically manifested, $\mathrm{MI}$ requires in-depth examination to identify the implications of the changes made. It is easier to identify elements in space than it is to identify elements in time (Gerring, 2007), and technical innovation can be observed in space whereas non-technical innovation can only be identified in time, though the implications of non-technical innovation may produce technically innovative changes that can be observed in space. Because of the subtlety in manifestation, a suitable exploration of such a non-technical innovative change requires more indepth exploration. 
This case study research will contribute to theories on the sources and processes of innovative changes in organisations. Opportunities for enriching existing innovation research can also be uncovered, in this attempt to reconcile other aspects of organisational activity with innovation studies. Van de Ven and Rogers (1988) criticised component-based theories of innovation where innovation attributes and variables were isolated and examined using mostly data from the inventor or data from top executives of organisations that adopted innovations. They caution that in addition to being temporally limited, these studies also discount the structural context of innovations and discard the accounts of the individuals whose actions implemented the innovations. In this study, knowledge of structural components of the organisation and multiple perspectives of organisation members are incorporated.

\subsection{Research Design}

Building on contributions from variance studies of the elements in play within and around innovation activities, process studies can be used for the study of developmental progressions in introducing and adopting innovation (Van de Ven and Poole, 2005). Process research is increasingly recognised and given attention in innovation studies. Initially, considerable research was conducted on the intraorganisational attributes of being innovative, and the inter-organisational dynamics of spreading innovations, but very little was known about "how" innovations actually came about in organisations. After Van de Ven and Rogers (1988) raised the inadequacy of solely focusing on innovation variables in diffusion studies and organisational components in innovative firms, Van de Ven and others produced a myriad of innovation studies using the process perspective. As a result of this interest, there have been developments in research methodologies for studying innovation processes.

Gerring (2007) notes that case study research has a reputation for using ambiguous and hazy methods for conducting research, which may be associated with the 
novelty factor in case study analysis. With each case, the subject(s) is explored individually and in greater detail than in cross-case studies, and because of the unique quirks uncovered in each case, it is difficult to employ formulaic methods. Instead, the methods for each case have to be tailored to match the characteristics of the case, or adapted to respond to the individual qualities uncovered. Gerring (2007) also mentions the perception that case study researchers have to figure it out as they go along, and therefore sometimes are unable to articulate everything that was done to conduct the study, and the specifics of the design. In this case however, process predecessors have already established functional designs and methodologies that can be adapted for the uses of this study. The view is much better if one can "stand on the shoulder of giants", and the methods used here are established by such views.

The availability of extensive research on the topic of innovation voids the need to invent the wheel (Silverman, 2005), therefore more productive research will build on existing research as opposed to re-inventing the wheel, which is less likely considering the limited scope and resources of this study. Therefore a postpositivist view of organisations can be permissible considering the wealth of existing research on goal setting and innovation. A post positivist view asserts that aspects of knowledge can be verified as truth, though perfect truth can never be verifiable. This choice allows the use of prior verified knowledge, as a basis to identify and verify future knowledge.

Following this approach to case study, interviews are used to collect data from organisation members, historical documents are reviewed on past events and implemented changes at IPONZ, as well as past performance volumes. Historical information is used to identify changes at IPONZ, which are verified by interview data, and process theories and change theories are investigated to inform conceptions of innovation. Thematic analysis is employed to understand the interview data, which is guided by both emergent topics from the interviews and aspects of innovation research. A literature review of innovation and goal-setting studies is also conducted to inform the understanding of innovation and 
performance management methods. The results are discussed in detail and findings are explained in light of IPONZ developments and achievements.

\subsection{Methods}

Understanding events at IPONZ within the environment that IPONZ operates, is key to understanding the innovative developments at IPONZ. Van de Ven and Poole (1990) reported a longitudinal study of multiple innovations over six years, including both technical and non-technical innovation. They proposed a construct definition for their data that can be consistently applied to all the different innovations. This clear conception of data constructs improves the validity of descriptions of phenomenon by explicitly laying out the properties that are used to understand the phenomenon. For example they used "incidents" and "events" with specifically defined parameters to understand the development of all the innovations they studied over time. Although this study looks at multiple innovations, it is important to apply the same constructs to all the different innovations in order to identify areas of difference between the innovations. The constructs will serve as a point of comparison to establish how the different innovations affected the organisation's development.

\subsubsection{Constructs from Current Theory}

Both goal-setting and innovation literature were reviewed, as well as publications on IPONZ. Locke and Latham's (1979) Goal Setting Theory (GST) for motivation was examined in detail as well as Locke, Latham, Saari and Shaw's (1981) Goal Setting prescriptions for task performance. The use of goals was also examined in high level organisational management, such as strategic goals involving explicit statements of purpose and intent.

Innovation literature can be compared to the woolly mammoth, because not only does it have a giant body of literature, it also has thick and long peripheral studies and topics that affect the manner in which the main body is perceived. Therefore 
after preliminary studies were conducted to understand conceptions of innovation, a delineated perspective of innovation studies was employed. The process perspective of innovation studies were adopted because they were suitable to the objectives of this study.

The empirical and field studies conducted on GST offers a theoretical framework for understanding the relationship between setting goals and performance. This framework is used to theoretically arrange the data collected that relates to goals and the perceptions of how those goals affect employees' work. Theories on the uses of goals in organisations other than the prescribed theory were derived from performance management and strategic management literature where goals or objectives describe an aim that attempts are made to achieve.

The examination of innovation as a change in organisations has the potential to uncover a rich understanding of innovation in organisations. Furthermore, the implementation of innovation is at the very core of organisational innovativeness which becomes evident because of the changes achieved by the organisation. Therefore understanding innovation as a type of change process makes it more compatible with other aspects of organisational activities which also undergo changes. It also reduces the mysticism and "black box" (Van de Ven and Poole, 1990) impressions people have of implementing innovation. Perhaps this is part of the appeal of innovating, but in terms of organisational activities, the less mystery there is, the more effectively managed the processes can be.

The literature served as a basis for understanding innovation and performance management phenomenon at IPONZ, which guided the structuring and understanding of the data during analysis (Weston et al, 2001). Although this study does not use deductive reasoning in that it seeks to uncover new the possibility of relationships, it is guided by previous theory and research. This is because it is difficult to understand large amounts of information without conceptual models (Van de Ven and Poole, 1990). The literature review serves as a source of structure for modelling a way of seeing the data, and a way of understanding the interplay of different elements, that can also be used for critical comparative analysis to identify 
differences in indications from the data. Van de Ven and Poole (1955) identified numerous differences when comparing previous theories and models to their studies of multiple innovations.

\subsubsection{Data Collection}

Both primary and secondary data is important for this study because it is an exploration of certain developments in the progressions through organising and delivering services over time. This requires an understanding of the history of IPONZ through the years as a background for employees' perceptions, especially in a case like IPONZ where many members of the organisation have been employed there for decades. Historical information helps to establish the progression of changes that had been implemented at the organisation. Exploring development also requires a perspective of the current state of IPONZ and expectations of the future state of IPONZ. Through interviews with organisation members in the different teams at IPONZ, perspectives of past events, present activities and future expectation is collected. These perspectives are used to verify the historical information collected, and confirm events identified through secondary data.

To collect historical information, a preliminary study was done to collect secondary data consisting of organisation reports and publicly accessible internal documentation. The information from this was combined with other media publications and documents concerning events that took place at or relating to IPONZ. Few articles were found in media publications, and some were found in archived organisation documentation relating to IPONZ and its overarching ministries which includes both Ministry of Economic Development (MED) now and Ministry of Justice in the past. Majority of the historic information was derived from pieces of legislation and legal publications. This is due to the perception that IPONZ work mainly concerns the administration of legislation, through legal regulation of business activity. Secondary data and other information were used to understand the progression of events that took place at IPONZ, and to identify significant changes that were implemented that shaped the development of the organisation. 
A total of 26 interviews included in this study. The information they provided served as primary data about the past and present state of IPONZ. 27 participants were interviewed, but one interview had to be eliminated from the data because it was poorly recorded. Organisation members were included from different levels and functions of operations. Interviews represent the expressed perspective of organisation members articulated in a formal setting. There can be critics of the use of interviews to inform researchers about the reality of events, such as the objection that interview participants can either exaggerate of play down certain aspects over others in their accounting of events. In the case of this research, the interviews are not received in isolation, and play the role of both primary information source and triangulation method. In addition to the interview and prior to the interviews being conducted, other sources of information about past and present events were explored. The individual perceptions of interview participant instead of being a disadvantage, actually improved the richness of the data by providing varying details of the same event.

Another possible objection to the use of interviews as a primary source is the methodological question about the extent to which a person's perceptions actually reflect reality (Silverman, 2006). Although this question directly relates to the relevance of chosen methods for the research question, part of the answer lies in the philosophical stance of the researcher. The case is projected to explore the possibility of a relationship between the use of administrative innovation and the use of goal setting as a performance management measure. This is done by exploring the implementation of $\mathrm{Ml}$ changes alongside the use of goal setting, using the accounts of organisation members to understand the goal setting and innovation activities in the organisation. The reliance on these accounts can be justified in the case of IPONZ because of the bureaucratic structure of the organisation and the pattern of Government agencies, where increased accountability and documentation measures have progressively increased (Scott, Bushnell and Sallee, 1990; Evans, Grimes, Wilkinson and Teece, 1996; Norman and Gregory, 2003). 
Documentation of activities means that more of the organisation will have access to the specifics of events and are less likely to use self-propelled assumptions to fill in the gaps in their mind. The use of accountability measures for both management and staff makes it more likely for them to keep track of major events, though focus might be concentrated on events that had the most impact on their person. Under a post-positivist view, although personal accounts cannot present comprehensively every single thing that happened at IPONZ, with the right use of interview questions the researcher can maintain focus on events that are relevant to the study and filter out details which can be validated from multiple sources.

Sampling measures were non-random, as participants were selected according to role availability and with permission from the managers. The technique for sampling can be viewed as or a combination of both accidental and purposive, (Bouma and Ling, 2004). Accidental sampling the result of convenience of participants and availability, while purposive sampling is based on an assumed typical representation of pre-defined criteria (Bouma and Ling, 2004). The intention of the researcher was to enlist participants with as much preferred characteristics as possible, characteristics such as high aptitude for organisational operations beyond their team, experience with multiple roles and multiple teams, lengthy employment tenure, and involvement with operations beyond the core functions of their role. As a balance between older employees and newer employees, participants were also chosen that had worked at IPONZ for less than two years. In these ways sampling attempts were purposive. However this was slightly restricted by the need to gain approval from the managers in charge of participant teams, and actual attendance of the interviews. There were cases where the most suitable participant in the team was either not available or was not approved to be interviewed, and in such cases a more convenient choice was accepted, making those choices more accidental than purposive.

The use of non-random sampling for a post-positivist paradigm does not appear conventional because positivist and post-positivist perspectives seek to establish knowledge of "reality". In order to do this, in most cases methodologies are designed to be generalizable to an entire population or a portion of a population. 
This requires a random sample of the target population because a non-random sample will restrict the application of results to the pre-defined criteria used to select the sample, restraining the reliability of generalisations (O'Leary, 2004). This research is looking into the activities relating to innovative change, as well as certain performance management techniques, with the intention of finding any relatedness in the processes involved. This not only requires in-depth exploration, but also will uncover findings that resulted from the unique configuration of people and activities at IPONZ. Therefore the choice of methodology will be more specifically tailored and less standardised, not leaning towards generalizability. The value of this kind of research is insight (Gerring, 2007) that illuminates the interplay between different aspects of organisations and contributes to knowledge about issues that are not obviously manifested.

The choice of research questions was made using logical relatedness to the research question. There are four sub questions that are constructed to inform the main question by looking for goals related to innovation, looking for changes related to innovation and looking for any clues of relationship between the two. The sequence of the questions is to first ascertain the effects of goals, then to ascertain the use of innovation, then to directly inquire into any relatedness. Interview questions were compiled to mirror the research question, without the use of questions that impose relatedness.

Interview questions were drafted differently for staff and for managers. Staff questions were drafted for semi-structured interviews because of the possibility that staff would require prompting to recall past events and express more detailed answers. Also because semi-structuring allows the freedom for participants to explore tangents of related topics that may not directly answer the question but informs the researcher of goal setting and innovation activities. The questions list was used to refocus the participants when tangents did not appear to be of relevance to the study.

Questions for managers were unstructured, where drafted points of discussion served as a reference for the flow of the interview, reminding the researcher of the 
topics that should be covered. Because of the leadership roles of managers and their anticipated involvement with the setting of objectives, they were allowed to discuss in detail their understanding of goal setting as a performance management method. They were also prompted to discuss their conceptions of innovation for IPONZ and the changes they had observed during their tenure. Unstructured interviews are suited for such discussions because it allows the managers the freedom to express their perceptions of how IPONZ activities should be conducted. This provides the researcher with contextual data for understanding some of the motivations behind the activities endorsed at IPONZ, and decisions to make changes. It also increases the likelihood of participants' genuine disclosure.

One challenge in conducting the interviews was the prior knowledge that the researcher had of the organisation and the methodological requirement not to "lead" participants towards biased answers. Prior employment at the organisation meant that the researcher had preconceived conceptions of the system of activities and organisation members. This prior knowledge had to be consciously put aside in conducting the interviews, and explicitly articulated to participants whenever there was a perceived tendency to show bias. In other words, the researcher approached interview participants with a carefully reclaimed "ignorance" of internal activities. Realistically, no claims of perfect objectivity can be made in conducting research, but according to the post-positivist perspective, possibilities of bias should be curtailed as much as is practicable to diminish inappropriate a priori judgements. In such circumstances the objective is to be cautious of opportunities for reinforcing prior understanding, and to favour more critical examination.

In order to understand the direction of desired goal achievement and expected benefit of end-results, each participant was asked to answer two questions related to the ultimate purpose of IPONZ the organisation. They were also asked to share their views of what a "perfect" IPONZ would look like. This technique was especially useful in exploring beyond obvious participant perceptions, using idealistic hypotheticals to open up expressions of internal motivations, in the context of their work. This method was adopted from a concept described by Mann (2004) called Ideal Final Result (IFR). According to Mann, understanding the IFR gives the 
organisation the opportunity to chart innovation achievements against the ultimate goal, thus increasing the likelihood of progression towards the goal.

With the two "purpose" questions, the objective was not to seek consistency in answers, but to explore areas of differentiation in the perceptions of individual members of IPONZ, which helps in understanding the motivational setting around performance and the use of innovation (Locke and Latham, 2004). This did not guarantee that every participant would expressed their personal motivations in their work, but it did provide a means for the researcher to discover some of the things individual members knew of the objectives of the organisation as a whole, and their perceptions about what they knew. The objectives of the study was also explained to every participant, as was the source of the idea behind the use of the two questions of ultimate objective, to clarify the need for their personal views.

\subsection{Methods of Analysis}

One imperative that is emphasised (Van de Ven and Rogers 1988; Van de Ven and Poole 1990; Van de Ven and Poole 1995) in their experiences with process research is consistency in the definition of constructs for the conceptual representations of a process. A construct can refer to categorically defined attributes of a phenomenon than can be discerned, though not necessarily quantifiable. In the case of innovation processes, Sapolsky (1967) in a study of structural influences on innovation discusses 'tasks and incentives' as constructs, Van de Ven and Poole (1990) in their longitudinal study of innovation, used 'ideas, people, context, outcomes and transactions' to describe the unfolding of innovation. Birkinshaw, Hamel and Mol (2008) used 'actions' of individuals and groups for explaining MI within, among and spreading across organisations. Constructs can be used to define and analyse the basic unit of data that relates to the research question, establishing a consistent basis for making inferences of the results of the research. 
According to Gerring (2007), the consistent use of clearly defined and easily discernible constructs significantly improves the validity of the findings. O'Leary (2004) suggests that when concerned with "truth and accuracy" or in the case of this research the informational value of individual perceptions, validity is what helps to establish a clear relationship between the subject and focus of the study and the measurements or indications used to represent the subject of study. The extent of validity also determines how dependable the conclusions drawn from those measures and indications are (O'Leary, 2004). In qualitative research, the use of quantified measures or indications is not always useful, because numerical representations can inappropriately give the impression of static states and spurious accuracy. In this particular study of events using the perceptions of people, measures and indications cannot be given permanent status. This is because, though the perceptions relate to physically discernible events, personal accounts of those events vary between individuals (O'Leary, 2004), and can also vary from the same individual at different times.

The benefits of the use of perceptions for this study are mostly in the information it provides about some implications of those events on the organisation as a whole, and also on individual members. It also serves as a source of confirmation for secondary data, as well as a means to enrich the plain and formal presentation of historical "facts" with personal details from multiple sources. Another benefit is that multiple personal perspectives can be used to understand a real case of the use of prescribed organisational techniques and methods such as goal setting and innovation. Figure $4.4 \mathrm{a}$ is used to demonstrate how perceptions are used to understand details of the events, and to understand some impacts the event had on the organisation.

It begins with the occurrence of the event, the individual makes physical and cognitive records of the event and stores them in memory. They then elicit this memory and communicate it to the researcher who uses it as data. This diagram was constructed using a model of the perceptual process presented by Goldstein (2009). As the diagram suggests the conceived perceptions, cognitive recognition and the physical experience and response to the event are all interconnected. The 
bi-directional arrows represent influence, and the curved arrows signify the lack of knowledge about the way in which this influence takes place. The straight arrows represent the direct influence on what is verbalised about the experience. It is the verbalised information that is used as primary data for the research, and that is used to represent the perception of the individual regarding a particular event.

Edwards (2000) notes Van de Ven and Rogers' (1988) proposal that an effective understanding in organisational studies of innovation processes can be achieved by "reconciling agency and structure". Edwards (2000) emphasises the importance of considering both actions and the context of action. Sapolsky (1967) mentions that organisations can be described using different "tasks" and "incentives".

\section{Understanding Events Through Perceptions}

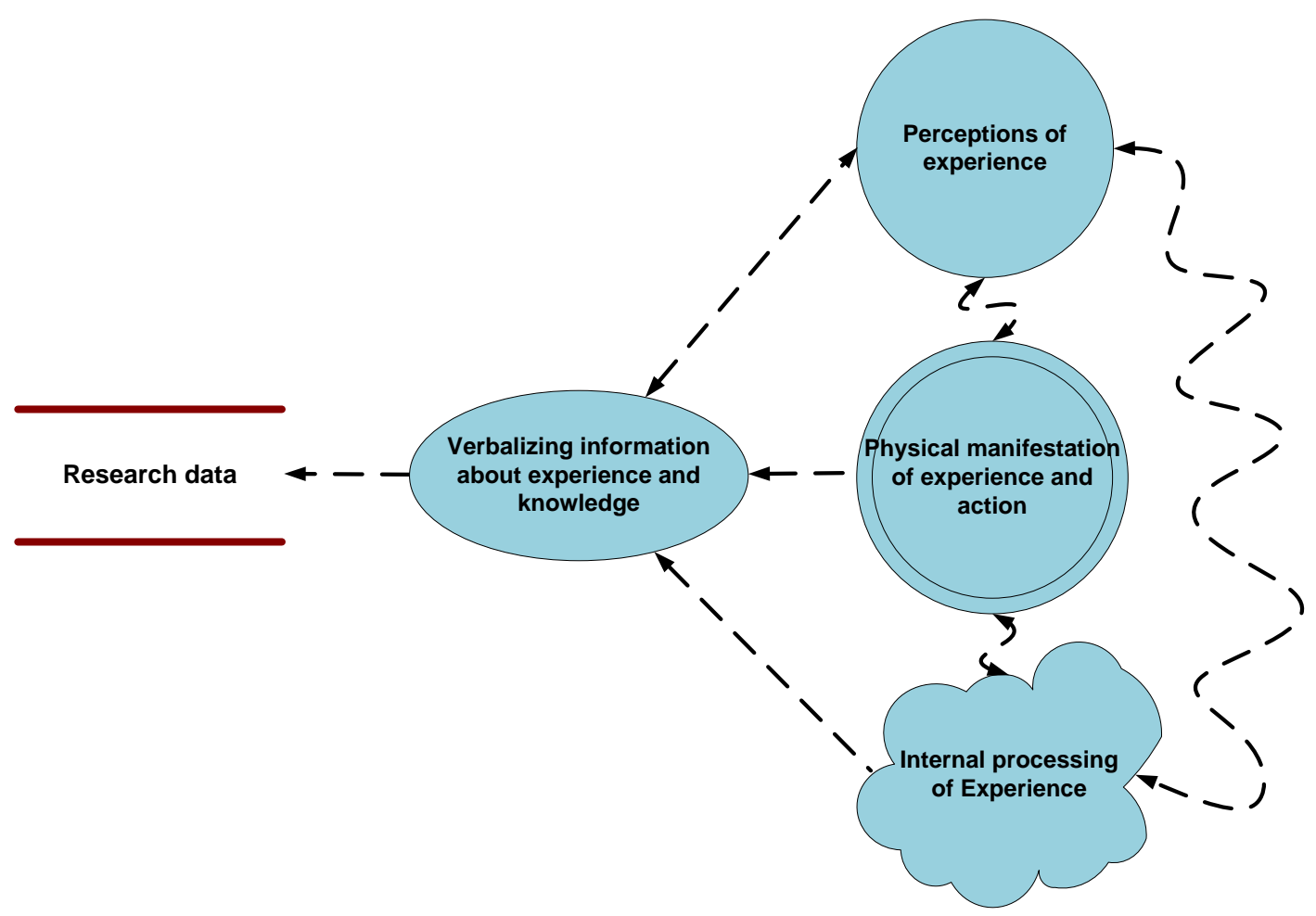

Figure 4.4a Working with perceptions (Goldstein, 2009) 
Tasks can refer to any human contribution, physical or non-physical, that is made within the organisation and for the organisation. Incentives can refer to the external stimulus and extrinsic motivational factors (Benabou and Tirole, 2003), that led to those contributions being made, including but not limited to the use of financial incentives. These two aspects are fundamental to any organisation because their concepts are basic enough and can be applied to any organisational activity. Therefore they present generic constructs that can be applied to processes that involve human intervention, as is the case with the generation and adoption of innovation (Van de Ven and Poole, 1990), and the use of goal setting.

There is a reservation in the use of "tasks" and "incentives" as generic constructs, and the traditional connotations attached to the two words. Tasks imply human contributions that are mainly physical in nature, therefore restricting the use of the concept to the physical implementation of deeds. The use of the word incentive is closely related to monetary incentives, also implying a restriction on the type of extrinsic motivation involved. Using tasks and incentives may have been appropriate for the time period in which Sapolsky's (1967) work was published, when monetary incentives were considered the main source of extrinsic motivation. Since then however, there have been various advancements in the study of organisations (see Jones and George, 2008) that have revealed that people in organisations are motivated by numerous other external and internal factors. In addition, though external motivation such as monetary incentives flow primarily in one direction from the giver to the receiver, other types of external motivation such as social recognition or "praise" can arise out of interaction between the giver and the receiver, which flows in both directions.

The modern organisation context and the knowledge prevalent in organisational studies require words that are more reflective of the multitude of both physical and non-physical aspects of human activities in organisations. It is suggested here that a constructs that are more generalised would serve better for understanding organisational activities. The use of the word "actions" is suggested instead of the word "tasks", as was used in Birkinshaw, Hamel and Mol's (2008) study of MI. The use of the word "transactions" is suggested instead of the word "incentives". 
Actions and Transactions are adopted here as the generic constructs for describing organisational processes. Actions refer to the agency aspect of the process, while transactions refer to the relational context within which the actions occur. For indepth analysis, the accounts of participants will be examined to identify indications of these two constructs, indications that represent both individual and group collective action.

According to Thompson (1967), when considering organisations as open systems affected by their surroundings, organisations can be considered to act in accordance with requirements placed on them by their changing environments. $\mathrm{He}$ also discussed the implications of environmental changes on the existence of the organisation proposing that one way in which organisations "buffer" the negative impact of uncontrollable changes is by inducing actions in the environment through transactions. Encouraging specific favourable actions in the environment provides a "buffer" that reduces the otherwise negative effects of environmental change. Although the consideration of Thompson's (1967) organisational action was focused on responses to environmental change, considerations of internal organisational actions are also important.

Internal action though coordinated and induced through incentives and motivation, cannot be entirely controlled without reliance on the personal choices of the individuals whose actions determine the state of the organisations. Therefore in addition to conventional incentives such as finances and social recognition, organisations can also utilise supplementary transactions within the organisation to further endorse favourable actions by organisation members. Transactions which form interactions that induce action, can be as simple as the exchange of tasks between and among organisational actors. For example, team leaders and managers recognizing team members, as well as endorsing them to senior management. This may encourage team members to seek new and effective actions for meeting the teams' goals that will make them stand out among other team members. 
Figure $4.4 \mathrm{~b}$ following shows the use of actions and transactions as constructs to understand the process of innovation. The framework is adapted from the stage models presented by Burns and Stalker (1967) who described the innovation process, and Birkinshaw, Hamel and Mol (2008) who described the MI process. The figure demonstrates how the use of the basic constructs open up the events for analysis, by applying the same unit of analysis for consistent understanding of the interconnected events that produce implications for the state of the organisation. The process begins with actions and transactions that identify a problem. This spurs actions and transactions that work towards the generation of an innovative solution. The solution is put to use through actions and transactions and evaluated for positive and negative outcomes. Each is interconnected to and likely overlapping with other phases in the process, and actions and transactions to implement the process is interrelated.

\section{Organisational Innovation Processes}

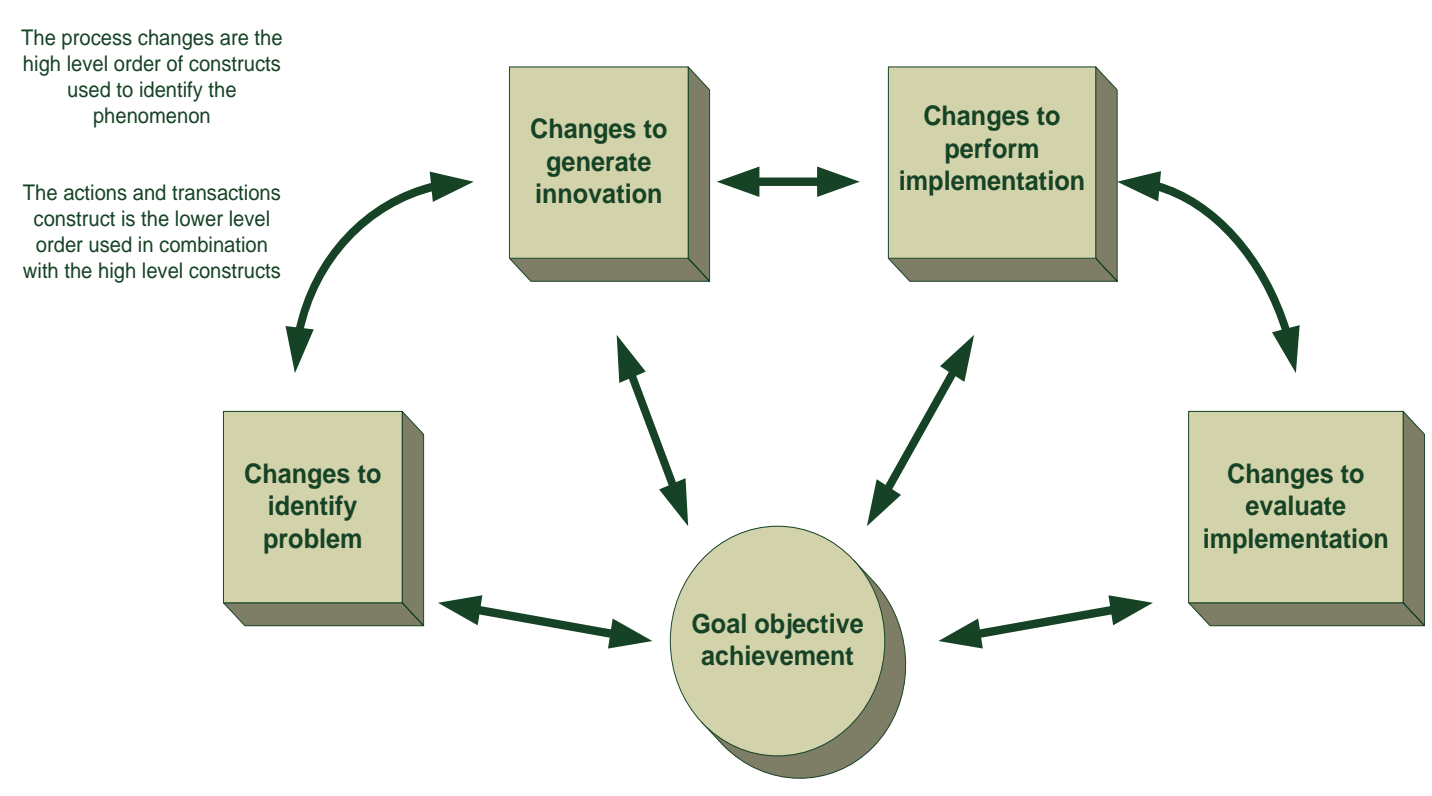

Actions and transactions 
Figure 4.4b Conceptual Framework for analysing the innovation process (Becker and Whisler, 1967; Birkinshaw, Hamel and Mol, 2008)

\subsubsection{Techniques and Tools}

Phenomenological methods are used to examine the world using the expressed experiences of people (Trochim, 2006). Phenomenology can also be considered a paradigm on its own, with a distinctive philosophy and set of methods that align with its philosophy. Phenomenological techniques were used to analyse both primary and secondary data. In this case phenomenology provides methods for using the experiences of people to understand change events at IPONZ, in the context of the expressed intentions and achievement efforts of the organisation. Interviews are a popular qualitative data collection method used in phenomenology, ranging from completely unstructured to face to face survey-type interviews. The use of interviews in this research provides a source of data that is complemented by the use of secondary data. The analysis of this data is done using a thematic coding system.

Interviews are the most widely used method for collecting the information about the experiences of people through the use of language, and all linguistic expression of experience is retrospective (Hycner, 1985). Although the amount of time that elapses differs from one interview to another, the use of recollection and reflection is inevitable in interviews. Phenomenology is typified by the use of retrospective expressions of experience, to study phenomenon. There are some criticisms to the use of retrospective expressions as primary source of data. Several are discussed by Hycner (1985) who identified the importance of phenomenology for discovering unique experiences of people and the differential nature of the human experience. Several of the criticisms discussed stem from attempts to squeeze qualitative approaches through quantitative-shaped holes.

Phenomenology is essentially the study of a specific phenomenon, however several different perspectives and approaches to understanding the phenomenon can be legitimised depending on the phenomenon in question and the focus of the study. Criticizing one perspective using requirements from another perspective renders 
insignificant the objectives or choice of purpose underlying the perspective being criticised. For example, criticizing the use case studies because it lacks generalizability (Hycner, 1985) assumes that the objective is to identify generic patterns of the phenomenon. This completely discounts the underlying case study purpose of deeper understanding through in-depth study.

Hycner (1985) also mentions other issues with phenomenological methods such as establishing validity and the accuracy of information provided through retrospective expressions. Validity is important to establish that the content of interviews reflects the information required to address whatever question the research poses. In order to confidently utilise interview data, it should be determined the level of accuracy that should be expected from the information contained in the interviews. In this way, the conclusions drawn from interview data can be considered valid. Trochim (2006) suggests that only the outcomes derived from the use of measures, specific designs and types of data can be considered "valid", as it is the claims and conclusions made using these that require the establishment of validity.

Hycner (1985) suggests that validity can be established through peer review, by consensually deciding the level of validity that can be attributed to the claims made using the data. In the case of this study peer review is not practicable, and another form of validity is utilised. Initially understanding the course of events at the IPONZ required the investigation of historical records, as far back as the year 1860, when the office was just an officer. Identifying the history of the organisation and how the purpose and main functions changed over the years allowed the researcher to identify the significance of specific events and the context of organisational members' actions.

The use of historical records and published official information allowed the researcher to establish what the boundaries were in terms of the events that should be focused on. It also acted as a triangulation source for the information provided in the interviews, by comparing the accounts of participants with the information from officially published records. Another method of establishing the 
accuracy of accounts was to use the non-random sample selection technique. By selecting participants from different teams, with some having worked in multiple teams, the different team accounts were used to triangulate each other. This method was especially enhanced because some members of the organisation in different teams had worked there for more than 15 years.

Once primary data was collected, the information contained was organised into themes, labelled through coding. Qualitative analysis software was used to separate the information into units, and each unit tagged with a code. In some cases, thematic units were defined by combining the theme related information with its context. In other cases, where themes were used to compile lists, only the thematic information was isolated if it was explicitly relevant to the theme. Units of information were coded as themes, and several related themes were grouped into categories. In total 32 codes were used in the analysis, organised into 6 categories. Table 4 below shows a list of the categories, the codes within categories and the themes that they represent. 


\begin{tabular}{|c|c|c|}
\hline Theme Category & Theme codes & Code Definition \\
\hline \multirow[t]{8}{*}{ Aspects of the organisation } & DT.A.1 & $\begin{array}{l}\text { Issues related to governance, carried out by the managers, } \\
\text { commissioners and MED officials }\end{array}$ \\
\hline & $\overline{\text { DT.A.2 }}$ & Clients of the organisation \\
\hline & \begin{tabular}{|l|l|} 
DT.A.3 \\
\end{tabular} & Issues related to client services \\
\hline & DT.A.4 & Identified operational processes \\
\hline & DT.A.5 & Employee and employment related issues \\
\hline & DT.A.6 & Issues related to IPONZ reputation and image \\
\hline & DT.A.7 & Legislation and legislative developments \\
\hline & DT.A.8 & IT systems and technical facilities \\
\hline \multirow[t]{10}{*}{ Goal focus } & DT.B.1 & Development of Information Technology and Communication \\
\hline & DT.B.2 & Clearing backlog files \\
\hline & DT.B.3 & Improving processes \\
\hline & DT.B.4 & Improving the structure of teams and the arrangement of work \\
\hline & DT.B.5 & Improving resources available to staff \\
\hline & DT.B.6 & Establishing formal systems of management \\
\hline & DT.B.7 & Improving organisational culture \\
\hline & DT.B.8 & Improving legislation and the legal jurisdiction of the Office \\
\hline & DT.B.9 & Timely processing of work \\
\hline & DT.B.10 & Increase service quality \\
\hline \multirow{3}{*}{ Perceptions of innovation } & DT.C.1 & Descriptions of what innovation is \\
\hline & DT.C.2 & List of innovations implemented at IPONZ \\
\hline & DT.C.3 & Perceptions of the most significant innovations \\
\hline \multirow[t]{2}{*}{ Perceptions of goals } & DT.D.1 & Descriptions of what goals are \\
\hline & DT.D.2 & Descriptions of how goals are used \\
\hline \multirow[t]{6}{*}{ Descriptions of change } & DT.E.1 & List of changes implemented \\
\hline & DT.E.2 & Description of how changes were implemented \\
\hline & DT.E.3+ & Description of the positive effects of implementing changes \\
\hline & DT.E.3- & Description of the negative effects of implementing changes \\
\hline & DT.E.4t & Description of positive effects of NOT implementing changes \\
\hline & DT.E.4- & Description of negative effects of NOT implementing changes \\
\hline \multirow{3}{*}{$\begin{array}{l}\text { Descriptions of Ideal Final } \\
\text { Result (IFR) }\end{array}$} & LC.D.1 & List of IFR \\
\hline & LC.D. 2 & Percieved benefits of IFR \\
\hline & LC.D.3 & Percieved set-backs in reaching IFR \\
\hline
\end{tabular}

Table 4 Analysis Coding 


\section{Chapter Five}

\subsection{FINDINGS}

The Statements of Intent (SOI) of MED, the Annual Reports of both MED and IPONZ, and official information published by the Office on their website, paint the picture that IPONZ plays a key part in delivering on priorities to establish an infrastructure conducive to innovativeness and growth (MED SOI 2001-2010). IPONZ as an organisation for the administration of IPR has existed for over 140 years. IP administration contributes to the regulatory functions of the Government, acting as a business registry and coordinating related quasi-judicial functions. Though the organisation started with just one officer in the Colonial Secretary's Office, the use and importance of IP in New Zealand has grown increasingly since. To date, in order to deliver an effectively-managed IP system, the organisation has employed over 70 people (PricewaterhouseCooper, 2009), maintaining over 250,000 items of intellectual property (IPONZ annual report 2010). The significance of IP is evident in the Government's priorities, set out in MED annual Statements of Intent.

\subsection{IPONZ Structure}

Within what has been referred to as the "Formal IP System" (Sharp, Morgan and Puckey, 2010), IPONZ serves the function of providing legislative boundaries for business activity. In addition to the formal IP system, there are also other methods of protecting IP, such as the use of secrecy in contractual agreements. IPONZ is responsible for administering four primary legislative acts for the protection of industrial patents, trade marks, designs and plant variety rights. In addition to these four acts, there are a number of other legislative provisions which IPONZ does not directly administer. These legislative provisions make IP formally protectable and 
assign specific rights to ownership, by incurring a penalty on anyone that infringes on those rights (Sharp, Morgan and Puckey, 2010).

As an agency accountable to the public, IPONZ officially publishes information on its website, including Annual Reports about its structural arrangements and responsibilities. Figure 5.1 displayed next, provides an organisational chart derived from the IPONZ website illustrating the structure of the divisions within IPONZ. This structural organisation of people has seen a number of changes in previous years. As the organisation advanced towards the increased use of information and communication technology, the need for support staff diminished with manual tasks being replaced by automated tasks. Despite the changes, the basic component groups of IPONZ members have steadily consisted of 3 groups. The first group is the Examination Services group of IP divisions, second is the Business group of management, administrative support and development, and third is the Hearings group for managing quasi-judicial functions. Figure 5.1 is a reflection of the current arrangements after the financial year ended in June 2011.

The agency holds 7 sub-divisions, and is the responsibility of the Commissioner of Patents, Trade Marks, Designs and Plant Variety Rights. As a direct report to the Commissioner, a Group Manager is appointed to oversee all the services IPONZ provides. A Trade Marks division examines applications and maintains the integrity of records for existing trade marks. Applications and records for patents, designs and plant variety rights are all examined and maintained within another division referred to as the Patents division. The Hearings division is in charge of coordinating official legal proceedings for the contest of IPONZ approved IP. The Business Support division deals with the administrative support of the previous 3 divisions and the management of records. Business Systems and Development division develops and maintains the IT and communication systems of the organisations, as well as performance monitoring and project operations.

As a result of the mandate to foster IP awareness, an External Relations and IP Awareness division was assigned to deal with promotional engagements with stakeholders and international relations. The last sub-division, the Corporate 
Services division is designated to the management of the entire Office, and the provision of financial and human resource support services. Every division is assigned a manager to coordinate the performance of operations, and to work collaboratively with other managers to set business directives. This group of managers form the management team at IPONZ, who establish goals and drive performance. 


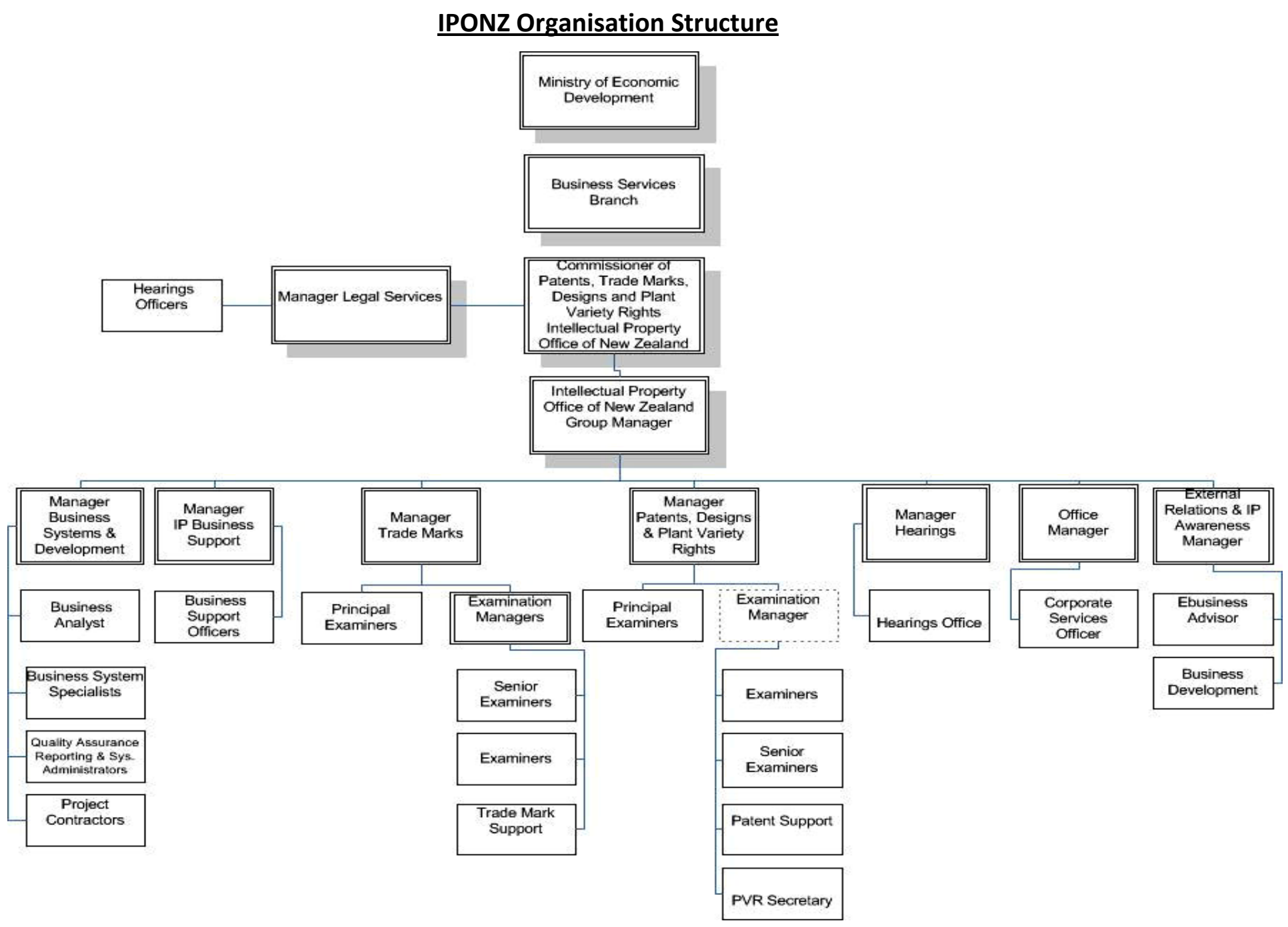




\subsection{Goal Setting Hierarchy}

After the reforms of the 1980's and 1990's, New Zealand became world famous for its unique system of public administration designed for greater effectiveness through increased delegation of authority and accountability measures. One of the central themes of the reforms across all state sectors was the separation of policy and administrative functions. In order to reduce self-serving bias the policy setting operations of Government was disconnected from operations of service delivery (Scott, Bushnell and Sallee, 1990; Evans, Grimes, Wilkinson and Teece, 1996). Under reformed management practice, accountability measures are used to monitor the consumption of resources. Procedural control methods are also minimised (Norman and Gregory, 2003), moving focus away from process accuracy towards outcome effectiveness.

Accordingly, MED implemented reform initiatives that aligned with the new norm. Under MED, IPONZ was also organised to utilise the new public management style of less control of operations, higher accountability for results and greater information transparency. As a result of the changes implemented in the reform MED is required to submit documentation to the governing state sector authorities, representing detailed strategic plans and objectives for 2-4 years. Established schedules of activities should also be explicitly aligned to strategic plans and objectives. IPONZ, a semi-autonomous branch of MED since 1997, became accountable for contributing to the mandate assigned to MED by New Zealand Government.

IPONZ has a number of priorities identified in secondary data that represents the requirements to meet the objectives formally set by Government through MED. These priorities are currently presented as organisational goals for IPONZ in MED's Statement of Intent. Shortly after the selection of the incumbent Group Manager in 2009, it was established that the organisation needed a coherent set of objectives that would adequately address the functions IPONZ was responsible for serving. 
This led to a Business Plan being drafted for IPONZ that presented all the goals of the organisation ${ }^{3}$, from the highest level of planning to operational tasks.

Before the introduction of the business plan there were no existing documents found for this research that contained a comprehensive statement of goals, specifically drafted for IPONZ. Past statements of IPONZ goals were made through MED Statements of Intent documents and Annual Reports, which contained primarily operational level goals in the form of quantitative performance targets. The goals in the business plan are incorporated into IPONZ as an addition to the performance targets set out by MED, and established as government expectations. According to an IPONZ manager, the Business Plan was carried forward and revised for the year 2010-2013, as they are medium to long term goals. The business plan document used as secondary data for this research is the revised version for 20102013.

The current formal system of goal-setting at IPONZ follows a hierarchical pattern. At the highest level are strategic goals, which are the overarching goals of the entire organisation. They define how IPONZ will function and the key areas where IPONZ will contribute to MED's wider economic goals. These goals are referred to as the Mission of the organisation in IPONZ Business Plan 2010-2013. The next level of goals can be referred to as objectives, which articulate exactly what outcome IPONZ needs to achieve in order to make progress towards its mission. In IPONZ Business Plan 2010-2013, these objectives are stated as the accomplishment of Capability, Capacity, Confidence and Credibility. These organisational conditions can be referred to as the 4 C's objective. Capability indicates the value of the organisation's internal configuration of people and resources, which are organised to serve IPONZ functions. Capacity relates to the physical and information management facilities that are set up for operations, such as the IT systems and business processes. Confidence refers to the fulfilment of service delivery and the extent to which it

\footnotetext{
${ }^{3}$ A summary of IPONZ goals from 2000--2013 is in Appendix 3.0
} 
meets predetermined standards. Credibility shows the effectiveness of the legislation, its implementation and development.

The next level of goal setting at IPONZ contains in more detail a specific list of activities and programs that can be used to achieve the $4 \mathrm{C}^{\prime}$ 's outcomes. The list of these activities in the business plan is not exhaustive, but rather appears to be a list of priorities for IPONZ, that will have the highest contribution to the objectives. In the business plan, the list consists of goals to achieve organisational development goals, and goals to achieve performance standards for core functions. Performance standards are government expectations for the level of proficiency with which IPONZ delivers its primary function.

From the interview data, several goals were identified that correspond to the current formal system of goal setting at IPONZ. Using analysis coding (outlined in Table 4, pp.82) a list of goals were derived from discussions with all 26 participants. Consistent with the objective goals listed in formal documentation, participants mentioned a number of goals that represent efforts to achieve the 4 C's. 17 participants (65\%) discussed goals to build the IT infrastructure of IPONZ, indicating that there were attempts to increase Capacity. The importance of inspiring the Confidence of clients was demonstrated in discussions with 15 participants (58\%) about timely processing of work, and 16 participants (62\%) about service quality. Nine of the participants (35\%) mentioned legislative developments, which would serve to improve the organisation's Credibility. Finally, 10 participants (38\%) mention efforts to improve the organisational culture of IPONZ, which supports the objective to improve Capability.

Some other goals were identified that refer to operational goals from the business plan, as well as operational goals from MED's Statement of Intent and Annual Reports. References were made to achieving timeframes for processes and quality standards, while other references pointed to efforts to contribute to the drafting of legislative works. The identification of timeframes and other quantitative goals for operations indicate the importance of maintaining a consistency in delivery of core services. Emphasis on developmental goals indicates that in addition to fulfilling 
core functions, improving the organisation for future service delivery is also a priority. A comparison of the goals below identified in interviews, and the goals in the business plan, shows that the 10 goals identified in interviews relate to 12 out of 15 objective goals and 15 out of 26 operational goals identified in the business plan. Although there were only a hand-full of specific references made about the exact quantities in performance expectations, there were 51 references from 15 participants that mentioned efforts to achieve these goals.

Table 5a shows the analysis category of Goal Focus, which is a collection of the themes that were used to classify references about goals. A ranking is made according to the number of units of information that were referenced under each theme. This ranking signifies the amount of discussion, measured by units of information that was made about the different goals identified. According to this ranking, the most discussion about goals were focused on the improvement of service quality, while the least focus in discussions were about establishing formal systems of management.

This is similar to the representation of the $4 \mathrm{Cs}$ in objectives from the business plan (see Appendix 3.2), where four out of nine objective goals (almost 50\%) that were set reflect efforts to achieve just the Confidence objective. Confidence represents the effective fulfilment of service standards, which quality service delivery makes a contribution to. Themes are also ranked according to the number of participants that units of information are sourced from. According to this ranking, improving resources available to organisation members was the most common goal discussed by participants, while clearing backlog files was the least common. This reflects their relative importance, as expressed by participants. 


\begin{tabular}{|c|c|c|c|c|c|}
\hline $\begin{array}{l}\text { Theme } \\
\text { Codes }\end{array}$ & Code Definitions & $\begin{array}{l}\text { No. of } \\
\text { sources }\end{array}$ & $\begin{array}{l}\text { No. of } \\
\text { units } \\
\text { coded }\end{array}$ & $\begin{array}{l}\text { Ranking } \\
\text { by no. of } \\
\text { sources }\end{array}$ & $\begin{array}{l}\text { Ranking } \\
\text { by no. of } \\
\text { units }\end{array}$ \\
\hline DT.B.1 & $\begin{array}{l}\text { Development of } \\
\text { Information Technology } \\
\text { and Communication }\end{array}$ & 17 & 35 & 2 & 5 \\
\hline DT.B.2 & Clearing backlog files & 5 & 14 & 10 & 9 \\
\hline DT.B.3 & Improving processes & 15 & 59 & $4=$ & 3 \\
\hline DT.B.4 & $\begin{array}{l}\text { Improving the structure of } \\
\text { teams and the } \\
\text { arrangement of work }\end{array}$ & 12 & 32 & 6 & 6 \\
\hline DT.B.5 & $\begin{array}{l}\text { Improving resources } \\
\text { available to staff }\end{array}$ & 19 & 73 & 1 & 2 \\
\hline DT.B.6 & $\begin{array}{l}\text { Establishing formal systems } \\
\text { of management }\end{array}$ & 5 & 11 & 9 & 10 \\
\hline DT.B.7 & $\begin{array}{l}\text { Improving organisational } \\
\text { culture }\end{array}$ & 10 & 24 & 7 & 7 \\
\hline DT.B.8 & $\begin{array}{l}\text { Improving legislation and } \\
\text { the legal jurisdiction of the } \\
\text { Office }\end{array}$ & 9 & 15 & 8 & 8 \\
\hline DT.B.9 & Timely processing of work & 15 & 51 & $4=$ & 4 \\
\hline DT.B.10 & Increase service quality & 16 & 84 & 3 & 1 \\
\hline
\end{tabular}

\section{Table 5a References classified into goal themes in the Goal Focus category}

\subsubsection{Strategic Goals}

According to Collins and Porras (1996), strategic goals define the purpose of the organisation, and are used to establish what the core functions are, and what the activities and requirements are for the future. IPONZ's strategic goals are outlined in the business plan and indirectly affirmed by the interview data. Discussions of goals that are adopted and achieved show that goals have influence on organisation members. There are high level goals, which have related intermediate objectives and operation specific targets. They express the role of the organisation in the 
development of New Zealand's economy, which is rendered to them by government mandate. IPONZ directly contributes to MED strategic priorities to increase the ease of doing business in New Zealand, international integration and to provide an effectively regulated economic environment. These requirements drive IPONZ purpose and functions.

In the private sector strategic intent can evolve and change over time (Burgelman, 1995), sometimes radically over a short period of time. With IPONZ, strategic goals have been established by a normative system of managing IP that has remained essentially the same for over a century. As a result, the strategic goals of IPONZ have not significantly changed in their essence. When the UK patent legislation was adopted in 1860, it provided the foundation for New Zealand to operate the letters patent system of property protection. Letters patent system utilises authority issued by the Crown or Government agency to individuals or groups, for the exclusive use of certain property, such as real estate, commercial ventures or certain operations within geographical areas. Over the 150 years since 1860, New Zealand has maintained that system of letters patent for the protection of IP.

Minor changes to strategic goals have been the result of changes in the core functions of the organisation. Since IPONZ's core functions are defined by the legislative framework of the IP system, the legislative frameworks has influenced the core functions of the organisation. Similarly, significant changes to the legislative framework have led to changes in the strategic goals of IPONZ. No revolutionary changes were found that radically altered the legislative framework under which letters patents are administered. However, some significant turning points have been documented that would have changed the methods through which rights are administered, and the extent of protection they allow.

One of the turning points noted is the transition from the use of simple filing and recording of IP applications, to the examination of patents starting in 1883. This took place progressively and has led to in-depth technical examination of patents, trade marks, designs and plant varieties before registration. This transition incorporated examinations of IP into the core functions of the Office, expanding its 
role beyond just registry services. Another notable change was the introduction of international linkages between the New Zealand IP system and international IP systems through treaties and conventions. A third notable change affecting the strategic identity and function of IPONZ was the progression towards electronic information management. A big leap towards this was made with the replacement of a physical library of records with an electronic database. These changes altered the core functions of IPONZ over time, and have brought about changes to the way it achieves its strategic goals.

\subsubsection{Objective and Operational Goals}

Over the years, the use of objectives and operational goals at IPONZ has increased and they have become more clearly articulated and promoted within the organisation. Appendix 3.0 has a summary of IPONZ Goals over the years, and it shows the increase in the number of goals used from 2000 to 2010, including the addition of supplementary transformation goals. The importance of IPONZ's role in contributing to economic development was recognised increasingly as the years progressed, and this is reflected in the use of operational goals to set IPONZ key performance indicators (MED SOI 2002-2010). These specific quantitative goals show explicitly, details of the Government's performance expectations for the Office.

Objectives and operational goals are expected to advance the organisation towards achieving strategic goals. Objectives specify desired outcomes that the organisation can work towards to increase the probability of fulfilling its purpose. They can be understood as the milestones along the way to the destination, whereupon reaching a milestone the traveller is assured that they are on the right track. Operational goals help the organisation get to these milestones. At IPONZ, objectives are set by top management who collaboratively decide what the priorities are. The objectives are presented in IPONZs business plans as the establishment of the 4 C's -Capability, Capacity, Confidence and Credibility.

These 4 Cs direct the use of operational goals which represent the standards with which activities and processes are performed. They are sometimes derived through 
reasoning and skilful decision-making, and not necessarily with the use of formal research and analysis technologies. Especially where qualitative measures are concerned, management science cannot always be "scientific". Choices of what goals to set may be made through expert reasoning and intuitive decision-making, in the face of uncertainty (Russo and Schoemaker, 1990; Hammond, Keeney and Raiffa, 1998). As a result of this uncertainty, operational goals of members have to be purposely aligned to objectives, and this can be through coordination. The merits of aligning goals were exemplified in these words:

"More importantly, the more connected you can get people's mind as much as you can get them thinking in the same direction, you are more likely to feed off other people's ideas as to how to achieve an outcome because as with a lot of these things it's not always just a so-called A-to-B type journey, there's a lot of variables that can be brought to bear, it's about really just having people swimming in the same direction, I guess more than anything else."

Operational standards are used to evaluate IPONZ performance annually. Performance statements are officially presented to the Government and the public in the form of Annual Reports from MED and IPONZ. Operational standards are used for individual and team specific targets, which are incorporated into performance agreements for IPONZ members. An example of operational goals is that all IPONZ decisions to register IP should be published for public viewing, and 99\% of those decisions should be upheld. This means that $99 \%$ of the decisions should not be successfully opposed in a hearings proceeding or invalidated as a result of IPONZ error.

Core operations, also known as "business as usual", are evaluated using some of these pre-established operational standards. Some goals are expectations of discrete volumes of work that the Office will produce, however these cannot be fully endorsed because IPONZ output volume of work is driven by the amount of demand that exists for its services. As a result IPONZ produces volumes according to how much work is requested by clients. Though standards include expected 
volumes in discrete numbers, there are also percentage standards which can be more appropriately applied to IPONZ operations. For example, one goal in 2010 is that $98 \%$ of all applications will be acknowledged and receipted within one clear business day of its submission. Appendix 3.1 shows the discrete goals for volumes of new IP grants, and renewal of previously granted IP. Percentage goals are shown for different types of official communication with clients, including first response to applications, issuance of receipts for payment, publication of decisions to grant or refuse applications.

One participant through the statement below acknowledged that in years past, members of IPONZ may not have fully understood the importance of achieving set targets:

"To tell you the truth, in the past we haven't been that great, and this is going back, maybe the last 5 or 6 years, we've gotten better at it and the Business Objectives and the SSPs [Statement of Service Performances] are more upfront so we know what we're working towards, whereas previously I must admit we were a bit slack......"

The interview with this participant was conducted early in 2011 , so working the time back $5-6$ years would relate their accounts to before 2005 . As is evident in the summary of goals in Appendix 3.1, though goals of expected volumes of work were continually presented, the more appropriate percentage goals were less comprehensive. Only 2 percentage goals were presented for the years 2000 to 2004, after which only 3 percentage goals are presented until 2006, and back to 2 percentage goals until 2008 when 5 percentage goals were presented.

In comparison to the indication from the previous account, one participant notes the impact of the general progression over time:

I think so, speaking to some of the principal examiners who have been here for quite a considerable amount of time, over 20yrs, they were saying when they started, they had to do 12 applications a month, now we have to examine up to 100 applications a month, so it's like 10 times more work 
done in the last 20 years, so things have got more efficient over that period of time.

This progression was not without incident as is evident from indications in MED Annual Reports summarised in the Appendix 3.1. There was progression in performance for the percentage goals that are presented, with actual performance meeting or exceeding expectations. However, in the year 2000 percentage goals were not met for first response to applications and provision of ministerial correspondence. Similarly in 2008 , goal achievement was at less than half the target for patent examination, and for general examination correspondence. This may have been the result of a notable increase in demand for patents, trade marks and designs in the years prior to 2000 and 2008, and inability to adequately recruit technical staff (MED, 1999-2000; MED 2007-2008). The positive progression returned in 2009 when performance levels had increased again to meet or exceed targets. Performance levels further increased in 2010 when all goals were achieved and all targets exceeded.

\subsubsection{Transformation Project Goals}

Establishing and maintaining Capacity, Capability, Confidence and Credibility to achieve strategic goals means that IPONZ has to respond appropriately to changes in its environment. Changes in IPONZ environment that affects its stakeholders affects its operations and service delivery, and consequently affects its sustainability. As a reflection of this, IPONZ has established change initiatives to upgrade existing systems for operations and service delivery. The determined requirements to achieve these are incorporated into the objective and operational goals of the Office.

As a result of the transition from physical file processing to electronic processing, information and communication systems have now become the back-bone of IPONZ operations. In 2008/2009 IPONZ began an organisation-wide programme of change to upgrade the IT infrastructure, which they called Project COMPASS. A list of project objectives was outlined to guide the implementation phases to completion, which is proposed for 2012. To meet these objectives, a schedule of 
transformation activities were incorporated into the operations of IPONZ, and executed along-side core functions.

Part of the objectives that were used to define the phases of Project COMPASS involved the implementation of changes that contributed to IT development. After a business evaluation was conducted by PricewaterhouseCoopers, IPONZ accepted recommendations to convert COMPASS from an IT project to a business transformation project (PricewaterhouseCoopers, 2009). Consequently Project COMPASS has been promoted throughout the organisation as a business transformation programme. Implementation efforts have also involved members from every team contributing to the project. However, the majority of project activities are conducted by temporary contract employees.

The evaluation report by PricewaterhouseCoopers (2009) outlines the objectives of the project. One objective is to introduce a new database and new information searching tools. This would cater to all areas of examination at IPONZ, and would provide more facilities for client-involvement in processes to examine, register and maintain IP. Other objectives included were to incorporate greater quality measures into operational processes and obtain ISO accreditation. Additional efforts were also made to address staffing issues related to longstanding high staff turnover, by improving work structures and incentives and increasing social engagement within the organisation.

The structure of transformation project work at IPONZ is significantly different from that of core business activities, and so is the means of performance management. Therefore transformation project goals sit alongside core function goals for permanent employees. Where permanent employees are expected to contribute to "business transformation", they are required to do so in addition to their core work which is referred to as "business as usual". For project work, transformation objective goals were set as key deliverables for the project, and transformation operational goals set as non-quantitative targets. Within the goal setting hierarchy of the organisation, they sit alongside objective level goals and operational level goals, as they are intended to motivate the continuous implementation of change 
projects alongside the performance of core function tasks, i.e. "business as usual" and "business transformation" side by side.

Figure 5.2 following summarises the strategic goals of IPONZ, its determined objective goals, and the operational goals that are set as the target for team and individual activities. The direction of influence follows a loop-like pattern represented by directional lines in the diagram. As the desire to achieve strategic goals steer what objectives are set, objectives establish outcome expectations for implementing operational and priority activities. Performances to achieve operational goals inform future modifications and reformation of strategic goals. At IPONZ, these modifications are derived through feedback obtained from team members in regular team meetings.

\section{Goal Setting Hierarchy}

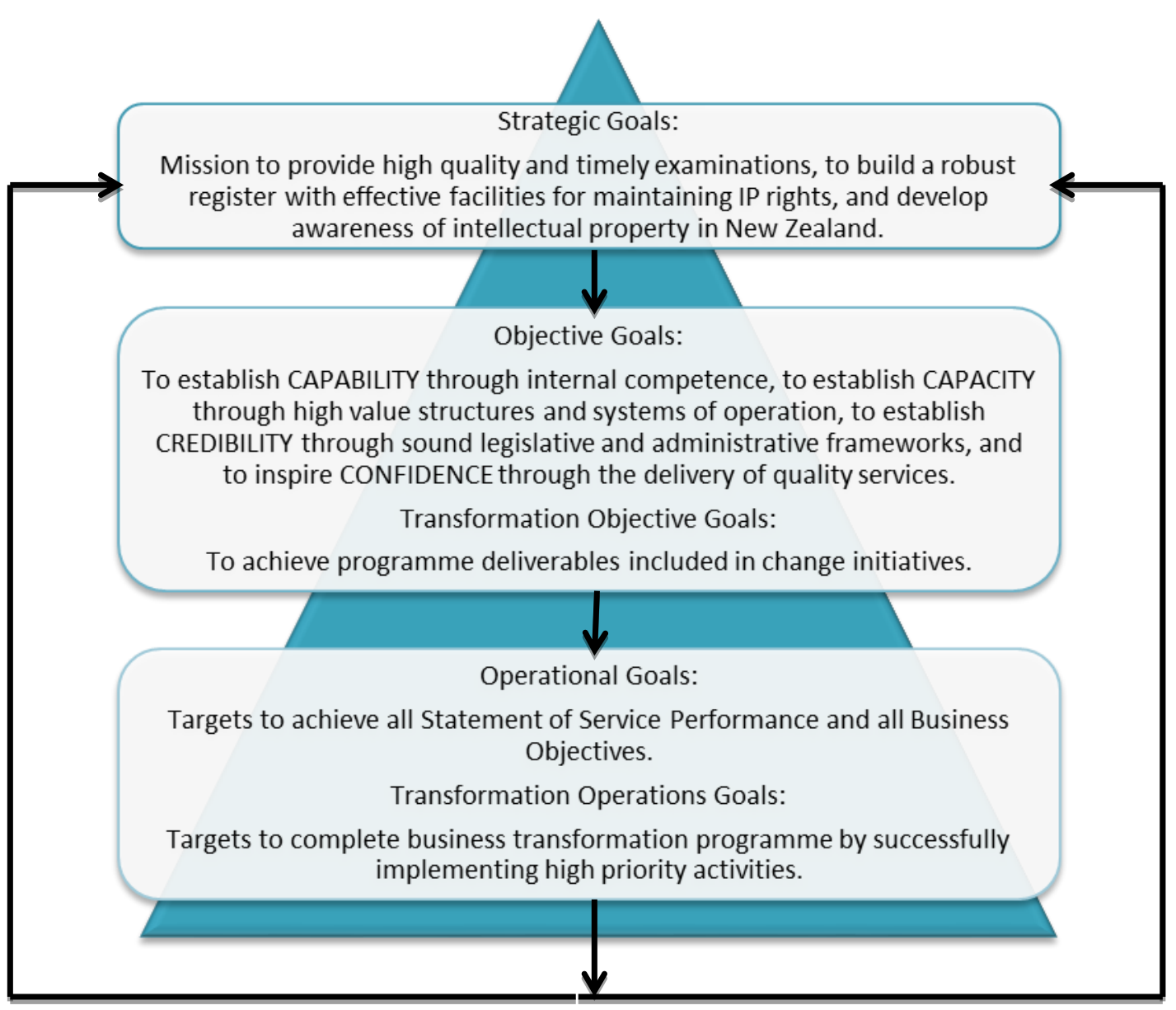

Figure 5.2 IPONZ goals within a hierarchy 


\subsection{Supplementary Goals}

In addition to officially published goals, participants also mentioned several supplementary goals that influenced performance. The goals identified in the Goal Setting Hierarchy have been established through formal performance management structures as part of the mandatory requirements for the organisation. There were other goals identified in interview data, not outlined in official documentation, that were mentioned as influencing performance. A mandatory goal can be identified by an officially published statement of an organisation's objective to which financial accountability is attached. A supplementary goal is communicated in writing or otherwise, as a desired objective but for which the organisation is not financially accountable. Team-specific and personal goals can be considered supplementary goals that are not represented in the hierarchical system of goal setting at IPONZ, because they were not found in the business plan, or annual reports. However, accounts from 22 out of 26 participants suggest that these goals influence performance.

One supplementary goal identified at the strategic level is a team-specific goal to create a legislative mandate for the compulsory use of online filing by clients. This goal was considered important by a team at IPONZ who is responsible for managing the online and electronic service facilities, and also for driving the online services adoption by clients. The achievement of such a goal would likely increase the payback from resources consumed to develop IT infrastructure for online filing. This would lead to more efficient online provisions, and significantly reduced internal inefficiencies related to handling and storing of physical paper.

An objective level supplementary goal was identified in a discussion about the new database proposed to be introduced at IPONZ in 2012. The participant, who was responsible for managing current IT systems at IPONZ, mentioned their personal goal to progress to the role of their team's Manager, as a way to make sure that the new database had an "owner" when the incumbent manager left. What they were referring to as an "owner" was someone who was capable of and responsible for managing the new system's adoption and development. One operational level 
supplementary goal was mentioned by a participant who discussed their personal interest in updating and improving current examination practice tools, such as the resource for examination procedural guidelines.

\subsubsection{Team-specific Goals}

In addition to formal operational goals, some IPONZ Managers set their teams goals, related to team-specific activities. Nine participants identified team-specific goals that they perceived influenced their performance. Teams use these goals to gauge the contribution of members to achieving the desired team performance, which is aligned to the organisation's objectives. For example, the Patent team has a point system, where each member has a number of points that they are expected to achieve, through the performance of a number of core activities. Members can also accumulate points by contributing to transformation. The achievement of the maximum possible number of points for would result in the most desirable quantitative outcome for the team's performance. This is reflected in the following statement by a participant:

"We have SSPS, which is all around turnaround times. I think they almost like being accountable for work being done so people can work to them, but I think within a team setting your own goals that are personal to the team, probably they often have more....they're more real to people and something different, like saying for example 'we'll do all our exam reports in 5 days', that often becomes the norm, but actually setting something that's over and above and that's the team goal, I think that's important, that's what motivates your team."

Another example of team-specific goals resulted from a number of changes to examination processes and techniques for training less-experienced examiners. The team was able to incorporate targets to increase the number of applications accepted to register after their first examination. Frequently the process involves multiple examinations and several correspondences, before registration can be accepted. The process includes the checking of formalities and the specifics of the 
item of IP, checking that it does not infringe on any existing IP, and that it does not present the threat of future constraint on public good.

When an examiner receives the application, they perform an initial examination within a specified time frame. If the IP item has incomplete information or the application lacks some of the legal formalities which are preventing it from being accepted for registration then an objection is raised and the details are sent for the applicant to respond. If the application responds sufficiently and meets the legal requirements for registration, then the application is accepted. However, if the application can be made suitable for registration from the outset, then the application can be accepted after the first examination without any objections. This saves correspondence and examination time and resources, as well as the extra time and effort it takes for the client to obtain acceptance for their application.

\subsubsection{Personal Goals}

Another type of supplementary goals discussed by participants is personal goals. These goals were discussed as relevant to the specific individual in question, an example being career advancement goals or articulated personal intrinsic motivational goals. Personal goals did not have a specific functional or operational focus, but ranged from short-term specific task goals to long-term life goals. These types of goals were often brought up by participants who expressed a perception that personal goals might possibly be one of the focuses of my study. The semistructured and unstructured nature of interviews helped open-up the interview for participants and encouraged their free discussion.

Half of the 26 interview participants discussed personal goals as important to their performance. Nine related a question about the use of goal setting to personal goals in addition to other types of goals, and another four related the question to their personal goals first before any other type of goals. The one-on-one nature of the interviewing process is likely a significant contributor to this response. However their keen discussion of personal goals is an indication that these goals have an effect on their work and performance. At IPONZ, efforts are made to include personal career development goals in periodic discussions of individual 
performance. These discussions are conducted between IPONZ members and their managers or the senior examiners to whom they report.

There was some confusion between personal goals, team-specific goals, and organisational goals, as is summarised in this instance where team-specific goals mentioned by a participant were also later referred to as personal goals by the same participant:

"I guess so, I'll probably make it the other way around. Achieving all your business objectives would go some way towards achieving your (personal) goals. Because if you have 10 pieces of mail on your queue, and you've got to examine 20 pieces of mail in a week, and you have to do those 10 you're half way to your goal, then you have a personal goal to work harder and do 10 more to achieve the goal."

The goals being described above as "personal goals" are at the operational level of goals in the hierarchy, and were described as team-specific goals by all the other participants in the same team, that is, goals that were related to the team as a whole and not just to individual members. The indication from this particular discussion about "personal goals" seems to be that both the organisation's operational goals and supplementary goals such as personal goals or the teamsspecific goals can be given high priority. To put the example mentioned above in other terms, whichever goal is higher takes prominence for the individual's performance. Because examination operations are demand driven, most of what comes in must be processed within the timeframes (operational goals), and what comes in can vary in number. Therefore in some cases the operational goals may be higher than team-specific goals which are fixed, while in times of lower demand for IP, the fixed team-specific goals would be higher than application volumes.

The above participant's use of the term "personal goals" to describe team-specific goals points to a perception that individual members of the team should take personal responsibility for the organisation's operational targets. This discussion of "personal goals" also relates to two other key issues mentioned by other team members about their system of goal setting. One issue is what was referred to as 
"buy-in" where team members are required to commit to the goal. This goal commitment is the same factor necessary to Locke and Latham's propositions for using goals to manage performance. By taking personal responsibility for the business objectives, they are buying-in to the achievement of organisational targets at the operational level.

The second issue relates to individual members' personal affiliation to the organisation. In discussions, personal goals were closely linked to organisational goals partly because career development goals were included in formal performance management discussions. The link was also a result of seven participants closely associating achieving organisational goals with achieving their personal goals. Personal affiliation is used here to refer to the extent with which the individual connects their role at IPONZ to their personal identity. It also refers to the extent to which they assign personal significance to their work and social activities at IPONZ. Goal commitment is not necessarily the same as commitment to the organisation, and therefore may not be an indication of personal affiliation with the organisation.

There were discussions where seven other participants mentioned times in the past when pressures from high volumes of backlog and challenging work circumstances led to people not showing commitment to the goals. At least five participants mentioned disconnecting personally from organisational goals that they perceived to be too difficult to be achieved. One of those participants mentioned converting to "do what we can" goals. Referring to similar circumstances in IPONZ history, one participant discussed how the backlog challenge negatively affected them by leading to them feeling personally dissatisfied with their performance at IPONZ.

According to the literature (Locke, Latham and Erez, 1988; Gist and Mitchell, 1992), self-efficacy affects the likelihood of goal commitment. An individual can make a commitment to achieve a goal in their professional capacity without making a personal commitment to the organisation. According to these discussions, commitment can be made to very challenging goals, but participants also discussed disconnecting from the same goals when other circumstances limited their ability to 
achieve them. There was an indication that relentless personal commitment to goals can occur when the individual has a personal affiliation to the organisation. The following statement provides a brief account for this likelihood:

"So much work and you just come into the office in the morning and you go home every day and you think....it feels like you didn't do anything at work because the backlog is still there, and it feels..... wasn't satisfied with going home every day, you know, it feels like you didn't do anything during the day, at all, but now it feels at ease, it's just (pause) yeah."

\subsection{IPONZ change and development}

A list of changes was derived from interview discussions about change, and plotted on a timeline to demonstrate the sequence of events over the years since 1994 . These changes are not an exhaustive list of every single change that was implemented at IPONZ, but rather represent changes that were identified as altering majority of IPONZ activities. The year 1994 had no special significance for IPONZ, and it is not a reference point to compare the impact of all subsequent change. However in the examination of changes and in charting the events that unfolded in the history of IPONZ, the most fluctuations in demand for IPONZ registration services were observed from 1994 onwards. This gives an indication of a dynamic and continuously changing external environment that is often associated with internal change (Milgrom and Robert, 1995; Walker, 2007). In addition, the starting point of the changes that have been introduced that still affect the performance of current operations began after 1994. These changes can be referred to as significant, and the phase within which they were introduced provides a clear scope for selecting the timeline in IPONZ development, which is the focus of this study.

The majority of changes identified were in legislation and information technology infrastructure. 14 out of 22 changes were related to either legislation or 
information technology. This shows the importance that these two areas carry for IPONZ operations. The remaining 8 changes were related to operational goals, physical facilities, social systems within IPONZ, and service provision. The following figure is a timeline illustrating the sequence and year in which the changes identified from the data occurred. Each change that was identified in the interview data was verified by information from secondary data such as the Statement of Intent and Annual Report documents from MED and IPONZ. The reverse was also the case where changes identified in secondary data were verified by primary data from interviews. 


\section{IPONZ Change Timeline}

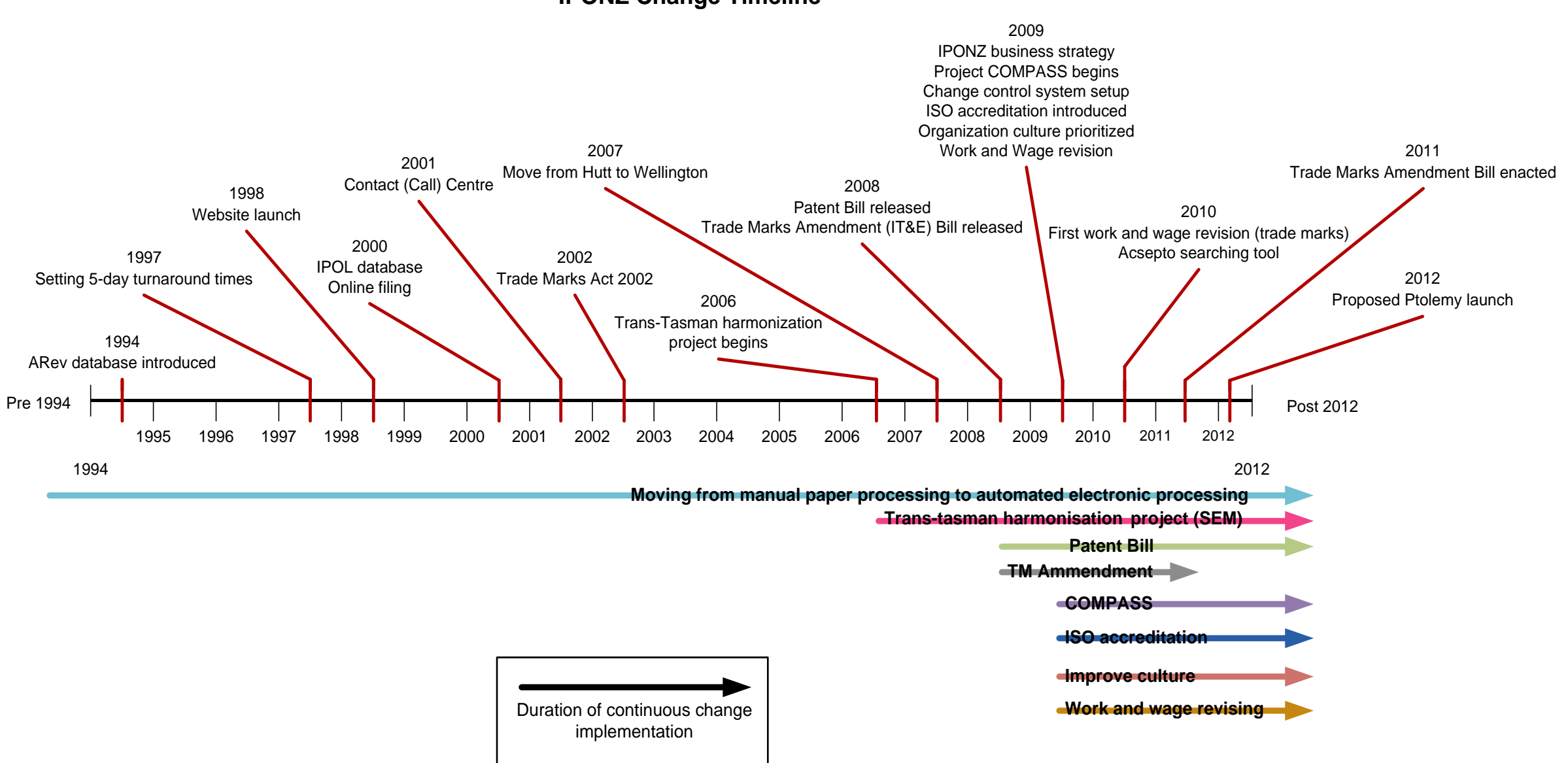

Figure 5.4 Changes since 1994 
In Figure 5.4, the red lines are connected to a list of changes which took place during that year. The coloured arrows drawn at the bottom of the timeline are used to illustrate the span of time involved in implementing some changes. Changes represented by arrows are changes that require continuous implementation for over one year, to be fully incorporated into IPONZ system. The most changes were identified in 2009, when a project to transform IPONZ facilities was introduced. This year shows a significant jump from the next highest change introductions in a year, which is 2 initiatives or projects in 2000,2006, 2008 and 2010. One participant indicated that prior to 2009 there was recognition of the need for several changes to be made in different areas. The implementation of this project called Project COMPASS, may have been advanced with the appointment of a new Group Manager that same year. This manager introduced a formal organisation-wide business plan that was subsequently promoted in all teams and at all levels of the organisation. The business plan included some of the change programs proposed, and endorsed them as a priority for the Office.

There are two major types of change developments emerging from the data. These two types combined, accounted for the highest number of changes introductions into IPONZ. The first major type of change development is that of the technological facilities and structures used for communication. Nine changes $(40 \%)$ related to technological facilities were identified, representing the biggest portion out of all the different types of changes since 1994. The second type of changes focused on legislative developments and the legal jurisdiction of New Zealand's IP system. Five changes were identified, representing almost $23 \%$ of all changes.

The 2 major types of change development give a reflection of the requirements to fulfil IPONZ functions. It administers rights according to legislation, and the legislation has to be kept relevant and in line with changes in business activities and in the economy. In order to administer rights they need to process and examine masses of information about the IP items, and then store that information for public use. This makes the management of information a crucial function for IPONZ, 
hence the need to constantly improve the IT infrastructure. Mann (2004) describes the Main Useful Function (MUF) of an organisation as the function which the organisation primarily exists to fulfil. Any other function only exists to support the fulfilment of the MUF. According to this definition, the MUF identified by the management at IPONZ is examination services, as per the following quote:

"It was very obvious that the area which this business would live and die on is in relation to its examinations... Because at the core of what we are charged to do under the respective statutes under which we operate is ultimately an examination and therein lies probably the next aspects.... If we constantly just simply make reference to our register that actually does not in any manner or form acknowledge the work that the majority of people in this place do every day and all day, which is examinations. So it's about valuing that."

This is a change from the historic main useful function of the Patent Office, which was originally a business registry where IP information was merely verified, recorded and stored. This is even reflected in the name used to refer to the MED branch that IPONZ operated under. IPONZ is part of what used to be referred to as the Business and Registries Branch. In 2001 it was re-named the Operations Branch and finally since 2003 it has been referred to as the Business Services Branch. Referring to IPONZ as primarily providing registry services implies that the records management function is the MUF, as opposed to examination services. The statement above underlines examination services as the main useful function of IPONZ and the central service around which all other services revolve. An essential part of delivering this MUF is the legislative framework which serves as the foundation for conducting examinations, and the IT infrastructure which is the platform on which those services are delivered.

Table $5 b$ next, is a matrix of coded units of information from interview data, generated by the analysis software -NVivo. It represents the intersection between discussions of changes in the organisation, and discussions of the different aspects of the organisation, as well as the different goals that were identified. That means 
that each cell represents how many people talked about change descriptions relating to either aspects of the organisation or identified goals. The number in the cell represents the number of sources from which information was derived that related to both themes at the same time. The codes in the first row represent all the themes categorised under "change descriptions" (DT.E.1-4), while the codes in the first column represent both the themes categorised under "aspects of organisation" (DT.A.1-8), and the themes categorised under "goal focus" (DT.B.110). A full list of all the information coded under each theme within each category is presented in Appendix 4.0.

Codes under "Change Descriptions"

\begin{tabular}{|c|c|c|c|c|c|c|c|}
\hline $\begin{array}{l}\text { Codes under } \\
\text { "Aspects of } \\
\text { Organisation" }\end{array}$ & DT.E.1 & DT.E.2 & DT.E.3- & DT.E.3+ & DT.E.4- & DT.E.4+ & Total \\
\hline DT.A.1 & 2 & 3 & 0 & 1 & 1 & 0 & 7 \\
\hline DT.A.2 & 3 & 3 & 0 & 4 & 2 & 0 & 12 \\
\hline DT.A.3 & 1 & 4 & 0 & 6 & 5 & 0 & 16 \\
\hline DT.A.4 & 7 & 7 & 2 & 4 & 6 & 0 & 26 \\
\hline \begin{tabular}{|l} 
DT.A. 5 \\
\end{tabular} & 6 & 5 & 1 & 7 & 8 & 1 & 28 \\
\hline \begin{tabular}{|l|} 
DT.A. 6 \\
\end{tabular} & 1 & 1 & 0 & 4 & 1 & 1 & 8 \\
\hline DT.A.7 & 4 & 2 & 1 & 5 & 5 & 1 & 18 \\
\hline DT.A.8 & 6 & 3 & 1 & 3 & 2 & 0 & 15 \\
\hline \multicolumn{8}{|l|}{$\begin{array}{l}\text { Codes under } \\
\text { "Goal Focus" }\end{array}$} \\
\hline DT.B.1 & 10 & 7 & 3 & 7 & 2 & 0 & 29 \\
\hline DT.B. 2 & 2 & 2 & 1 & 1 & 2 & 2 & 10 \\
\hline DT.B. 3 & 7 & 8 & 4 & 11 & 7 & 0 & 37 \\
\hline DT.B.4 & 7 & 4 & 3 & 6 & 5 & 1 & 26 \\
\hline DT.B.5 & 11 & 11 & 5 & 13 & 6 & 1 & 47 \\
\hline DT.B. 6 & 2 & 2 & 2 & 3 & 1 & 1 & 11 \\
\hline DT.B.7 & 2 & 5 & 2 & 7 & 2 & 0 & 18 \\
\hline DT.B. 8 & 10 & 3 & 5 & 3 & 0 & 3 & 24 \\
\hline DT.B.9 & 6 & 10 & 3 & 8 & 6 & 0 & 33 \\
\hline DT.B.10 & 8 & 6 & 4 & 12 & 9 & 1 & 40 \\
\hline Total & 95 & 86 & 37 & 105 & 70 & 12 & \\
\hline
\end{tabular}

Table 5b Change descriptions referring to aspects of the organisation, and organisational goals 
As shown in this table, the highest number of sources overall, which was 13 people (50\%), talked about positive effects of changes (DT.E.3+) related to the introduction of resources for clients and staff (DT.B.5). Resources include both technical resources such as tools and physical facilities, and non-technical resources such as team meetings and practice guidelines. Second to the overall highest was 12 (46\%), the number of people that mentioned positive changes to improve the quality of IPONZ services. In the column for descriptions of what has been changed at IPONZ (DT.E.1), the highest number of people also talked about changes related to the provision of resources for clients and staff. Second to that number was 10, representing $38 \%$ of all participants discussing changes related to both Legislative developments (DT.B.8) and IT developments (DT.B.1).

The highest number of change descriptions that are intersecting falls under change descriptions about positive effects of change implementations (DT.E.3+). This is also consistent with the highest number of units coded under one theme, out of all the themes in all the categories. 235 units of information fall under the theme for positive effects of change implementation (DT.E.3+). Appendix 4.0 shows that this is the highest number of units of information coded in the analysis. This is also 36 units more than the second highest which is 199 units of information, coded under descriptions of how changes were made. This indicates that the most discussion was about successful change implementations, and about the positive effects of those changes. The column under DT.E.3+ shows the number of people who discussed positive effects of changes, and what they related the changes to.

\subsubsection{Legislative Changes}

New Zealand IP legislation is historically a mirror of developments in the UK. The original legislation was adopted from the UK, and subsequent changes made to the UK legislation were also made to the New Zealand legislation until after 1953. In the three decades following the 1953 legislation, New Zealand became more internationally engaged, exploring legislation developments in countries other than those taking place in the UK. In 1992, legislation was passed that provided the platform for IPONZ to process international patents under the Patent Cooperation 
Treaty (PCT). Amendments in all three pieces of legislation continued as a response to practical and administrative needs for the registration of IP and maintenance of records. As IP regulation became more complex with the use of technical examination and developments in international IP systems, some changes to legislation incorporated more drastic changes to the norm. An example is the inclusion of sound and colour marks in the definition of "sign" under the trade marks amendment 1994. Legislative developments that moved IPONZ from the Trade Marks Act 1953 to the Trade Marks Act 2002, adopted changes from Singaporean IP legislation (New Zealand Parliamentary Debates, 2002; Wallis, 2003). These changes made provisions for efficient and effective administrative practices at IPONZ.

The prior consolidation of patents, trade marks and design law signifies the regard of all three types of property having the same value-award system. However, giving the name "Patent Office" to the whole Office may be a reflection of the priority given to patents, which may have been considered at that time to be the most economically beneficial. These three laws were eventually given their own distinct status, and other forms of IP besides the 3 were incorporating into the work of the Office. This was finally consummated in the change of the agency's name from "Patent Office" to "Intellectual Property Office" in 1997.

The legislative responsibility of IPONZ to provide information services to stakeholders including the public, created a mandate for the organisation to develop its library of IP information. The first library was set up in 1990, containing physical records of IP details such as the owners' contact information and specifications of invention and use. It also contained administrative information for the public in the form of a Patent Office Report. This library had to be moved to different locations in order to increase the space for storage of physical files, and eventually a separate location was procured to store physical back files of IP information. This amassing of physical paper files would have increased recognition of the need to adopt electronic storage and processing. 
Adding to this would have been increased political pressure to adequately cater to the rising demands for IP. With public demand outgrowing the agency's capacity in the 1990s, huge volumes of backlogs started to accumulate, igniting political recognition of not only the significance of the agency, but its economic importance. This would have contributed to decisions in 1995 to amend the State Sector Act 1988, moving the Office away from the Ministry of Justice and placing it under the Ministry of Commerce (MED). The benefits of a well-managed IP system for New Zealand would have also increased in the post-reform environment with liberalised foreign trade (Evans, Grimes, Wilkinson and Teece, 1996). This opened the economy up to international business activity that needed to be regulated. In accordance, amendments to the patent legislation were made in 1991, and to the trade marks legislation in 1994. These amendments increased legislative alignment with international standards in the Patent Cooperation Treaty (PCT), and the Trade Related Aspects of Intellectual Property Rights (TRIPS) agreement. All these external changes would have also contributed to establishment in 1997, of the five-day timeframe for issuing an initial response to applications, increasing internal pressure to improve IPONZ services.

The latest trade marks act was enacted in 2002, and it extended New Zealand's international practices by including aspects from Singaporean IP legislation. It also included provision for the protection of indigenously sources trade marks, addressing cultural issues with the IP system. Significant amendments were proposed for this trade marks legislation in 2008 to make it conducive for New Zealand to implement requirements for the Madrid Protocol, the Nice Agreement for the international classification of goods and services related to trade marks, and the Singapore Treaty on the law of trade marks (New Zealand Parliamentary Debates, 2009). These changes were introduced in the Trade Marks Amendment (International Treaties and Enforcement) Bill, and enacted in 2011. Also in 2008, a new Patents bill was introduced to provide a better suited legislation for both internal IP management effectiveness and international alignment. The Patent Bill is still in the process of review, and will also require significant future changes to the nature of examination and the structure of service fees. Some of those changes 
include legislation for the introduction of inventive step, international novelty, examination request and IP maintenance fees.

Examination request provides clients more flexibility in managing the application and registration process. IP Maintenance fees could help to reinforce clients' awareness of the importance of effectively managing their IP to maintain their protection. By transferring at least part of the cost to clients, maintenance fees could also be counter-productive for the system. Clients trying to evade extra costs may purposely avoid or defer making changes to their IP information at IPONZ, even if those changes ensure the integrity of their IP.

Both the introduction of examination request and maintenance fees help increase the effectiveness of IPONZ administration by incorporating a fees structure that drives more productive client behaviour. Inventive step incorporates a greater depth of examination to the patent registration process in order to establish the novelty value of patents. This will be a new addition to the requirements for registering a patent. International novelty on the other hand, although not previously included in legislation, was already a considered in examination which is carried out using international searching facilities.

From the interview data, 8 out of 26 participants suggested that New Zealand's IP system would benefit from alignment with international IP systems. This can afford New Zealanders greater access to foreign markets and would open New Zealand up to opportunities from overseas. However, the rigour of international standards would require more complex examination processes to establish compliance. In addition, technological and economic progress would lead to higher volumes of demand that require effective registration processes to sift the viable from the inadequate. This would require future development in operational effectiveness and higher service quality.

\subsubsection{Information Systems Changes}

Increasing internal pressures from rising backlogs and policy developments that dictate efficient and effective business practices, combined with external technological developments in information processing for organisations set the 
precedence for adopting electronic processing. According to the accounts of two participants, the first move towards electronic processing was made by digitizing paper records so that they could be stored to aid more convenient processing of files. The job of capturing the records electronically was outsourced to an organisation in the Philippines (IPONZ Annual Report, 1992). A contract was also awarded to build a computer system for the processing of those digitised records. However, this attempt was unsuccessful and that system never eventuated. Subsequently in 1994 an electronic files processor was developed in-house using Advanced Revelation (ARev) technology. This was used for storing the digitised records and processing correspondence files, while other files were still being processed manually.

This partial operation of electronic filing signalled the beginning of IPONZ shifting filing operations from manual paper-based to electronic and automated processing. Two participants mentioned that for a period of time, data from paper files had to be manually entered into computers so that they could be processed electronically. The previously scanned data records, and ARev storage allowed the Patent Office to provide electronic searching facilities for clients, patent attorneys and examiners through an internal network of computers. In addition, in 1993 the captured trade mark files were made available online for clients to search through a National Library facility called "Kiwinet" (New Zealand National Law Librarians Association, 2011).

A few years following ARev, in 1999, a custom-built database was developed specifically for IPONZ. Efforts were made to capture past IP paper files and store them electronically on this new database which was launched in 2000. This allowed for the processing of applications without the use of manual paper operations, though the paper files were still stored physically. Unlike the ARev database which was not universally novel but existed before it was adopted by IPONZ, "IPOL" was unique and therefore as a technological product was universally novel. One of the innovative benefits of IPOL was that it was capable of not only being a database but also being web-based, providing the infrastructure for online searching and filing facilities directly from IPONZ. 
Although IPOL was at the time of its launch considered functional, because of its novel technology, it took a few years of operating it for the system to become sufficiently adjusted for the uses of IPONZ. Six participants discuss certain issues with the processing of information on IPOL that required "fixes" and "workarounds". "Fixes" refers to extra work that had to be done to ensure that IPOL was functional, and "workarounds" refers to alternative courses of action that were taken to complete certain processes which otherwise could not be completed. Once IPOL was launched the progress towards electronic information processing accelerated, with online searching facilities for the trade marks files that had already been captured, and adding on other trade mark files, then patents and design files. The provision of online filing facilities followed the same pattern, starting with trade mark applications filing, then facilities for the renewal of trade marks, patents and designs were provided. The latest has been the provision of patents and design application filing facilities in 2008/2009. As of June 2010, IPONZ online filings has increased to $93 \%$ of all trade marks applications, $93 \%$ of all design applications and 61\% of all patent applications (IPONZ Annual Report, 2009-2010).

This transition however, was not fully embraced by all IPONZ clients, which contributes to the slow pace with which clients are taking up the online filing facilities. One participant, who had been an examiner for many years, makes the following comment about online services adoption by clients:

"Basically the way the world is going is increased technology and doing business more online, that's a fact. But some clients, we've got a couple in particular, that like the idea of still being able to file on paper. I mean [they think] it's cumbersome for them, but for us there's less risk of losing things if they file online ....it's more cost effective in terms of killing less trees, it's easier to process, yeah you can see where it's going, it's efficient in terms of time and how long it takes to get to us."

According to two participants, after 10 years of using IPOL, the technology became out-dated and unfit for expected future demand, and efforts began to replace it with a new database. Project COMPASS was initiated, and the adoption of a new 
database was included in the objectives, along with other changes that would improve IT facilities. The main focus of the project was to improve the resources and processes with which IPONZ carries out its core operations and delivers its services.

Throughout the developments of the Office's information systems, members of the organisation in their different teams had to quickly learn and adapt to the changes, and in several cases, especially with the use of IPOL, had to learn how to manipulate the system in order for it to function adequately. This was especially challenging prior to 2007 when the Office did not have a manager in-house that was mainly responsible for managing information systems. At that time IPONZ had to access support services remotely. Three participants discussed issues that were raised when IPOL was introduced, that did not get resolved until the information systems manager was employed. The following statement represents this point:

".....we raised an enhancement for IPOL to help us with the changes of names and addresses, which had been raised other times as well. We kept suggesting it and suggesting it and it kept getting put on the back burner, and then we were still working with a slight backlog because the turnaround times were so short, and then I think, we carried that for a little while. Then the development -when the current manager for Business Systems actually came in, we raised our enhancement with him and he okay-ed it and pushed it through. That helped a lot."

IPONZ is expecting to launch its new database, which replaces IPOL in 2012. The solutions to several pending issues with operational processes are expected to be incorporated into the new information system. One such solution relates to the issue of internal communication during the processing of applications. From the receipt of the file to the acceptance of the file, multiple individuals work on each application, and the only means to record updates to the application is through a note-taking facility in the database. With the new system, work done on the application will be automatically recorded and will allow review by other members involved in the processing of the application or file. 


\subsubsection{Innovative Changes in Management}

Changes identified from the primary and secondary data gathered, were filtered through a set of criteria to identify what constitutes Management Innovation (MI). MI can be defined as significant novel changes to the activities involved in arranging and coordinating people, tasks and resources (Hamel, 2006; Hargrave and Van de Ven, 2006; Birkinshaw, Hamel and Mol, 2008; Graetz and Smith, 2009). MI can be universally novel or novel to the organisation (Teece, 1980; Abrahamson, 1991; Birkinshaw and Mol, 2006). Using these definitions derived through the literature review, the following criteria were listed and applied to the changes identified in an attempt to distinguish $\mathrm{Ml}$ changes from other forms of change:

1. The change must be primarily non-technical

2. The change must be directly related to management activities

3. The change must be at least novel to IPONZ, and demonstrate a significant departure from any previous management practices that were reviewed in both primary and secondary data from IPONZ.

4. The change implementation must require the involvement of multiple members of IPONZ

There were 22 changes discussed by participants and verified by secondary data which have been included in this study. The changes are charted in Figure 5.4 presented previously, which illustrates IPONZ change history in a timeline, and from which MI was identified. Each change was examined to consider whether it qualified as novel to IPONZ, and whether it was implemented to become fully incorporated into the Office's on-going operations. A list of 15 changes were shortlisted that can be considered innovative, and this shortlist was then further filtered to identify those that can be considered MI according to the four previously mentioned criteria. Table $5 c$ shows a list of all the changes identified, the innovative changes identified and finally the management innovation changes. All eight of the changes identified as MI meet the four criteria set out previously. As the table shows, out of the eight management innovations identified, five were introduced or fully implemented in 2009. 


\begin{tabular}{|c|c|c|c|}
\hline & \multicolumn{3}{|c|}{ FILTERING FOR MANAGEMENT INNOVATION } \\
\hline & List of changes & $\begin{array}{l}\text { List of innovative } \\
\text { changes }\end{array}$ & $\begin{array}{l}\text { List of management } \\
\text { innovation }\end{array}$ \\
\hline 1 & Ptolemy (2012) & Acsepto (2010) & $\begin{array}{l}\text { Work and wage revision } \\
(2009)\end{array}$ \\
\hline 2 & $\begin{array}{l}\text { Trade Marks Amendment } \\
\text { (International Treaties and } \\
\text { Enforcement) Bill (2011) }\end{array}$ & $\begin{array}{l}\text { Work and wage revision } \\
\text { (2010-date) }\end{array}$ & $\begin{array}{l}\text { ISO accreditation with } \\
\text { process mapping (2009) }\end{array}$ \\
\hline 3 & Acsepto (2010) & $\begin{array}{l}\text { ISO accreditation with } \\
\text { process mapping (2009- } \\
\text { date) }\end{array}$ & $\begin{array}{l}\text { Change control system } \\
\text { (2009) }\end{array}$ \\
\hline 4 & $\begin{array}{l}\text { Work and Wage revision } \\
\text { (2010-date) }\end{array}$ & $\begin{array}{l}\text { Change control system } \\
\text { (2009) }\end{array}$ & $\begin{array}{l}\text { Articulating a formal } \\
\text { business plan document } \\
\text { (2009) }\end{array}$ \\
\hline 5 & Changing culture (2009-date) & $\begin{array}{l}\text { Articulating a formal } \\
\text { business plan/document } \\
\text { (2009) }\end{array}$ & $\begin{array}{l}\text { Patent Bill } 2009 \text { (novel } \\
\text { changes in examination } \\
\text { process and fee } \\
\text { structure) }\end{array}$ \\
\hline 6 & $\begin{array}{l}\text { Getting ISO accreditation } \\
\text { (2009-date) }\end{array}$ & $\begin{array}{l}\text { Patent Bill } 2009 \text { (novel } \\
\text { changes in examination } \\
\text { and fee structure) }\end{array}$ & $\begin{array}{l}\text { Establishment of } \\
\text { Business Systems and } \\
\text { Development team } \\
(2008) \\
\end{array}$ \\
\hline 7 & Change control system (2009) & $\begin{array}{l}\text { Establishment of Business } \\
\text { Systems and } \\
\text { Development team (2008) }\end{array}$ & $\begin{array}{l}\text { SEM Trans-Tasman } \\
\text { Harmonization (2006) }\end{array}$ \\
\hline 8 & $\begin{array}{l}\text { COMPASS (includes ISO, IT } \\
\text { upgrade, culture change and } \\
\text { restructure) (2009-date) }\end{array}$ & $\begin{array}{l}\text { SEM Trans-Tasman } \\
\text { Harmonization (2006) }\end{array}$ & Contact Centre (2001) \\
\hline 9 & $\begin{array}{l}\text { Articulating a formal business } \\
\text { plan/document (2009) }\end{array}$ & Contact Centre (2001) & \\
\hline 10 & Patent Bill 2009 & Online filing (2000) & \\
\hline 11 & $\begin{array}{l}\text { Establishment of Business } \\
\text { Systems and Development } \\
\text { team (2008) }\end{array}$ & IPOL database (2000) & \\
\hline 12 & Moving office locations (2007) & Website (1998) & \\
\hline 13 & $\begin{array}{l}\text { SEM Trans-Tasman } \\
\text { Harmonization (2006) }\end{array}$ & Arev database (1994) & \\
\hline 14 & Trade Marks Act 2002 & Trade Marks Act 2002 & \\
\hline 15 & Contact Centre (2001) & $\begin{array}{l}\text { Electronic processing (pre } \\
\text { 1994-date) }\end{array}$ & \\
\hline 16 & Online filing (2000) & & \\
\hline 17 & IPOL database (2000) & & \\
\hline 18 & Website (1998) & & \\
\hline 19 & $\begin{array}{l}\text { Fixing 5-day turnaround times } \\
\text { (1997) }\end{array}$ & & \\
\hline 20 & Arev database (1994) & & \\
\hline 21 & International linkages & & \\
\hline 22 & $\begin{array}{l}\text { Electronic processing begins } \\
1989 \text { (pre 1994-date) }\end{array}$ & & \\
\hline
\end{tabular}

Table 5c Identifying Management Innovation 


\subsection{Management Innovation Process}

Becker and Whisler (1967) suggested a framework for the stages through which innovative changes are incorporated into organisations. They describe the innovation process as involving the identification of a stimulus to innovate, conception of an innovation to respond to the stimulus, a proposal to adopt the innovation, and the implementation of changes to incorporate the innovation into the organisation. Birkinshaw, Hamel and Mol (2008) identified a similar process for management innovation. Their framework incorporated various activities unfolding within processes to identify motivations to innovate, to generate the innovation, to implement the innovation and to theorise and label (produce feedback for) the innovation. The Birkinshaw, Hamel and Mol (2008) framework carries more relevance for this study because it is specifically adapted to studies of management innovation.

Overall eight changes were identified that can be considered management innovation changes, and charting those changes on a timeline reveals that five of the changes were introduced in 2009, representing over $60 \%$ of all the management innovations identified. The most recently introduced management innovation is the work and wage revision started in 2010. This developed from business transformation efforts in Project COMPASS. The implementation of this change required the introduction of a new way of evaluating the work of examiners. It introduced novel elements to the structure of the two examination teams, and re-assessed compensation in a way that has not been identified in previous IPONZ management practice. It was acknowledged by four participants that as the years progressed towards 2009, part of the issues contributing to the high staff turnover at IPONZ was the perception of limited career progression for examiners. This lack of progression also corresponds to a perception that compensation was inequitable, as salary increases were limited to ranges in the payment band of examiner positions, which offered limited advancement opportunities. In the matrix in Table $5 b$, in the row for aspects of the organisation, the highest number of sources (8 people) discussed negative effects of not successfully implementing changes. These changes were related to the issues facing employees of the organisation. These 
issues presented the motivation to make changes to the structure of work and compensation.

High staff turnover was an issue experienced at IPONZ since its earlier days after the first appointment of technical examiners in the 1940's (IPONZ History, 2008). Not only did it negatively affect productivity, it also further restricted the Office's capacity to handle increasing filing volumes, which led to the existence of backlogs (PricewaterhouseCoopers, 2009). After the appointment of a new Group Manager in 2009, efforts were put into devising a solution for the staffing problems. Revising the structure of work and payment system was considered part of the solution to curtailing high turnover. The revisions conceived involved the introduction of 2 new roles that improved and properly defined a progression path for examiners. A new system of compensation was also introduced, that set different pay bands to reflect the position of the examiner along that progression path. This new structure was implemented in 2010 for the trade marks division, and its implementation will continue for the patents division and other divisions within IPONZ. From the matrix in Table 5b, six participants (23\%) within and outside the trade marks division mention positive implications of this new structure.

The Office achieved ISO Accreditation in 2010 for its Patents, Trade Marks and Designs Examinations teams (IPONZ, 2011). IPONZ set up a quality management system for examination processes in 2009 , and by adequately complying with quality standards IPONZ was able to pass audits for accreditation (IPONZ, 2009). IPONZ processes were visually represented on a map, and evaluated to ensure that inefficiencies such as duplication of work and resource wastage can be reduced. There had been previous attempts to officially document processes, but the tools produced were not extensively adopted by IPONZ members, and therefore were neither comprehensive nor adequately managed. With an accurate documentation of processes, a quality management system could then be drafted and implemented to maintain or improve their effectiveness. One participant mentions how the process map was an attempt to understand, evaluate and improve processes. This stimulus to map processes also presented the opportunity to certify 
the quality of those processes, as a means of endorsing confidence in IPONZ services.

Also in 2009 under Project COMPASS, preparations began to introduce new searching facilities for the trade marks division, and a new database for the whole office. According to 2 participants, in order for these facilities to be effective, they needed to be designed for efficient implementation of IPONZ work processes. This also required the mapping and evaluation of processes. According to another participant, the process map helps improve knowledge sharing.

Closely related to the process mapping exercise, was the establishment of a change control system at IPONZ, which according to one participant was not entirely novel. It was included in the list of innovative changes because the extent and nature of its use was unprecedented at IPONZ. Before the change control system was put in place, a work improvement tool had been introduced that created a platform for members of IPONZ to communicate and promote the implementation of changes, which they identified as leading to better processes and/or resources. However this tool did not deliver according to expectations until it was redesigned into a management tool to share and coordinate the implementation of any changes that were proposed for IPONZ. Sharing and managing change implementation was the motivation behind the implementation of this tool.

The work improvement tool was re-named the "change control system" and was remodelled to provide a means for changes to be proposed, recorded, evaluated and implemented in a coordinated way. The success of the change control systems extensive implementation at IPONZ, was attributed to its use by the management team, who likely awarded it the legitimacy that was lacking in the older work improvement tool. The following statement was made by a member of the management team regarding some benefits of the coordination of change efforts, using documentation, so every team in the organisation had a means to contribute:

"More importantly from our [management team's] perspective, is that when we actually sign off on a change, we've brought to bear the thinking across the business as to whether or not we'll fix or break things, because the 
problem when you've got such complex processes is that you might go and tweak something individually or even as a team, thinking that you are doing the right thing and you have all the right motives for doing so, but inadvertently break something else somewhere else, so that's [the change control system] trying to capture that."

This statement implies an issue that has been previously addressed by many scholars (Goldratt, 1997; Dettmer, 1997; Mabin and Balderstone, 2000; Dettmer, 2007) in the field of Operations Management. It relates to the need to take a systems view of changes, identifying its effects on the entire system in addition to its effect in a local unit. A change in a specific unit of an organisation could be positive for that individual unit, but have an overall negative effect on the entire organisation.

Another innovation, which came out of the management team, is the formal articulation of a Business Plan for IPONZ. It was novel to IPONZ at the time it was introduced. Although it was a simple document representing IPONZ purpose and functions, and it was drafted to be a simple representation of that, it was used to establish a unifying ethos that was previously non-existent in the organisation. Five participants (19\%) commented on the perceived lack of coordination among the teams of the organisation and the related lack of communication between team managers in previous years. These 5 participants are out of a total of 20 participants interviewed that had worked at IPONZ for at least 2 years.

The motivation to establish unified operations raised a need to provide a business plan document that could be understood and shared throughout the organisation, and by every member. According to one of the managers, the members of the management team co-operated together to draft the business plan. They used the document as a basis and reference for promoting changes that their teams would be involved in implementing. The document was also given to every member of IPONZ, and placed in areas within the Office where it would be viewed frequently. The business plan can be a means to giving direction and momentum to 
coordinated change efforts, in such a way that each team head knew that their accountability would be towards the entire organisation, not just their team.

A management innovation was identified from proposed changes in the new patent legislation, planned to be released. The legislation will legally require examiners to check the novelty of the patent internationally, and to test the inventiveness of the product. Both of these provisions did not exist in the previous legislation. Changes in the new legislation were stimulated by pressure from stakeholders to improve the scope of patentability, and to make provisions better aligned to international standards (New Zealand Parliament, 2009). The legislation also proposes some changes to the system of charging fees, and certain new service requests that clients can make. One of the new services allowed in the legislation is the request to halt examination of the patent, for justifiable reasons. This is unprecedented in New Zealand, and will take IPONZs relationship with clients to a higher level of collaboration and communication.

The Bill for this legislation is still under review by selects committees, after its first reading in parliament. All these changes represented in proposed legislation demonstrate attempts by IPONZ to engage with clients at an unprecedented level. It also presents opportunities for IPONZ to increase the credibility of examinations, which is the main useful function of the Office. Though these changes are still in the process of being implemented, preparations have to be made in order for IPONZ to have the capability to fulfil requirements under the new legislation.

One structural change classified as management innovation is the formation of a Business Systems and Development team. This change wasn't included in the timeline because the time of its introduction could not be identified, and its implementation was gradual. In 2007 a manager was hired on a limited term contract, to oversee the implementation of a project to roll out a new website for the Office. After the appointment of this manager, several other technological issues were raised over time that the manager was also given responsibility for. Finally the role of the manager was expanded to also include projects to procure examination tools and a new database. With the expansion of the managers role, 
came the motivation to appoint a team to work on those projects, included in Project COMAPSS. The new team was given sole responsibility for the managing the existing IT facilities, which had never been done at IPONZ. As a result of this team existing in-house, IPONZ was able to manage the multiple projects that were undertaken to conduct business transformation initiatives. One of the managers described this team as "a team that actually do a lot of the doing in the organisation".

Since 2006, IPONZ has made efforts to harmonise examination processes and patent attorney registration services with the Intellectual Property Office of Australia (IPA). These efforts are part of attempts to achieve the Single Economic Market (SEM) strategy of the New Zealand Government, which was conceived to broaden the nation's economic scope for business growth and jobs creation (New Zealand Treasury, 2009). Implementation began with the comparison of both countries' legislative regimes and both administrative systems. Although the legislation administered through IPA is not identical to that administered in New Zealand, it was found that enough similarities existed and could be assumed between the two regimes that would allow the harmonization of examination processes for trade mark registrations and patent attorney registration (IPONZ, 2009). A trial has been completed to coordinate the examination of trade marks in both countries. Though the implementation of these changes is still underway, the government issued mandate for the SEM strategy gives the project legitimacy within IPONZ.

The earliest management innovation identified was the creation of a contact (call) centre to provide support to clients through the "0508-4-IPONZ" service. The contact centre was introduced in 2001 (IPONZ History, 2008), and currently combines what used to be the technical support service and the library client service centre. In the days when the Office maintained a physical library of records and later electronic searching tools, client services were delivered both through telephone and face-to-face facilities. After online searching facilities were set up, and online filing facilities were launched they negated the need for face-to-face client services delivery. It operates as an important supplement to the electronic 
facilities for clients, and is delivered mainly through telephone and email. One participant suggests that though it is not operated in-house, it provides a cost effective method for assisting clients who require information and support for filing. An externally managed client services centre frees IPONZ members up to focus on core examination and records management processes.

When comparing the list of $\mathrm{MI}$ identified, and examining the business plan document that IPONZ operates with, there were indications that the majority of changes implemented are directly related to a majority of the objectives outlined in the business plan. The Business Plan document contains a list of six objectives that the organisation is set to work towards till 2013, and five out of those involve the implementation of MI identified. The majority of the innovations identified by participants are also formally stated as the organisation's objectives in the IPONZ Business Plan and Annual Reports. This reinforces the finding that change implementation is carried out according to previously set objectives for the organisation. In the case of $\mathrm{MI}$ at IPONZ, innovations were adopted and implemented in direct attempts to achieve organisational objectives for specific periods. Some innovations were set as the objective for a specific area. The finding that innovations identified were implemented as a direct result of set goals is also in line with previous definitions of MI. Birkinshaw, Hamel and Mol (2008) define MI as something new to management practice, process, structure of technique, that contributes to the achievement of organisational goals. 


\section{Chapter Six}

\subsection{ANALYSIS DISCUSSION}

This study set out to explore possible relationships between the use of Goal Setting and the development of innovation at the Intellectual Property Office of New Zealand (IPONZ). For this exploration to be possible, the organisation had to be examined to uncover how goals were used within the organisation, and it had to be established whether there were innovative changes implemented at the Office. Having prior knowledge of the organisation before the research commenced, the researcher was able to determine that there was some use of goals. Nevertheless, this had to be verified using both primary and secondary data, which also made it possible to clarify the nature and extent of use. In addition, it had to be established whether the organisation prioritised the generation and adoption of innovation, and if there were goals set for the development of innovation. If the organisation made deliberate attempts to be innovative, an obvious connection could be the use of goals to encourage innovativeness. Also, according to literature, innovativeness fosters the achievement of goals. Other possible relationships would require deeper exploration to uncover. The research questions posed are as follows:

\section{Is there a relationship between goal setting and the} development of innovation in managing the administrative function of an organisation?

1. Do changes implemented at IPONZ contribute to the achievement of goals set at the Intellectual Property Office of New Zealand?

2. Are there changes implemented at IPONZ that can be considered "innovative"?

3. Have there been organisational goals at IPONZ, which were set for the development of innovation within the organisation? 
4. Are there clearly identifiable management innovation changes that have been implemented at IPONZ that contributed to the achievement of set goals?

Goal setting at IPONZ was found to follow a hierarchical pattern, starting with operational goals set as official performance expectations, then expanding in recent years to include strategic goals that gave the organisation direction, and objective goals that helped the organisation stay on strategic course. In 2009, a business transformation project was introduced, and objectives to implement this project became part of IPONZ official goals. 4 out of 6 (67\%) changes introduced in 2009 were set as operational goals in the business transformation project. These goals are outline in IPONZ Business Plan 2010-2013, a summary of which is presented in Appendix 3.0. Prior to 2009, identified goals were operational and quantitatively set and measured. These goals only served as performance expectations for the services of the Office, such as timeframes and process output quality, and they presented no indication that changes were a requirement, though the goals themselves frequently changed. The strategic direction of the organisation was determined by the intent of its parent organisation -MED.

IPONZ implemented changes consistent with developments in the New Zealand public sector, including changes to comply with reform initiatives and changes to increase international integration. With the exception of the year 2009, the number of changes identified as significant were relatively constant at one or two changes implemented every year. In 2009 there were six changes implemented, two with short-term implementation and four implemented for over a year. One technical innovation was identified that was universally novel, or novel to the state of the art. 15 (68\% of change introductions) contextual innovations, novel to IPONZ, were identified that had been introduced into the Office. Six innovations $(27 \%)$ were a direct result of efforts to achieve goals. Among the 15 innovations, eight management innovations (36\%) were identified that represented four introduced in efforts to achieve goals and four introduced as goals in themselves. The following is a chart, showing the proportion of changes that were identified innovation and management innovations: 


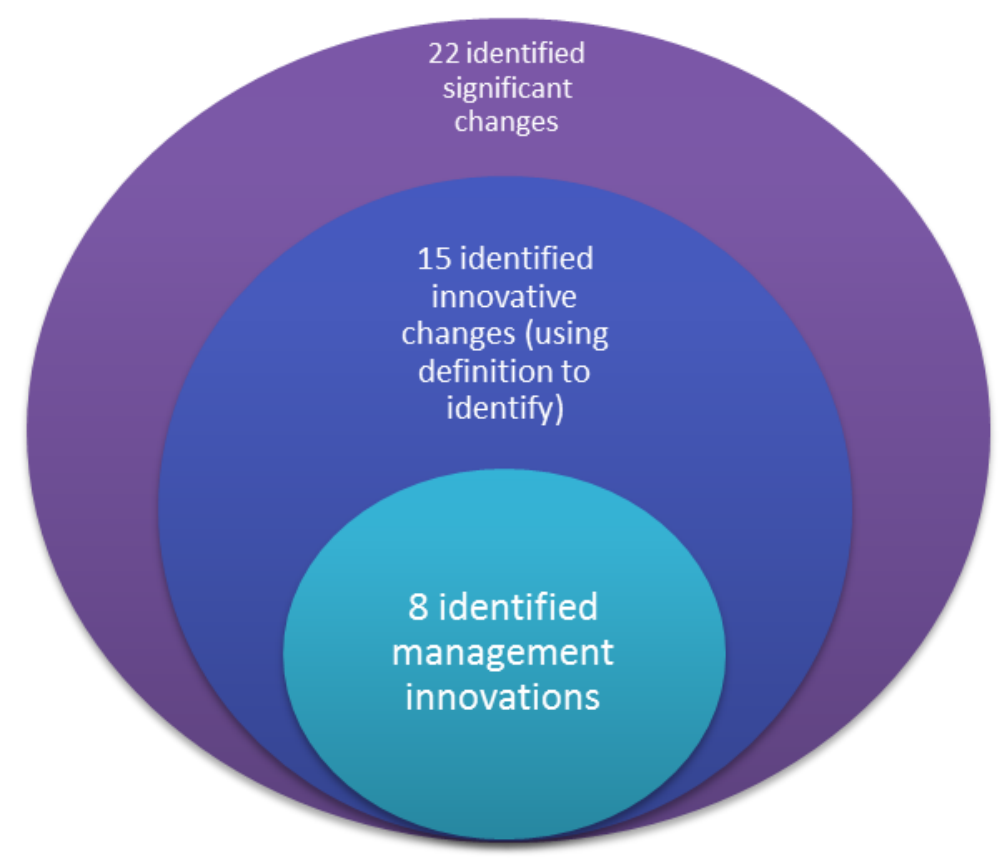

Chart 6 IPONZ innovations

\subsection{Preaching and supporting practice}

Prior to 2009, the use of goals were inconsistent and not always an application of Locke and Latham's (1979) prescriptions. Locke and Latham's Goals Setting Theory proposes that specifically set difficult goals lead to more performance motivation than vaguely set easy goals or no goals at all. In the case of IPONZ, though goals were specifically set, they did not pose a consistent level of difficulty over the years. The targets set for some years can be considered difficult, while others years did not pose the same or higher level of difficulty from the preceding year. This can be attributed to the condition of demand driven service volumes (IPONZ, 2000-2010). This is the case where quantities of service delivery are determined by levels of demand, which are not consistent or controllable, and therefore present different requirements from year to year. In terms of quantity, this means that the goal difficulty for service volumes changed from year to year depending on how much more or less demand was, compared to the previous year. Another dimension of difficulty could be the requirement to manage service delivery to respond to 
fluctuating levels of demand. However, this requirement was not stated in official goals.

Figure 6.1 shows the goal achievement percentages, representing the number of goals achieved out of the total number of quantitative goals set for the a year (MED 2000-2010). Goals without achievement data in the Annual Reports were considered non-achievement. The table showing the percentage calculation is presented in Appendix 3.3. The figure shows that goal achievement significantly exceeded $70 \%$ from 2006, and reached $100 \%$ in 2010 . Though the nature of quantitative goals didn't change, the chart shows a gradual increase in goal achievement.

As discussed earlier from Table $5 b$, the provision of resources was found to be discussed by the most people, who pointed out positive effects of the changes. Resources introduced in 2009 may have contributed to 100\% achievement in 2010. Another condition that can be attributed to this trend is the increase in competency of IPONZ members, as their experience with existing systems increased over the years.

These findings suggest that preaching through Goal Setting is not enough to ensure task performance. In the case of IPONZ, the provision of resources could have been an indication to members that not only were there expectations for performance, but there was a commitment by management to see those expectations met. Therefore supporting the practice preached could also be a significant factor in high task performance. 


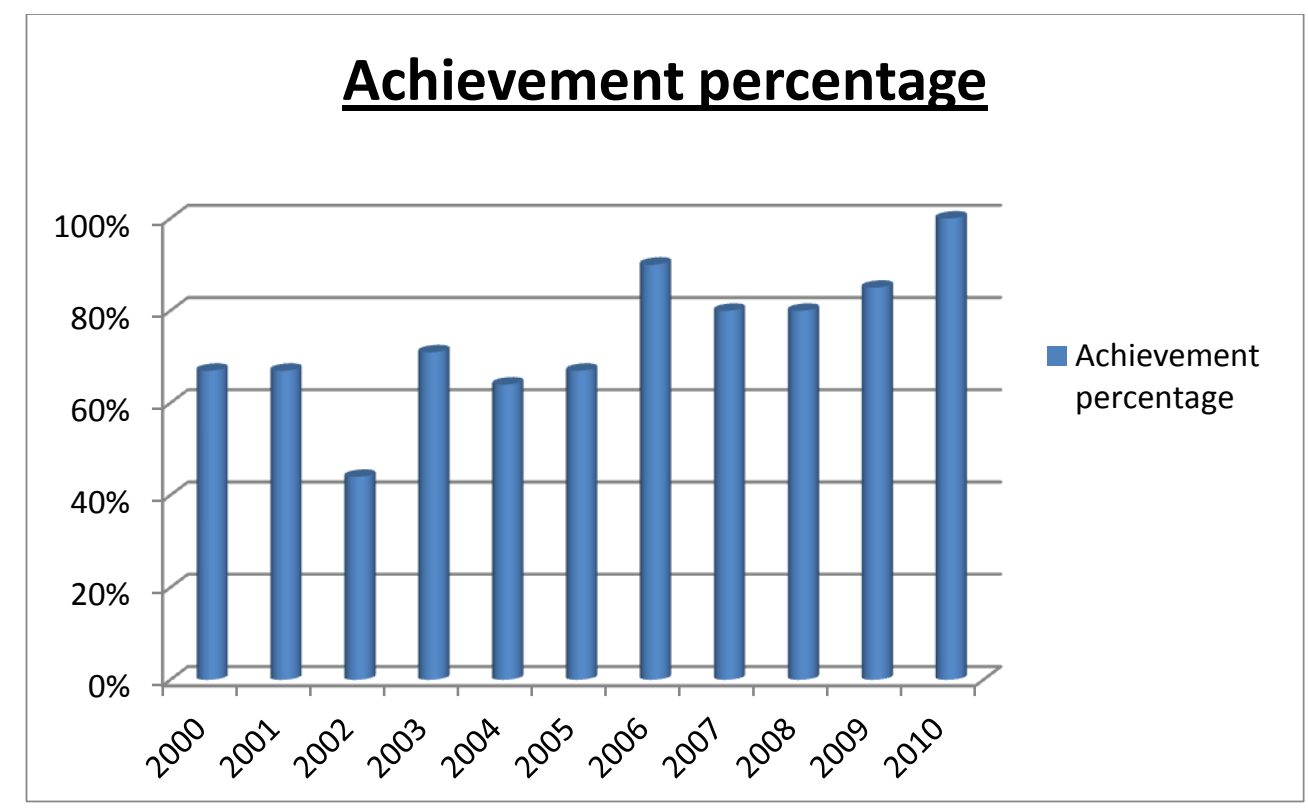

Figure 6.1 Percentage of goals achieved each year

\subsection{Respecting the Pulpit}

The significant changes identified in past IPONZ events were charted on a Timeline in Figure 5.4. The Timeline was included in the "IPONZ Change and Development" section, to show the course of events over the years. Clearly shown in the timeline, is significant variation in the number of changes identified in 2009 , when compared with other years. This variation can be related to the identification that prior to 2009, there were no goals relating to change officially set for IPONZ. This relation is affirmed by the match between several goals set from 2009 and changes implemented in 2009.

Table 6a following shows a list of summarised goals from IPONZ Business Plan (2010-2013), also shown in Appendix 3.0, and a list of changes which were introduced to achieve those goals. IPONZ Business Plan (2010-2013) is carried forward from IPONZ Business Plan (2009). The changes in the table are numbered according to which goals they correspond to. There are changes introduced into the Office were not included in the Timeline, only those changes which required the 
involvement of multiple members of the organisations and affected the performance of operations in more than one area of the organisation.

For a full list of all the goals from 2000 to 2010, please see Appendix 3.0. From 2009, quantitative operational goals were supplemented by strategic and objective goals, as well as detailed qualitative transformation goals. Table 6a shows that 17 out of 26 transformation goals were achieved through change introductions, representing $65 \%$ achievement of goals.

When IPONZ goals were mainly quantitative and focused on core operations, 1-2 significant changes were introduced a year in only nine years between 1994 and 2008. When quantitative goals were supplemented by strategic goals, objective goals, and non-quantitative transformation goals, 6 significant changes were introduced in 1 year. It is likely that the use of transformation goals contributed to the difference. These findings point to a link between the nature of goals set and change introductions. It appears that change goals lead to higher change introductions, when included in official statements. However, it is necessary to note that after 2009 change introductions reduced again to 1-2 a year, though the period for IPONZ Business Plan activities extending to 2013. Some considerations for these findings would be whether the initial introduction of Strategic endorsement temporarily boosted a comparatively higher rate of change introduction, or whether change introductions in 2009 were considered sufficient to achieve goals without further frequent introductions in the interim.

This may be related to what Goldratt (1992) refers to as inertia in a system, where effects of certain stimulus or change wears off and the system returns to its initial level of activity and remains relatively constant. This relatively constant level of activity is also discussed by Weick and Quinn (1999) when considering patterns of changing in organisations. They describe when an organisation's relatively stable level of activities are interrupted by an injection of radical change, and after changes have been well incorporated, the organisation returns to relative stability. 


\begin{tabular}{|c|c|c|c|c|c|}
\hline \multicolumn{5}{|c|}{ GOALS } & \multirow{2}{*}{$\begin{array}{c}\text { GOAL ACHIEVEMENT } \\
\text { Operational Goals Achievement }\end{array}$} \\
\hline & Objectives & Operational & Transformation Objectives & Transformation Operational & \\
\hline Credibility: & $\begin{array}{l}\text { 1. Effective } \\
\text { implementation of } \\
\text { legislation } \\
\text { 2. Developed stakeholder } \\
\text { relationships }\end{array}$ & $\begin{array}{l}\text { Decision } \\
\text { Quality and } \\
\text { Accuracy }\end{array}$ & $\begin{array}{l}\text { 1. New Patent and Trade } \\
\text { Marks Act } \\
\text { 2. Implement Single } \\
\text { Economic Market initiatives }\end{array}$ & $\begin{array}{l}\text { 1. Examine for inventive step } \\
\text { 2. Draft regulations for the new legislation } \\
\text { 3. Implement the requirements of Madrid Protocol for } \\
\text { trade marks } \\
\text { 4. Incorporate the Nice Convention and Singapore Treaty } \\
\text { 5. Increase alignment with Australia for trade marks, } \\
\text { patents and PVR registration activities } \\
\text { 6. Explore further opportunities of international } \\
\text { integration } \\
\text { 7. Improve IP enforcement facilities }\end{array}$ & $\begin{array}{l}\text { 3. Requirements for Madrid Protocol } \\
\text { introduced } \\
\text { 4. Nice Convention and Singapore } \\
\text { Treaty Introduced } \\
\text { 5. SEM alignment for trade marks and } \\
\text { patent attorney registration introduced }\end{array}$ \\
\hline Capacity: & $\begin{array}{l}\text { 3. Advanced IT systems } \\
\text { 4. Effective business } \\
\text { processes }\end{array}$ & $\begin{array}{l}\text { Journal } \\
\text { Production }\end{array}$ & $\begin{array}{l}\text { 3. Develop new IT systems } \\
\text { 4. Conduct fees review }\end{array}$ & $\begin{array}{l}\text { 8. Introduce new automated processes } \\
\text { 9. Develop the technical capacity to deliver new } \\
\text { legislative requirements } \\
\text { 10. Introduce new technical resources for examination } \\
\text { 11. Improve the integrity of records } \\
\text { 12. Develop process maps and operational policies } \\
\text { 13. Increase the effectiveness of business processes }\end{array}$ & $\begin{array}{l}\text { 8. New automated searches introduced } \\
\text { 9. New database being built for } \\
\text { introduction in } 2012 \\
\text { 10. New search tool (Acsepto) } \\
\text { introduced } \\
\text { 12. Process maps developed }\end{array}$ \\
\hline Confidence: & $\begin{array}{l}\text { 5. Achieving timeframes } \\
\text { 6. Quality management } \\
\text { systems } \\
\text { 7. Maintaining client } \\
\text { focus } \\
\text { 8. Provision of quality } \\
\text { examinations }\end{array}$ & Timeliness & $\begin{array}{l}\text { 5. Develop quality } \\
\text { management systems }\end{array}$ & $\begin{array}{l}\text { 14. Introduce new fee structures that drive behaviours } \\
\text { 15. Introduce ISO certification for processes and } \\
\text { examination } \\
\text { 16. Develop auditable quality systems } \\
\text { 17. Explore SEM quality audit programmes } \\
\text { 18. Maintain the delivery of core operations } \\
\text { 19. Achieve Statement of Service Performance (SSP) } \\
\text { standards and Business Objectives } \\
\text { 20. Promote online services and new services adoption } \\
\text { 21. Develop and utilize IP awareness partnerships }\end{array}$ & $\begin{array}{l}\text { 15. ISO certification introduced } \\
\text { 16. Quality management systems } \\
\text { introduced } \\
\text { 18. Maintained "business as usual" } \\
\text { 19. Exceeded SSPs in } 2009 \text { and } 2010 \\
\text { 20. Online service adoption promoted } \\
\text { 21. IP awareness partnerships built } \\
\text { within the education system, and with } \\
\text { prominent New Zealand inventors } \\
\text { (IPONZ, 2010). }\end{array}$ \\
\hline Capability: & $\begin{array}{l}\text { 9. Equipped and } \\
\text { resourced organisation } \\
\text { members }\end{array}$ & $\begin{array}{l}\text { Examination } \\
\text { and Support } \\
\text { output }\end{array}$ & $\begin{array}{l}\text { 6. Improve the Office } \\
\text { culture }\end{array}$ & $\begin{array}{l}\text { 22. Improve staff recognition } \\
\text { 23. Develop staff engagement } \\
24 \text {. Update role descriptions and introduce a career path } \\
\text { framework } \\
25 \text {. Improve examination training and Quality Assurance } \\
\text { programmes } \\
26 \text {. Perform quality and timely staff performance reviews }\end{array}$ & $\begin{array}{l}\text { 22. New compensation structures } \\
\text { 23. Social participation initiatives } \\
\text { introduced } \\
\text { 24. Revised work structures include } \\
\text { new roles } \\
\text { 26. Staff performance reviews } \\
\text { periodically conducted }\end{array}$ \\
\hline
\end{tabular}

Table 6a Goal achievement 2009-2010 
These patterns can be applied to the rate of change introductions, but not to the volumes of service output, which are continuously fluctuating with demand, even in periods of change. Within periods of both high and low change implementation, output levels show IPONZ achieving officially set goals. Core operational goals related to speed of delivery (timeframes) were not changed during periods of high change implementation. IPONZ members achieved and exceeded speed of delivery goals, even with the add-on of transformation operations and a $1.2 \%$ increase in demand from 2009 to 2010. This achievement was likely supported by the employment of short-term employees for project work, and the appointment of a team specially focused on change initiatives.

Seijts, Latham, Tasa and Latham (2004) suggest that the goal orientation facilitates the effects of specific goals. Indications from Appendix 3.0 are that IPONZ utilised quantitative goals for familiar, long-standing core operations where orientation to perform is high. For transformation operations where orientation to perform may be lower, non-quantitative goals were used. This is consistent with goal setting theory propositions. Core operations would likely have higher performance orientation because they have been performed continuously for over 10 years. Change implementations would likely have comparatively lower performance orientation, because it involves tasks that IPONZ members would be less familiar with. This finding is aligned with previous research discussed by Locke and Latham (2002), where "vague" performance goals and specific learning goals lead to higher performance when performance orientation is low.

IPONZ uses quantitative goals extensively to ensure clients are receiving adequate standards of service. However, goals representing only quantity are not necessarily sufficient to ensure quality. This was noted by several participants. Ordonez, Schweitzer, Galinsky and Bazerman (2009a) pointed out that goals only focused on end results can be manipulated to give the appearance of goal achievement without full implementation of the tasks necessary to deliver satisfactory quality. In such cases a suggestion would be to complement output quality goals with process quality goals. IPONZ use of a quality management system provides a means through which process quality can also be evaluated. 


\subsection{A Clear Message from Above}

As part of its transformation goals, IPONZ established a schedule of activities that were set to introduce changes into the organisation. Using the summary from Appendix 3.0, goals to introduce innovative changes were identified which represents official intentions. In addition to goals set officially, several non-official supplementary goals were found that represents intentions to implement innovative changes. Table $6 \mathrm{~b}$ displayed next shows examples of both official and supplementary innovative goals identified from interview data. Goals are differentiated according to which one of the $4 C^{\prime}$ 's objective they contribute to.

As Table $6 \mathrm{~b}$ indicates, the formation of supplementary goals was not published for all the $4 C^{\prime}$ s. This can be expected, considering findings that these goals were not established as official goals for the Office. For Capacity, there was an indication that a supplementary goal for the development of IPONZ capacity exists. It was found in a statement made by the manager, which was published in the media and presented on IPONZ website for News (2009). There were also indications in an officially released business evaluation report, conducted by PricewaterhouseCooper (2009), that IPONZ would require the construction of an extensive process map, to increase business intelligence for the management of the organisation. The implementation of the process mapping exercise to facilitate ISO accreditation in 2009 was novel to IPONZ. However the maps developed did not reflect end-to-end processes, and would have to be extended to achieve the level of comprehension indicated in the evaluation report.

Table $5 \mathrm{c}$ in the findings chapter that lists significant changes implemented at IPONZ. All the significant changes were filtered by requirements from literature to identify management innovation. Findings show evidence that the outcomes for the goals mentioned above have been achieved fully for the introduction of Acsepto and the development of IPONZ current database, to build capacity. The table also shows that although the new Patent Act has not been enacted, the Bill has been released in 2009, and is under current review. This represents partial achievement for the Credibility objective. 
In relation to the process of innovation (Becker and Whisler, 1967; Birkinshaw, Hamel and Mol, 2008), innovative goals in Table 6b were not set to conceive innovations, but to implement already conceived innovations. In this way goal setting was not used to generate solutions to identified problems, they were used to boost motivation to ensure that solutions are incorporated into the organisation. This may be an indication that in the innovation process at IPONZ, implementation has the highest relevance for operations than any other phase, possibly due to the comparatively higher level of resources required at the implementation phase.

According to Locke and Latham (1981), the use of specific difficult goals increase task performance. In the case of IPONZ goals to implement innovations, the specificity of goals was high because the aim of the goal was an outcome that would be clearly manifested. However the difficulty level of the goal could not be determined because of the novelty involved. In goal setting theory, the difficulty level is determined in comparison to alternative levels of performance proficiency. For example, if a goal is set to achieve $90 \%$ pass in an exam, the difficulty of this goal is only determined by comparison to a goal of say $70 \%$ pass. In the case of innovative goals, there is no basis for difficulty comparison within IPONZ, because of the novelty of the outcome. There might be a basis for difficulty comparison between implementation of the innovation at IPONZ, and implementation at another organisation, provided adequate similarities in size and capability was established. From Table 6b, highly specific innovative goals set in 2009/2010, had no identifiable difficulty level, but have still led to partial and full achievement of outcomes.

These findings paint a picture that IPONZ has not only utilised general goal setting for core operations, but that it has utilised goal setting to establish patterns of change to support the organisation's core functions. In other words, goal setting is an established part of the organisation's management system, even for innovation generation and implementation. The organisation has clarified its aims by making outcomes expected from individual and group performance explicit (Linnenbrink and Pintrich, 2000). 


\begin{tabular}{|c|c|c|c|c|}
\hline \multirow[b]{2}{*}{ Objectives } & \multicolumn{2}{|l|}{ Mandatory } & \multicolumn{2}{|l|}{ Supplementary } \\
\hline & Published (IPONZ, 2010) & Personal Interviews & Published & Personal Interviews \\
\hline Credibility: & $\begin{array}{l}\text { Implementing new } \\
\text { legislation with novel } \\
\text { provisions for } \\
\text { examination. } \\
\text { Implement novel changes } \\
\text { to achieve Trans-Tasman } \\
\text { Harmonization. }\end{array}$ & $\begin{array}{l}\text { "....firstly we've got } \\
\text { the legislative } \\
\text { changes which are } \\
\text { facing the } \\
\text { organisation.... will } \\
\text { require quite } \\
\text { significant change } \\
\text { just in order to } \\
\text { organize ourselves } \\
\text { to deliver that." }\end{array}$ & & $\begin{array}{l}\text { "We developed our first strategic } \\
\text { business plan.... There are some } \\
\text { easily definable activities that } \\
\text { weren't just rhetoric, but made a } \\
\text { real impact and sense, well } \\
\text { hopefully, that was the intention } \\
\text { anyway...." }\end{array}$ \\
\hline Capacity: & $\begin{array}{l}\text { Introducing Acsepto } \\
\text { which provides automatic } \\
\text { searching facilities for } \\
\text { trade marks and designs. }\end{array}$ & $\begin{array}{l}\text { "....the Acsepto } \\
\text { system, the new } \\
\text { search tool that } \\
\text { we've got .... that's } \\
\text { another thing to } \\
\text { make sure we get } \\
\text { the forefront in } \\
\text { terms of } \\
\text { examination tools." }\end{array}$ & $\begin{array}{l}\text { Increasing } \\
\text { innovativenes } \\
\text { S (Van de } \\
\text { Schyff, IPONZ, } \\
\text { 2009) }\end{array}$ & $\begin{array}{l}\text { "....they'd had in place for about a } \\
\text { year the sort of idea that they } \\
\text { weren't going to be making any } \\
\text { changes in IPOL because they were } \\
\text { going to replace it.....There's no } \\
\text { reason why you still can't spend } \\
\text { money in your old system if you're } \\
\text { going to get benefits out of it....." } \\
\text { ".....we've done some small stuff, } \\
\text { come up with some ideas and } \\
\text { made some updates to our system } \\
\text { that nobody else in the world is } \\
\text { doing, but they're quite small." }\end{array}$ \\
\hline Capability: & $\begin{array}{l}\text { Improve culture by } \\
\text { updating role } \\
\text { descriptions and the } \\
\text { introduction of a novel } \\
\text { career path framework }\end{array}$ & $\begin{array}{l}\text { "The structure we } \\
\text { had was that we } \\
\text { were bringing } \\
\text { people in.... and } \\
\text { then they got } \\
\text { stuck.... So there } \\
\text { was no career of } \\
\text { progression } \\
\text { components.... and } \\
\text { an enormous } \\
\text { amount of effort } \\
\text { went in last year to } \\
\text { change that." }\end{array}$ & & $\begin{array}{l}\text { "....we're not trying to catch people } \\
\text { out, it's more about 'well have we } \\
\text { described it correctly? Are there } \\
\text { better ways of doing work?'.... } \\
\text { We've driven that even harder by } \\
\text { introducing the change control } \\
\text { process ....that they can actually } \\
\text { see what's happening in other } \\
\text { spaces." }\end{array}$ \\
\hline Confidence: & $\begin{array}{l}\text { Obtaining ISO } \\
\text { accreditation for quality } \\
\text { management, and using } \\
\text { mapping processes to } \\
\text { improve management }\end{array}$ & $\begin{array}{l}\text { "So we'll change } \\
\text { our business } \\
\text { objectives again this } \\
\text { year to sort of put } \\
\text { in Iso_... that our } \\
\text { ISO processes are } \\
\text { working and we're } \\
\text { following the } \\
\text { correct order or } \\
\text { procedure that will } \\
\text { drive the behaviour } \\
\text { if people know that } \\
\text { we do follow } \\
\text { procedure." }\end{array}$ & $\begin{array}{l}\text { Future } \\
\text { utilization of } \\
\text { business } \\
\text { intelligence } \\
\text { through the } \\
\text { end-to-end } \\
\text { mapping of } \\
\text { processes, to } \\
\text { track and } \\
\text { manage } \\
\text { performance } \\
\text { (PwC, 2009) }\end{array}$ & $\begin{array}{l}\text { "With Iso, the goal is to obtain } \\
\text { certification within a year, and } \\
\text { to ....and I'm quite keen now to get } \\
\text { more of the team involved .....to } \\
\text { get more ownership within the } \\
\text { organisation so that becomes part } \\
\text { of the day-to-day stuff as well and } \\
\text { part of their roles as well." } \\
\text { "But it's broader than just } \\
\text { internal.... it an end-to-end thing, } \\
\text { and the whole process behind it is } \\
\text { continual improvement." }\end{array}$ \\
\hline
\end{tabular}

Table 6b Innovative Goals 


\subsection{Purposeful Novelty}

Innovations implemented at IPONZ were all contextually novel, with the exception of one technical innovation, which was created and implemented specifically and solely for IPONZ. Issues with technical functionality might have affected its legitimacy and acceptance within the organisation, as well as its lack of adoption outside the organisation. All eight management innovations were contextually novel. Five management innovations were either attempts to achieve set goals or goals in themselves, while three emerged unplanned and appeared to directly contribute to the achievement of organisational goals.

One of the questions that participants were asked was regarding their conception of innovation and their ideas about the implementation of innovation at IPONZ. Out of the 26 participants included in the study, 20 (80\%) participants viewed innovation as an improvement to what already exists. Out of the remaining 6 participants, 2 (7\%) participants viewed innovation as novel but not necessarily requiring a positive or negative value and another 2 (7\%) participants did not specify any other characteristics of innovation other than novelty. 6 (23\%) participants included in their views of implementing innovation the need to ask the question "why are we doing things in this way". A total of 18 (69\%) participants identified innovation in at least one of the 2 major types of changes that were identified in findings. 17 (65\%) participants identified innovation taking place in information technology developments, and $6(23 \%)$ viewed changes in legislation as innovative. Overall, 3 (11\%) participants did not recognise any changes taking place at IPONZ as innovative, because of their view that innovation was a revolutionary change that radically altered the nature of activities throughout IPONZ, or a change that was universally new to the state of the art (see also definition by Birkinshaw, Hamel and Mol, 2008).

All the changes identified as MI were discussed as directly contributing to the achievement of organisational goals at the strategic level, and contributing to the achievement of operational goals or to objective goals. Participants that discussed each management innovation also discussed details of how the change contributed 
to the achievement of explicitly stated organisational goals. The following diagram is an illustration of the alignment between changes identified and goals identified from discussion with participants and from the documents used as secondary data sources, particularly the IPONZ Business Plan document.

Figure 6.4 illustrates using quadrants, that all management innovation changes contribute to the management of the entire organisation and propel operational activities towards the development of the $4 \mathrm{Cs}$, which are Credibility, Capability, Capacity and Confidence. The 4 Cs represent organisational objectives identified in IPONZ Business Plan 2010-2013. These Cs are interrelated and interdependent, and this is illustrated with the use of two arrows connecting all 4 quadrants. Connected to the quadrants are the strategic goals related to each of the $4 \mathrm{Cs}$, and the innovative management changes that were discussed as directly contributing to them. 


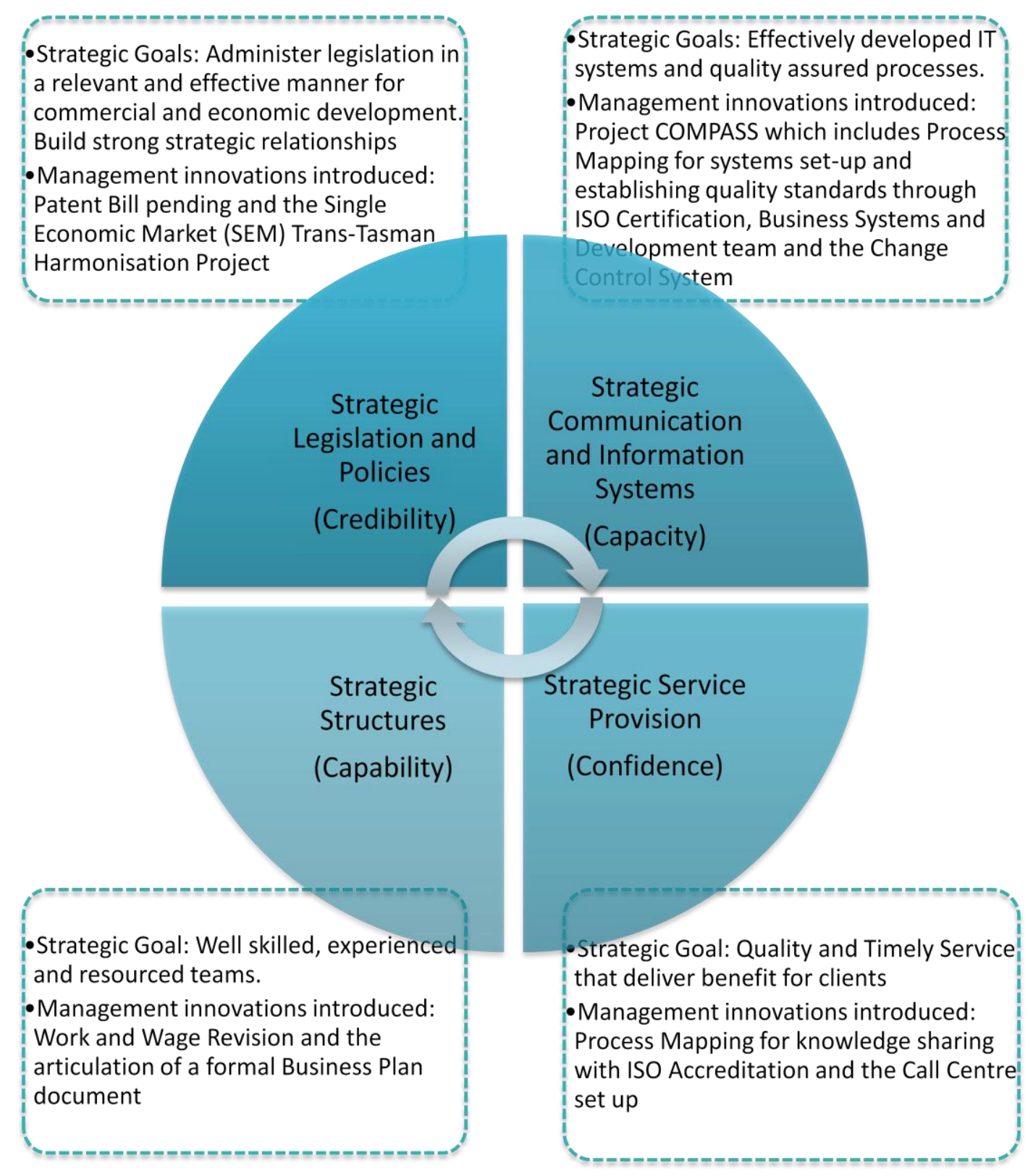

Figure 6.4 Management Innovation to achieve goals

The top left quadrant represents the drive to contribute to and maintain effective legislation and policies for the Office in the administration of IP rights. IPONZ is not responsible for the establishment of legislation, under the separation of legislative and administrative functions practiced in the New Zealand public sector. Nonetheless, they do play a key role in contributing to its development. Understanding the implications of proposed legislation is important to establishing sound legislative mandates. Providing prime information for that understanding is a key part of IPONZ role. The Office is also solely responsible for the administration of 
the established legislation, as well as developing legal practice guidelines for implementing legislation. Providing advisory services for the establishment of the Patent Bill released on 2008 has contributed to changes in not only the scope of IP protection, but also in the methods with which examinations are conducted and priced. To implement the new legislation, the Office will need to implement some innovative changes that will affect management practice. There will likely need to be some novel changes to the organisation of examiners' tasks, in order to make their workload conducive to the new considerations for examination.

The Trans-Tasman harmonization project was implemented for the establishment of a Single Economic Market between Australia and New Zealand. It currently represents contextual novelty to IPONZ for trade marks legal jurisdiction and patent attorney registration. This not only provides the opportunity for streamlining business processes, but also provides the opportunity to advance the development of legislation by combining effective practices from both IP regimes. The legislative mandate would be to harness regulatory similarities and integrate trade marks, patents and PVR registration services, as well as patent attorney registration services. This would significantly increase the efficiency of providing those services between Australia and New Zealand, and will present the opportunity for sizeable cost saving for IP seekers.

The top right quadrant represents the strategic drive to develop effective communication and information systems within the organisation. These systems would need the capacity to sufficiently deliver services via electronic means. IPONZ communication and information systems also needs to be able to provide a constructive platform for internal processing needs, being dynamic enough to be adjusted to internal changes in the nature of activities. Part of making sure that information systems are effective is making sure that work processes are effective because work processes determine the structural configuration of the systems. Therefore processes also need to be developed and maintained effectively to deliver quality services. 
One of the innovative changes implemented, which contributed to the development of information systems was the change control system. The introduction of this innovation was not part of prioritised activities set in the business plan, however its implementation played a significant role in ensuring that changes to the systems were well managed, monitored and evaluated.

The examination of processes and their detailed representation supported the establishment of a quality management system that secured the Office ISO accreditation. Both changes represent novel introductions to management practices, for enhancing the effectiveness and efficiency of internal processes. ISO certification of the Office indicates that external audits have been done to test some techniques for maintaining and developing the implementation of work processes. Though accreditation does not offer a $100 \%$ guarantee of high quality, it represents a significant and novel step towards the effective management of processes.

As Figure 6.4 shows, set up of a Business Development Team significantly contributes to managing the development and maintenance of information systems. The same team was also responsible for managing other projects being implemented at IPONZ that contributes to the management of information systems. Some members of the Business Systems and Development Team are not permanent employees of IPONZ, and so are managed separately from permanent employees who are managed according to MED's of human resource management system. Temporary team members are primarily responsible for change implementation, while longer term members are primarily responsible for contributing to core processes.

The bottom left quadrant represents the strategic mandate to foster a structural arrangement of people and relationships that is conducive to successful performance of IPONZ functions. An effective structure will be conducive to the achievement of the other 3 strategic directives, and will create an environment for IPONZ members to develop individually and thrive together. Two long standing issues identified as detrimental to the achievement of this strategic mandate are 
high staff turnover and a defective organisational culture. Both issues were directly addressed with the work and wage revision and the articulation of an organisationwide business plan. The work and wage revision is intended to reduce the high turnover that was affecting performance within IPONZ, while the business plan was intended to provide a unifying ethos and a means of setting priorities for the organisation.

The last quadrant at the bottom right signifies the importance of a service provision that clients can have confidence in. It is the strategic directive for high quality services that leads to client satisfaction. Participants have discussed the importance of harnessing BOTH efficiency and effectiveness, though they are sometimes portrayed as trade-offs. Efficiency is what increases when the same measure of input is used to produce a higher output than was produced previously. Effectiveness is achieved when the output produced is what was expected or intended (Merriam Webster, 2012). There was a perception with some of the participants that to increase effectiveness, efficiency had to be deferred, therefore sacrificing efficiency for effectiveness. However, all the participants who discussed IPONZ service provision mentioned the importance of both efficiency and effectiveness. This implies that IPONZ members not only seek to provide effective services, but also to provide them efficiently, in accordance with the Business Plan statement for 2010-2013. Goldratt (1992) introduced a methodology called "Theory of Constraints" that can be used by organisations to achieve seemingly contradicting goals, at the same time.

A related requirement is the need for client focus in service delivery. This is a crucial aspect of service delivery because there needs to be a connection between the needs of the client and the provision of the service. Efficient provision of intended or expected services has no benefit if they do not actually meet the needs of clients. IPONZ clientele is vast and varied, ranging from the New Zealand public, to patent attorneys, to independent IP owners, to the public. Different categories of clients have different needs, and respond to services in different ways. The size of IPONZ does not allow for the provision of customised service delivery, therefore the 
organisation has to deliver standardised services in a way that is sufficiently accessible to all the different categories of clients.

One of the changes introduced that contributed to meeting this directive is the setting up of a contact centre for customer service. With the advent of online services and the decrease in the use of physical files, IPONZ provided a service for clients that offered personal assistance related to filing applications and finding information. This entailed a telephone service provided through contact centre facilities managed outside IPONZ.

The examination and evaluation of internal processes through process mapping and ISO accreditation also contributes to quality service provision. The need for efficiency required eradicating waste such as duplication of work, inadequate use of resources and lack of coordination that leads to counter-productive processes. Through the use of the process mapping exercise, detailed progressions of services were articulated and sources of inefficiency were made manifest for correction. The use of a quality management system with ISO accreditation improves the opportunities for the Office to maintain effective services and increase utility. 


\section{Chapter Seven}

\subsection{CONCLUSION}

The importance of understanding processes in the generation and adoption of innovation in organisations is extensively recognised. However this recognition is largely focused on technical innovation and its management. Innovation can be understood as an action to create novel change for the achievement of organisational goals, and these changes can be manifested in either technical or non-technical forms. Management innovation is a form of non-technical innovation, occurring as novel changes in activities to arrange and coordinate people tasks and resources for organisational action.

From previous studies of innovation clear definitions of innovation have been derived, and these definitions present constructs through which innovation can be identified. One such construct is "change" as an organisational action. Change as a general organisational reality is studied extensively, and in this particular study it is the fundamental building block at the core of every innovation. The use of change as the construct for understanding innovation is useful because change is also one of the key components in the achievement of an organisation's goal. This makes it an appropriate point of reference for organisational action, and a bridge across various management activities including innovation. By examining innovation, not in isolation, but as a part of a whole system of organisational management, a more extensive understanding of the implications of innovating were perceived. Understanding the context of innovation also opened up insights into the implementation process, by shining light on the momentum that drives the process.

A historical study of the case organisation allowed the researcher to uncover how the purpose and functions of the organisation were established. Understanding past events in history also afforded the opportunity to identify evidence of developments, in their performance management systems to date. This in turn exposed scenes for discovering the uses of goals, and the manner in which goal 
setting contributes to performance management. Face-to-face interviews were the primary source of data, and interview accounts were compared with secondary information derived from official documentation, and historical reports of past events. The secondary data served as a triangulation method for personal accounts, and personal accounts enriched official information about past events.

\subsection{Preaching Goals and Practising Innovations}

In this study, the expressed purpose and functions of the organisation were examined as the context within which innovation is implemented. This is because innovation is viewed as contributing to the fulfilment of organisational purposes and functions, which are represented by goals. Findings show that organisational goals influenced the performance of activities, and changes were introduced to support the achievement of goals. Core operation goals were achieved and exceeded, even in periods where transformation goals were added on to core operation goals. Goal setting endorsed the implementation of innovation, by directing the performance of organisation members towards activities that lead to the incorporation of innovative changes. This indicates that there is a strong link between the use of goals and the implementation of innovation, as the manner in which goals were set affected the number of innovative changes introduced.

The strategic environment of IPONZ in the public sector is relatively stable, compared with the environment of private sector organisations. This is due to the highly centralised locus of authority over the Office. IPONZ is directly accountable to the New Zealand Government, who promotes the interests of the public and place a mandate on IPONZ to adequately cater to those interests. The government is also responsible for establishing the regulatory measures necessary to develop the nation's economy. Therefore the pressures imposed on IPONZ are somewhat unified because their source is centralised in the government, and the government 
explicitly expresses its intentions. This leads to relative stability in comparison to other organisations that are subject to multiple and often opposing pressures from various sources in the environment. This relative stability would likely have supported IPONZ's ability to maintain commitment to established goals. This is because the conditions within which set goals would be fulfilled would not have changed frequently or dramatically, as may often be the case with similar firms that are independently operated and subject to all market forces.

IPONZ's style of strategic management can be considered a classic model, where strategy is "set" for the future. Significant debate exists about the plausibility of setting strategy, as many academics dispute the effectiveness of "setting" in a continuously changing environment. However in this case, because strategy was "set" in a relatively stable environment, the achievement of strategic goals are more likely than if the environment was less stable. This capability to implement set strategy would have played a significant part in the Office's ability to achieve change goals. Subsequently this allowed the organisation to drive the achievement of comparatively high change introductions within a year, in addition to achieving and exceeding core-function operational goals.

\subsection{Implications}

The construction of IPONZ under the public management system puts certain limitations on the types of organisational actions that can be taken. Driven by legislative mandate, the organisation is required to conform to pre-established structures of management and operations. This makes the possibilities of change somewhat limited to the boundaries set by Government. This is not necessarily a negative point, as the monopolistic nature of IPONZ business requires a strong arrangement of accountability that can be used to maximise benefits to public users of IPONZ services, and minimise the cost of acquiring those services. However, the freedom afforded by private sector conditions allows management systems to be 
more varied, and changes more likely to be significantly different from the norm, or universally novel to the state of the art.

The imperative for transparency in the public system of accountability also means that IPONZ has to set performance management methods, and strictly adhere to them. This provided the pre-conditions necessary to successfully conduct this study. Significant changes in performance management methods would require the use of controlled change management processes, which would be documented. As a result, there were new considerations for theory found in IPONZ's use of goal setting. Findings point to implications that other extrinsic motivational factors can also lead to higher task performance, even without making goals difficult. In the absence of goal difficulty, other external motivation factors such as the provision of resources may also lead to increased task performance. For innovation generation and adoption, a strong emphasis on change in organisational goals can present a significant advantage, when considering the impact goal setting has on performance.

Since innovation helps to achieve goals, and goals can be used to foster innovation, more effective use of innovation will establish its role as part of a holistic management effort, and consider its implication for the entire organisation's purpose. Therefore innovation, though one of the most popular concepts in organisations, is still connected to, and only effective with, the successful implementation of other aspects of organisational activities, including the management of performance. Considerations of implementing innovation at IPONZ were strongly connected to the implementation of core operations, and were set to contribute to future implementation of core operations.

\subsection{Limitations and Future Research}

The applicability of findings in this study to other organisations and previous field studies is limited by the focus on contextual novelty only. With the exception of one 
innovation, all other innovations identified were contextually novel to IPONZ, meaning that their novelty is only established within IPONZ. The implications of implementing contextual novelty will vary significantly to implications of implementing universal novelty, which is new to the state of the art. With contextual novelty, knowledge for implementation can be borrowed from previous implementation outside IPONZ, whereas with universal novelty no such prior knowledge exists. This changes the applicability of innovation implementation, in conjunction with other organisational activities, because the organisation will require more extensive learning activities. This also leads to a variation in the manner in which the process of implementation unfolds.

Another limitation of this study is the lack of comparison between IPONZ achievement and the achievement of other IP offices. Developments in legislation and information technology cannot be evaluated in comparison to other IP offices. Though developments involved a high number of change introductions in one year, there was no data to establish IPONZ advancement overall, or the extent of progression towards international IP system standards.

Future research will benefit from further examination of the use of goals, not only for operational tasks, but also for strategic directives, and how changes in these affect the performance at the operational level. With regards to innovation, future research focusing more on the implementation phase of the innovation process will significantly contribute to improving practice. Emphasis on the implementation phase of the innovation process will be especially beneficial to organisations that undergo continuous implementation efforts over long periods of time, as is the case with IPONZ. 


\section{BIBLIOGRAPHY}

Aberbach, J. D., \& Christensen, T. (2001). Radical Reform in New Zealand: Crisis, Windows of Opportunity, and Rational Actors. Public Administration, 79(2), 403-422.

Abrahamson, E. (1991). Managerial Fads and Fashions: The Diffusion and Rejection of Innovations. The Academy of Management Review, 16(3), 586-612.

Andrade, A. D. (2009). Interpretive Research Aiming at Theory Building: Adopting and Adapting the Case Study Design. The Qualitative Report, 14(1), 42-60.

Andriani, P., \& Hall, R. (2002). Managing Knowledge for Innovation. Long Range Planning, 2002(35), 29-48.

Angwin, D., Cummings, S., \& Smith, C. (2011). The strategy pathfinder: Core concepts and live cases. Chichester: Wiley.

Ansoff, H. I. (1980). Strategic Issue Management. Strategic Management Journal, 1(2), 131-148.

Archives New Zealand. (2008a). Patent office [record group] administrative history. Wellington, New Zealand: Archives New Zealand. Retrieved October 2010, from http://www.archway.archives.govt.nz/ViewFullAgencyHistory.do.

Archives New Zealand. (2008b). The Intellectual Property Office of New Zealand administrative history. Wellington, New Zealand: Archives New Zealand. Retrieved October 2010, from http://www.archway.archives.govt.nz/ViewFullAgencyHistory.do

Archives New Zealand. (2009). Appraisal report. Wellington, New Zealand: IPONZ. Retrieved September 2011, from http://archives.govt.nz/advice/intentionsdispose/ministry-economic-development-intellectual-property-office

Archives New Zealand. (2011). Appraisal report. Wellington, New Zealand. IPONZ. Retrieved September 2011, from http://archives.govt.nz/advice/intentionsdispose/ministry-economic-development-intellectual-property-office-0 
Armbruster, H., Bikfalvi, A., Kinkel, S., \& Lay, G. (2008). Organisational Innovation: The Challenge of Measuring Non-Technical Innovation in Large-Scale Surveys. Technovation, 28(10), 644-657.

Becker, S. W., \& Whisler, T. L. (1967). The Innovative Organisation: A Selective View of Current Theory and Research. The Journal of Business, 40(4), 462-469.

Beer, M., \& Walton, A. E. (1987). Organisation Change and Development. Annual Review of Psychology, 38(1), 339-367.

Beer, S. (1984). The Viable System Model: Its Provenance, Development, Methodology, and Pathology. The Journal of the Operational Research Society, 35(1), 7.

Bénabou, R., \& Tirole, J. (2003). Intrinsic and Extrinsic Motivation. Review of Economic Studies, 70(3), 489-520.

Binder, A. K., \& Rae, J. B. (Eds.). (2011) Automotive Industry. Encyclopaedia Britannica: Academic Edition. Retrieved May 2011, from http://www.britannica.com/EBchecked/topic/45050/automotive-industry

Birkinshaw, J., Hamel, G., \& Mol, M. J. (2008). Management Innovation. Academy of Management Review, 33(4), 825-845.

Bouma, G. D., \& Ling, R. (2004). The research process. New York: Oxford University Press.

Boyatzis, R. E. (1998). Transforming qualitative information: Thematic analysis and code development. Thousand Oaks, CA: Sage Publications.

Brown, A. (2011). Legislative developments: Current developments in New Zealand. Retrieved October 2010, from http://www.andrewbrown.co.nz/legislative/

Burgelman, R. A. (1991). Intraorganisational Ecology of Strategy Making and Organisational Adaptation: Theory and Field Research. Organisation Science, 2(3), 239-262. 
Burns, T., \& Stalker, G. M. (1961). The management of innovation. London: Tavistock Publications.

Cavana, R. Y., Delahaye, B. L., \& Sekaran, U. (2001). Applied business research: Qualitative and quantitative methods. Milton QLD, Australia: J. Wiley.

Collins, J. C., \& Porras, J. I. (1996). Building Your Company's Vision. Harvard Business Review, 74(5), 65-77.

Cummings, S., \& Daellenbach, U. (2009). A Guide to the Future of Strategy?: The History of Long Range Planning. Long Range Planning, 42(2), 234-263.

Cummings, T. G., \& Worley, C. G. (2009). Organisational development and change (9th ed.). Mason, $\mathrm{OH}$ : South-Western, Cengage Learning.

Daft, R. L. (1978). A Dual-Core Model of Organisational Innovation. The Academy of Management Journal, 21(2), 193-210.

Damanpour, F. (1991). Organisational Innovation: A Meta-Analysis of Effects of Determinants and Moderators. The Academy of Management Journal, 34(3), 555-590.

Damanpour, F., \& Gopalakrishnan, S. (1998). Theories of Organisational Structure and Innovation Adoption: The Role of Environmental Change. Journal of Engineering and Technology Management, 1998(15), 1-24.

Dettmer, H. W. (1997). Goldratt's theory of constraints: A systems approach to continuous improvement. Milwaukee: American Society for Quality, Quality Press.

Dettmer, W. H. (2007). The logical thinking process: A systems approach to complex problem solving. Milwaukee: American Society for Quality, Quality Press.

Earley, P. C., Northcraft, G. B., Lee, C., \& Lituchy, T. R. (1990). Impact of Process and Outcome Feedback on the Relation of Goal Setting to Task Performance. The Academy of Management Journal, 33(1), 87-105. 
Economics and Statistics Division, W. I. P. O. (2010a). Statistics on patents.

Retrieved November 2010, from

http://www.wipo.int/export/sites/www/ipstats/en/statistics/patents/pdf/941_ 2010.pdf

Economics and Statistics Division, W. I. P. O. (2010b). Statistics on trade marks.

Retrieved November 2010, from

http://www.wipo.int/ipstats/en/statistics/marks

Economics and Statistics Division, W. I. P. O. (2010c). Statistics on industrial designs.

Retrieved November 2010, from

http://www.wipo.int/ipstats/en/statistics/designs/

Economics and Statistics Division, W. I. P. O. (2010d). Statistics on plant varieties.

Retrieved November 2010, from

http://www.wipo.int/ipstats/en/statistics/plants/

Economics and Statistics Division, W. I. P. O. (2010e). Statistics on the PCT system.

Retrieved November 2010, from

http://www.wipo.int/pct/en/activity/index.html

Economics and Statistics Division, W. I. P. O. (2011). World intellectual property

indicators - 2011 edition. Retrieved August 2011, from

http://www.wipo.int/ipstats/en/wipi/index.html

Edwards, T. (2000). Innovation and Organisational Change: Developments Towards an Interactive Process Perspective. Technology Analysis \& Strategic Management, 12(4), 445-464.

Evans, L., Grimes, A., Wilkinson, B., \& Teece, D. (1996). Economic Reform in New Zealand 1984-95: The Pursuit of Efficiency. Journal of Economic Literature, 34(4), 1856-1902.

Fennell, M. L. (1984). Synergy, Influence, and Information in the Adoption of Administrative Innovations. The Academy of Management Journal, 27(1), 113129. 
Fereday, J., \& Muir-Cochrane, E. (2006). Demonstrating Rigor Using Thematic Analysis: A Hybrid Approach of Inductive and Deductive Coding and Theme Development. International Journal of Qualitative Methods, 5(1), 1-11.

Frankel, S., \& McLay, G. (2002). Intellectual property in New Zealand (First ed.). Wellington, New Zealand: LexisNexis Butterworths.

Gavin, M., \& Brereton, W. (2007). New Zealand: Changing times for IP legislation. Auckland, New Zealand: Russell McVeagh.

Gerring, J. (2007). Case study research: Principles and practices. New York: Cambridge University Press.

Gist, M. E. (1987). Self-Efficacy: Implications for Organisational Behavior and Human Resource Management. The Academy of Management Review, 12(3), 472-485.

Gist, M. E., \& Mitchell, T. R. (1992). Self-Efficacy: A Theoretical Analysis of Its Determinants and Malleability. The Academy of Management Review, 17(2), 183-211.

Glass, G. V. (1976). Primary, Secondary, and Meta-Analysis of Research. Educational Researcher, 5(10), 3-8.

Goldratt, E. M., \& Cox, J. (1992). The goal: A process of ongoing improvement. New York: North River Press.

Goldstein, B. E. (2009). Introduction to perception. Sensation and perception (8th ed.). Belmont: Wadsworth Cengage Learning.

Gopalakrishnan, S., Kessler, E. H., \& Scillitoe, J. L. (2010). Navigating the Innovation Landscape: Past Research, Present Practice, and Future Trends. Organisation Management Journal, 7(4), 262-277.

Govindarajan, V., \& Trimble, C. (2004). Top 10 Lessons on the New Business of Innovation: Strategic Innovation and the Science of Learning. MIT Sloan Management Review, 2011, 19-49. 
Govindarajan, V., \& Trimble, C. (2005a). Organisational DNA for Strategic Innovation. California Management Review, 47(3), 47-76.

Govindarajan, V., \& Trimble, C. (2005b). Building Breakthrough Businesses within Established Organisations. Harvard Business Review, 83(5), 11.

Graetz, F., \& Smith, A. (2005). Organising Forms in Change Management: The Role of Structures, Processes and Boundaries in a Longitudinal Case Analysis. Journal of Change Management, 5(3), 311-328.

Greve, H. R., \& Taylor, A. (2000). Innovations as Catalysts for Organisational Change: Shifts in Organisational Cognition and Search. Administrative Science Quarterly, 45(1), 54-80.

Guba, E. G., \& Lincoln, Y. S. (1994). Competing paradigms in qualitative research. In N. K. Denzin \& Y. S. Lincoln (Eds.), Handbook of qualitative research. Thousand Oaks, CA: Sage Publications, Inc.

Hamel, G. (2006). The Why, What, and How of Management Innovation. Harvard Business Review (February).

Hammond, J. S., Keeney, R. L., \& Raiffa, H. (1998). The Hidden Traps in Decision Making. Harvard Business Review, 76(5), 47-52.

Hargrave, T. J., \& Van De Ven, A. H. (2006). A Collective Action Model of Institutional Innovation. The Academy of Management Review, 31(4), 864-888.

Her Majestys Stationary Office, H. M. S. O. (2011). Letters patent act 1571: 1571 chapter 6. Retrieved from http://www.legislation.gov.uk/aep/Eliz1/13/6.

Hof, R. (2012). Five things yahoo's new CEO Scott Thompson must do -fast. Forbes, (January). Retrieved January 2012, from http://www.forbes.com/sites/roberthof/2012/01/04/five-things-yahoos-newceo-scott-thompson-must-do-fast/

Hoverstadt, P., Kendrick, I., \& Morlidge, S. (2007). Viability as a Basis for Performance Measurement. Measuring Business Excellence, 11(1). 
Hycner, R. H. (1985). Some Guidelines for the Phenomenological Analysis of Interview Data. Human Studies, 8(3), 279-303.

Intellectual Property Office New Zealand, I. P. O. N. Z. (1992). Report of the commissioner of patents, trade marks, and designs. Wellington, New Zealand: Ministry of Economic Development.

Intellectual Property Office New Zealand, I. P. O. N. Z. (1993). Report of the commissioner of patents, trade marks, and designs. Wellington, New Zealand: Ministry of Economic Development.

Intellectual Property Office New Zealand, I. P. O. N. Z. (1994). Report of the commissioner of patents, trade marks, and designs. Wellington, New Zealand: Ministry of Economic Development.

Intellectual Property Office New Zealand, I. P. O. N. Z. (1995). Report of the commissioner of patents, trade marks, and designs. Wellington, New Zealand: Ministry of Economic Development.

Intellectual Property Office New Zealand, I. P. O. N. Z. (1996). Report of the commissioner of patents, trade marks, and designs. Wellington, New Zealand: Ministry of Economic Development.

Intellectual Property Office New Zealand, I. P. O. N. Z. (1997). Report of the commissioner of patents, trade marks, and designs. Wellington, New Zealand: Ministry of Economic Development.

Intellectual Property Office New Zealand, I. P. O. N. Z. (1998). Report of the commissioner of patents, trade marks, and designs. Wellington, New Zealand: Ministry of Economic Development.

Intellectual Property Office New Zealand, I. P. O. N. Z. (1999). Report of the commissioner of patents, trade marks, and designs. Wellington, New Zealand: Ministry of Economic Development. 
Intellectual Property Office of New Zealand, I. P. O. N. Z. (2000). Report of the commissioner of patents, trade marks, and designs. Wellington, New Zealand: Ministry of Economic Development. Retrieved June 2011, from http://www.iponz.govt.nz/cms/pdf-library/iponz/annual-reports/annualreport-1999-2000-749-kb-pdf

Intellectual Property Office New Zealand, I. P. O. N. Z. (2001). Report of the commissioner of patents, trade marks, and designs. Wellington, New Zealand: Ministry of Economic Development. Retrieved June 2011, from http://www.iponz.govt.nz/cms/pdf-library/iponz/annual-reports/annualreport-2000-2001-196-kb-pdf

Intellectual Property Office New Zealand, I. P. O. N. Z. (2002). Report of the commissioner of patents, trade marks, and designs. Wellington, New Zealand: Ministry of Economic Development. Retrieved June 2011, from http://www.iponz.govt.nz/cms/pdf-library/iponz/annual-reports/annualreport-2001-2002-65-kb-pdf

Intellectual Property Office New Zealand, I. P. O. N. Z. (2003). Report of the commissioner of patents, trade marks, and designs. Wellington, New Zealand: Ministry of Economic Development. Retrieved June 2011, from http://www.iponz.govt.nz/cms/pdf-library/iponz/annual-reports/annualreport-2002-2003-113-kb-pdf

Intellectual Property Office New Zealand, I. P. O. N. Z. (2004). Report of the commissioner of patents, trade marks, and designs. Wellington, New Zealand: Ministry of Economic Development. Retrieved June 2011, from http://www.iponz.govt.nz/cms/pdf-library/iponz/annual-reports/annualreport-2003-2004-173-kb-pdf

Intellectual Property Office New Zealand, I. P. O. N. Z. (2005). Report of the commissioner of patents, trade marks, and designs. Wellington, New Zealand: Ministry of Economic Development. Retrieved June 2011, from 
http://www.iponz.govt.nz/cms/pdf-library/iponz/annual-reports/annualreport-2004-2005-117-kb-pdf

Intellectual Property Office New Zealand, I. P. O. N. Z. (2006). Report of the commissioner of patents, trade marks, and designs. Wellington, New Zealand: Ministry of Economic Development. Retrieved June 2011, from http://www.iponz.govt.nz/cms/pdf-library/iponz/annual-reports/annualreport-2005-2006-116-kb-pdf

Intellectual Property Office New Zealand, I. P. O. N. Z. (2007). Report of the commissioner of patents, trade marks, and designs. Wellington, New Zealand: Ministry of Economic Development. Retrieved June 2011, from http://www.iponz.govt.nz/cms/pdf-library/iponz/annual-reports/annualreport-2006-2007-885-kb-pdf

Intellectual Property Office New Zealand, I. P. O. N. Z. (2008a). Report of the commissioner of patents, trade marks, and designs. Wellington, New Zealand: Ministry of Economic Development. Retrieved June 2011, from http://www.iponz.govt.nz/cms/pdf-library/iponz/annual-reports/annualreport-2007-2008-kb-pdf

Intellectual Property Office New Zealand, I. P. O. N. Z. (2008b). About IPONZ. Retrieved February 2010, from http://www.iponz.govt.nz/cms/iponz Intellectual Property Office New Zealand, I. P. O. N. Z. (2008c). History of intellectual property in New Zealand. Retrieved February 2011, from http://www.iponz.govt.nz/cms/what-is-ip/history-of-intellectual-property-innew-zealand

Intellectual Property Office New Zealand, I. P. O. N. Z. (2009a). Report of the commissioner of patents, trade marks, and designs. Wellington, New Zealand: Ministry of Economic Development. Retrieved June 2011, from http://www.iponz.govt.nz/cms/pdf-library/iponz/annualreports/IPONZ\%20Annual\%20Report\%202008-09.pdf 
Intellectual Property Office New Zealand, I. P. O. N. Z. (2009b). IPONZ wins Vero Excellence in Business Support Award. Archived News. Retrieved September 2010, from http://www.iponz.govt.nz/cms/iponz/latest-news/archived-news-1

Intellectual Property Office New Zealand, I. P. O. N. Z. (2009c). Trans-tasman harmonisation project. Archived News. Retrieved February 2011, from http://www.iponz.govt.nz/cms/iponz/latest-news/expired-items/trans-tasmanharmonisation-project/view

Intellectual Property Office New Zealand, I. P. O. N. Z. (2010a). Report of the commissioner of patents, trade marks, and designs. Wellington, New Zealand: Ministry of Economic Development. Retrieved June 2011, from http://www.iponz.govt.nz/cms/pdf-library/iponz/annualreports/Report_of_the_Commissioner_of_Patents_Trade_Marks_and_Design s_for_the_year_ending_30_June_2010.pdf

Intellectual Property Office New Zealand, I. P. O. N. Z. (2010a). IPONZ business plan 2010-2013. Wellington, New Zealand: IPONZ.

International Union for the Protection of New Varieties of Plants, U. P. O. V. (2011). Plant variety protection statistics for the period 2006-2010. Retrieved 2011, from http://www.upov.int/databases/en/statistics.html James and Wells Intellectual Property. (2007). Intellectual property law in New Zealand. Wellington, New Zealand: Brookers Ltd.

James and Wells Intellectual Property. (2009). Guide to the protection of innovation and goodwill. Wellington, New Zealand: James and Wells.

Johannessen, J., Olsen, B., \& Olaisen, J. (1999). Aspects of Innovation Theory Based on Knowledge-Management. International Journal of Information Management, 1999(19), 121-139.

Jones, G., \& George, J. (2008). The evolution of management theory. Contemporary management (7 ed.). Boston: McGraw-Hill Irwin. 
Klein, J. H., Wesson, J. M., Hollenbeck, R. J., \& Alge, J. B. (1999). Goal Commitment and the Goal-Setting Process: Conceptual Clarification and Empirical Synthesis. Journal of Applied Psychology, 84(6).

Latham, G. P., \& Locke, E. A. (1979). Goal Setting--a Motivational Technique That Works. Organisational Dynamics, 8(2), 68-80.

Latham, G. P., \& Locke, E. A. (1991). Self-Regulation through Goal Setting. Organisational Behavior and Human Decision Processes, 50(2), 212-247.

Latham, G. P., \& Saari, L. M. (1979). The Effects of Holding Goal Difficulty Constant on Assigned and Participatively Set Goals. The Academy of Management Journal, 22(1), 163-168.

Latham, G. P., \& Yukl, G. A. (1975). A Review of Research on the Application of Goal Setting in Organisations. Academy of Management Journal, 18(4), 824-845.

Leonard, A. (2009). The Viable System Model and Its Application to Complex Organisations. Systemic Practice and Action Research, 22(4), 11.

Lieberman, M. B., \& Montgomery, D. B. (1988). First-Mover Advantages. Strategic Management Journal, 9(S1), 41-58.

Lieberman, M. B., \& Montgomery, D. B. (1998). First-Mover (Dis)Advantages: Retrospective and Link with the Resource-Based View. Strategic Management Journal, 19(12), 1111-1125.

Linnenbrink, E. A., \& Pintrich, P. R. (2000). Intrinsic and extrinsic motivation: The search for optimal motivation and performance. San Diego, CA: Academic Press.

Locke, E. A. (1968). Toward a Theory of Task Motivation and Incentives. Organisational Behavior and Human Performance, 3(2), 157-189.

Locke, E. A., \& Latham, G. P. (1990). Work Motivation and Satisfaction: Light at the End of the Tunnel. Psychological Science, 1(4), 240-246. 
Locke, E. A., \& Latham, G. P. (2002). Building a Practically Useful Theory of Goal Setting and Task Motivation: A 35-Year Odyssey. American Psychologist, 57(9), 705-717.

Locke, E. A., \& Latham, G. P. (2006a). Enhancing the Benefits and Overcoming the Pitfalls of Goal Setting. Organisational Dynamics, 35(4), 332-340.

Locke, E. A., \& Latham, G. P. (2006b). New Directions in Goal-Setting Theory. Current Directions in Psychological Science, 15(5), 265-268.

Locke, E. A., Frederick, E., Lee, C., \& Bobko, P. (1984). Effect of Self-Efficacy, Goals and Task Strategies on Task Performance. Journal of Applied Psychology (69), 241-251.

Locke, E. A., Latham, G. P., \& Erez, M. (1988). The Determinants of Goal Commitment. The Academy of Management Review, 13(1), 23-39.

Locke, E., \& Latham, G. (2009). Has Goal Setting Gone Wild, or Have Its Attackers Abandoned Good Scholarship? The Academy of Management Perspectives, 23(1), 17-23.

Locke, E., Shaw, K., Saari, L., \& Latham, G. (1981). Goal Setting and Task Performance: 1969-1980. Psychological Bulletin, 90(1), 125-152.

Mabin, V. J., \& Balderstone, S. J. (2000). The world of the theory of constraints: A review of the international literature. Boca Raton, FL: St. Lucie Press.

Mahajan, V., Sharma, S., \& Bettis, R. A. (1988). The Adoption of the M-Form Organisational Structure: A Test of Imitation Hypothesis. Management Science, 34(10), 1188-1201.

Mann, D. (2004). Hands-on systematic innovation: For business and management. Malaysia: IFR Press.

Merriam-Webster. (2011). "Innovation". Merriam-Webster Online Dictionary. Retrieved 2010, from http://www.merriamwebster.com/dictionary/innovation?show $=0 \& \mathrm{t}=1332367025$ 
Merriam-Webster. (2012). "Effective". Merriam-Webster Online Dictionary.

Retrieved 2012, from http://www.merriam-webster.com/dictionary/effective

Mesch, D. J., Farh, J., \& Podsakoff, P. M. (1994). Effects of Feedback Sign on Group Goal Setting, Strategies, and Perfromance. Group \& Organisation Studies, 13(3), 309-333.

Milgrom, P., \& Roberts, J. (1995). Complementarities and Fit Strategy, Structure, and Organisational Change in Manufacturing. Journal of Accounting and Economics, 19(2-3), 179-208.

Ministry of Commerce. (1999). Strategic business plan: 1999 and beyond.

Wellington, New Zealand: Ministry of Commerce. Retrieved November 2011, from

http://www.med.govt.nz/templates/MultipageDocumentTOC 4562.aspx

Ministry of Economic Development, M. E. D. (2000a). Annual report 2000. Wellington, New Zealand: Ministry of Economic Development. Retrieved November 2011, from http://www.med.govt.nz/aboutus/publications/corporate-publications/annual-report-archive

Ministry of Economic Development, M. E. D. (2000b). Departmental forecast report 2000/2001. Wellington, New Zealand: Ministry of Economic Development. Retrieved November 2011, from http://www.med.govt.nz/aboutus/publications/corporate-publications/annual-report-archive

Ministry of Economic Development, M. E. D. (2001a). Report of the Ministry of Economic Development for the year ended 30 June 2001. Wellington, New Zealand: Ministry of Economic Development. Retrieved November 2011, from http://www.med.govt.nz/about-us/publications/corporatepublications/annual-report-archive

Ministry of Economic Development, M. E. D. (2001b). Departmental forecast report 2001. Wellington, New Zealand: Ministry of Economic Development. Retrieved 
November 2011, from http://www.med.govt.nz/about-

us/publications/corporate-publications/annual-report-archive

Ministry of Economic Development, M. E. D. (2002a). Annual report 2001/2002.

Wellington, New Zealand: Ministry of Economic Development. Retrieved

November 2011, from http://www.med.govt.nz/about-

us/publications/corporate-publications/annual-report-archive

Ministry of Economic Development, M. E. D. (2002b). Statement of intent 2002-

2005. Wellington, New Zealand: Ministry of Economic Development. Retrieved August 2011, from http://www.med.govt.nz/about-us/publications/corporatepublications/statement-of-intent-archive

Ministry of Economic Development, M. E. D. (2003a). Annual report 2002/2003. Wellington, New Zealand: Ministry of Economic Development. Retrieved November 2011, from http://www.med.govt.nz/aboutus/publications/corporate-publications/annual-report-archive

Ministry of Economic Development, M. E. D. (2003b). Statement of intent 20032006. Wellington, New Zealand: Ministry of Economic Development. Retrieved August 2011, from http://www.med.govt.nz/about-us/publications/corporatepublications/statement-of-intent-archive

Ministry of Economic Development, M. E. D. (2004a). Annual report 2003/2004. Wellington, New Zealand: Ministry of Economic Development. Retrieved November 2011, from http://www.med.govt.nz/aboutus/publications/corporate-publications/annual-report-archive

Ministry of Economic Development, M. E. D. (2004b). Statement of intent 20042007. Wellington, New Zealand: Ministry of Economic Development. Retrieved August 2011, from http://www.med.govt.nz/about-us/publications/corporatepublications/statement-of-intent-archive

Ministry of Economic Development, M. E. D. (2005a). Annual report 2004/2005. Wellington, New Zealand: Ministry of Economic Development. Retrieved 
November 2011, from http://www.med.govt.nz/about-

us/publications/corporate-publications/annual-report-archive

Ministry of Economic Development, M. E. D. (2005b). Statement of intent 20052008. Wellington, New Zealand: Ministry of Economic Development. Retrieved August 2011, from http://www.med.govt.nz/about-us/publications/corporatepublications/statement-of-intent-archive

Ministry of Economic Development, M. E. D. (2006a). Annual report 2005/2006. Wellington, New Zealand: Ministry of Economic Development. Retrieved November 2011, from http://www.med.govt.nz/aboutus/publications/corporate-publications/annual-report-archive

Ministry of Economic Development, M. E. D. (2006b). Statement of intent 20062009. Wellington, New Zealand: Ministry of Economic Development. Retrieved August 2011, from http://www.med.govt.nz/about-us/publications/corporatepublications/statement-of-intent-archive

Ministry of Economic Development, M. E. D. (2007a). Annual report 2006/2007. Wellington, New Zealand: Ministry of Economic Development. Retrieved November 2011, from http://www.med.govt.nz/aboutus/publications/corporate-publications/annual-report-archive

Ministry of Economic Development, M. E. D. (2007b). Statement of intent 20072010. Wellington, New Zealand: Ministry of Economic Development. Retrieved August 2011, from http://www.med.govt.nz/about-us/publications/corporatepublications/statement-of-intent-archive

Ministry of Economic Development, M. E. D. (2008a). Annual report 2007/2008. Wellington, New Zealand: Ministry of Economic Development. Retrieved November 2011, from http://www.med.govt.nz/aboutus/publications/corporate-publications/annual-report-archive Ministry of Economic Development, M. E. D. (2008b). Statement of intent 20082011. Wellington, New Zealand: Ministry of Economic Development. Retrieved 
August 2011, from http://www.med.govt.nz/about-us/publications/corporatepublications/statement-of-intent-archive

Ministry of Economic Development, M. E. D. (2009a). Annual report 2008/2009. Wellington, New Zealand: Ministry of Economic Development. Retrieved November 2011, from http://www.med.govt.nz/aboutus/publications/corporate-publications/annual-report-archive

Ministry of Economic Development, M. E. D. (2009b). Statement of intent 20092012. Wellington, New Zealand: Ministry of Economic Development. Retrieved August 2011, from http://www.med.govt.nz/about-us/publications/corporatepublications/statement-of-intent-archive

Ministry of Economic Development, M. E. D. (2009c). Single economic market. Economic Relations with Australia. Wellington, New Zealand: Ministry of Economic Development. Retrieved November 2011, from http://www.med.govt.nz/business/trade-tariffs/trade-environment/economicrelationship-with-australia/single-economic-market

Ministry of Economic Development, M. E. D. (2010a). Annual report 2009/10. Wellington, New Zealand: Ministry of Economic Development. Retrieved November 2011, from http://www.med.govt.nz/aboutus/publications/corporate-publications/annual-report-archive/2009-2010pdf/view

Ministry of Economic Development, M. E. D. (2010b). Statement of intent 20102013. Wellington, New Zealand: Ministry of Economic Development. Retrieved August 2011, from http://www.med.govt.nz/about-us/publications/corporatepublications/statement-of-intent-archive

Ministry of Economic Development, M. E. D. (2011a). Annual report 2010/11. Wellington, New Zealand: Ministry of Economic Development. Retrieved November 2011, from http://www.med.govt.nz/aboutus/publications/corporate-publications/annual-report-current 
Ministry of Economic Development, M. E. D. (2011b). Statement of intent 20112014. Wellington, New Zealand:Ministry of Economic Development. Retrieved February 2012, from http://www.med.govt.nz/aboutus/publications/corporate-publications/statement-of-intent-current

Ministry of Economic Development, M. E. D. (2011c). Neville Harris. Strategic Leadership Team. Wellington, New Zealand: Ministry of Economic Development. Retrieved November 2011, from http://www.med.govt.nz/about-us/slt/n-harris New Zealand Commission to Inquire into and report upon the Law of Patents. (1950). Report of the commission. Wellington, New Zealand: R.E. Owen, Government Printer.

New Zealand Law Librarians' Association. (2011). About us: Our heritage. About Us. Retrieved December 2011, from http://www.nzlla.org.nz/about-us/ourheritage/

New Zealand Parliament. (2009). Patent Bill 2008. Bills Digest, 1674(April).

New Zealand Parliament. (2009). Trade Marks (International Treaties and Enforcement) Amendment Bill - First Reading. Hansard and Journals, 653.

New Zealand Parliament. (2010). Patents Bill. Retrieved August 2011, from http://www.parliament.nz/enNZ/PB/Legislation/Bills/a/f/2/00DBHOH_BILL8651_1-Patents-Bill.htm.

Norman, R., \& Gregory, R. (2003). Paradoxes and Pendulum Swings: Performance Management in New Zealand's Public Sector. Australian Journal of Public Administration, 62(4), 35-49.

O'Leary, Z. (2004). The essential guide to doing research. London, UK: SAGE.

Ordóñez, L., Schweitzer, M., Galinsky, A., \& Bazerman, M. (2009a). Goals Gone Wild: The Systematic Side Effects of Overprescribing Goal Setting. The Academy of Management Perspectives, 23(1), 6-16. 
Ordóñez, L., Schweitzer, M., Galinsky, A., \& Bazerman, M. (2009b). On Good Scholarship, Goal Setting, and Scholars Gone Wild. The Academy of Management Perspectives, 23(3), 82-87.

Organisation for Economic Co-operation and Development, O.E.C.D. (2011).

Business: Unequal opportunities - why entrepreneurs thrive in some countries more than others. Newsroom. Retrieved 7/07/11, from http://www.oecd.org/document/8/0,3746,en_21571361_44315115_48276232 _1_1_1_1,00.html\#

Organisation for Economic Co-operation and Development, O.E.C.D. (2011). Intellectual property rights. Science and Technology. Retrieved February 2011, from http://www.oecd.org/about/0,3347,en_2649_34797_1_1_1_1_37437,00.html

Organisation for Economic Co-operation and Development, O. E. C. D. (2005). Oslo Manual: The measurement of scientific and technological activities, proposed guidelines for collecting and interpreting technological innovation data.

Retrieved September 2011, from www.oecd.org/sti/oslomanual

Pessiglione, M., Schmidt, L., Draganski, B., Kalisch, R., Lau, H., Dolan, R. J., \& Frith, C. D. (2007). How the Brain Translates Money into Force: A Neuroimaging Study of Subliminal Motivation. Science, 316(5826), 904-906.

Pettigrew, A. M., Woodman, R. W., \& Cameron, K. S. (2001). Studying Organisational Change and Development: Challenges for Future Research. The Academy of Management Journal, 44(4), 697-713.

Podsakoff, P. M., \& Farh, J. (1989). Effects of Feedback Sign and Credibility on Goal Setting and Task Performance. Organisational Behavior and Human Decision Processes, 44(1), 45-67.

Potocan, V., \& Mulej, M. (2006). What Is Business Cybernetics? Journal of American Academy of Business, Cambridge, 9(2), 7. 
Practice guidelines: Multiple or partial convention priority §2b.3.4 (2009). Intellectual Property Office of New Zealand. Retrieved May 2011, from http://www.iponz.govt.nz/cms/trade-marks/practice-guidelines-index/practiceguidelines/02b-priority-of-trade-mark-applications/3-convention-priority/3-4multiple-or-partial-convention-priority

PricewaterhouseCoopers. (2009). Business evaluation of the intellectual property office of New Zealand: Final report. Wellington, New Zealand: IPONZ. Retrieved February 2011, from http://www.iponz.govt.nz/cms/iponz/latestnews/expired-items/iponz-business-evaluation

Probine, M. (1987). Report on a review of the patent office and the administration of intellectual property law. Wellington, New Zealand: Department of Justice.

Q S R International. (2011). Our history. About QSR. Retrieved October, from http://www.qsrinternational.com/about-qsr_history.aspx

Romanelli, E., \& Tushman, M. L. (1994). Organisational Transformation as Punctuated Equilibrium: An Empirical Test. Academy of Management Journal, 37(5), 1141-1166

Rowe, L. A., \& Boise, W. B. (1974). Organisational Innovation: Current Research and Evolving Concepts. Public Administration Review, 34(3), 284-293.

Russo, J. E., \& Schoemaker, P. J. H. (1990). Decision traps: Ten barriers to brilliant decision-making and how to overcome them. New York: Simon \& Schuster.

Sapolsky, H. M. (1967). Organisational Structure and Innovation. The Journal of Business, 40(4), 497-510.

Schumpeter, J. A. (1934). The theory of economic development: An inquiry into profits, capital, credit, interest, and the business cycle. New Jersey: Transaction Books.

Scott, G. C. (1996). Government reform in New Zealand. Washington, DC: International Monetary Fund, Pulication Services. 
Scott, G., Bushnell, P., \& Sallee, N. (1990). Reform of the Core Public Sector: New Zealand Experience. Governance, 3(2), 138-167.

Scott, W. R. (2004). Reflections on a Half-Century of Organisational Sociology. Annual Review of Sociology, 30, 1-21.

Seijts, G. H., Latham, G. P., Tasa, K., \& Brandon, W. L. (2004). Goal Setting and Goal Orientation: An Integration of Two Different yet Related Literatures. The Academy of Management Journal, 47(2), 227-239.

Sharma, S., \& Vredenburg, H. (1998). Proactive Corporate Environmental Strategy and the Development of Competitively Valuable Organisational Capabilities. Strategic Management Journal, 19(8), 729-753.

Sharp, B., Morgan, O., \& Puckey, A. (2010). Review of the New Zealand intellectual property system. Auckland, New Zealand: The University of Auckland.

Silverman, D. (2006). Interpreting qualitative data: Methods for analyzing talk, text, and interaction. London, UK: SAGE Publications.

Slappendel, C. (1996). Perspectives on Innovation in Organisations. Organisation Studies, 17(1), 107-129.

Smallman, C. (2010). Process organisation and management studies: Methods and examples from production management and tourism management. In V. M. S. Seminar. Wellington, New Zealand: Victoria University of Wellington.

Stata, R. (1994). Organisational learning: The key to management innovation. In C. E. Schneier (Ed.), The training and development sourcebook (2 ed.). New York: Human Resource Development Press.

Steers, R. M. (1975). Problems in the Measurement of Organisational Effectiveness. Administrative Science Quarterly, 20(4), 546-558.

Teece, D. J. (1980). The Diffusion of an Administrative Innovation. Management Science, 26(5), 464-470. 
Teece, D. J. (1981). Internal Organisation and Economic Performance: An Empirical Analysis of the Profitability of Principal Firms. The Journal of Industrial Economics, 30(2), 173-199.

Terziovski, M., Samson, D., \& Dow, D. (1997). The Business Value of Quality Management Systems Certification: Evidence from Australia and New Zealand. Journal of Operations Management, 1997(15), 1-18.

The New Patent Act. (1889, Thursday, November 14th). Hawke's Bay Herald. p. 2. Retrieved February 2011, from http://paperspast.natlib.govt.nz/cgibin/paperspast?a=d\&d=HBH18891114.2.7\&

Thompson, J. D. (1967). Organisations in action: Social science bases of administrative theory. New York: Transaction Publishers.

Trans-tasman economic market: Intellectual property co-ordination. (2004, December 17). Scoop Independent News. Retrieved November 2011, from http://www.scoop.co.nz/stories/BU0412/S00263/trans-tasman-intellectualproperty-co-ordination.html

Treasury New Zealand (2009). Joint statement of intent: Single economic market outcomes framework. Wellington, New Zealand: Treasury New Zealand. Retrieved November 2011, from http://www.treasury.gov.au/ttoig/content/statement_of_intent.asp

Trochim, W. M. (2006). The Research Methods Knowledge Base. Retrieved May 2011, from http://www.socialresearchmethods.net/kb/index.php

Van de Schyff, R. (2011). Ross van de schyff. Linkedin Profile. Retrieved November, from http://www.linkedin.com/pub/ross-van-der-schyff/a/76b/7a8

Van de Ven, A. H., \& Huber, G. P. (1990). Longitudinal Field Research Methods for Studying Processes of Organisational Change. Organisation Science, 1(3), 213219. 
Van de Ven, A. H., \& Poole, M. S. (1990). Methods for Studying Innovation Development in the Minnesota Innovation Research Program. Organisation Science, 1(3), 313-335.

Van de Ven, A. H., \& Poole, M. S. (1995). Explaining Development and Change in Organisations. The Academy of Management Review, 20(3), 510-540.

Van de Ven, A. H., \& Poole, M. S. (2005). Alternative Approaches for Studying Organisational Change. Organisation Studies, 26(9), 1377-1404.

Van de Ven, A. H., \& Rogers, E. M. (1988). Innovations and Organisations. Communication Research, 15(5), 632-651.

van Melle, B. (2010). State of the Nation's Innovation. New Zealand Intellectual Property Journal, 2010(6).

Walker, R. (2007). An Empirical Evaluation of Innovation Types and Organisational and Environmental Characteristics: Towards a Configuration Framework. Journal of Public Administration Research and Theory, 2007(18), 591-615.

Wallis, R. (2003). Trade mark law gets historical overhaul. Baldwins Intellectual Property News, 2003 (August). Retrieved February 2011, from http://www.baldwins.com/trade-mark-law-gets-historical-overhaul

Weick, K. E., \& Quinn, R. E. (1999). Organisational Change and Development. Annual Review of Psychology, 50(1), 361-386.

Weston, C., Gandell, T., Beauchamp, J., McAlpine, L., Wiseman, C., \& Beauchamp, C. (2001). Analyzing Interview Data: The Development and Evolution of a Coding System. Qualitative Sociology, 24(3), 381-400.

White, E. (2008). Quest for inovation, motivation inspires the gurus: Leading thinkers apply varied skills for global solutions. The Wall Street Journal, U.S. Business News. Retrieved May 2011, from http://online.wsj.com/public/article/SB120994652485566323.html 
Whittington, R., Pettigrew, A., Peck, S., Fenton, E., \& Conyon, M. (1999). Change and Complementarities in the New Competitive Landscape: A European Panel Study, 1992-1996. Organisation Science, 10(5), 583-600.

WIPO Statistical Database (2010). Intellectual property statistics. Retrieved 2010, from http://www.wipo.int/ipstats/en/

Wolfe, R. A. (1994). Organisational Innovation: Review, Critique and Suggested Research Directions. Journal of Management Studies, 31(3), 405-431.

Wood, R., \& Bandura, A. (1989). Social Cognitive Theory of Organisational Management. The Academy of Management Review, 14(3), 361-384.

Yearta, S. K., Maitlis, S., \& Briner, R. B. (1995). An Exploratory Study of Goal Setting in Theory and Practice: A Motivational Technique That Works? Journal of Occupational \& Organisational Psychology, 68(3), 237-252.

Zook, C., \& Allen, J. (2011). The Great Repeatable Business Model. Harvard Business Review, 89(11), 106-114. 


\section{APPENDICES}




\subsection{IPONZ Output Volumes 1950-2008}

\section{(WIP0 Statistics Database, 2010) ${ }^{4}$}

\begin{tabular}{|c|c|c|c|c|c|c|c|c|c|c|}
\hline & \multicolumn{2}{|c|}{ Patents } & \multicolumn{2}{|c|}{ Trade Marks } & \multicolumn{2}{|c|}{ Designs } & \multicolumn{2}{|c|}{ Plant Variety Rights } & \multicolumn{2}{|c|}{ All IP } \\
\hline & Filed & Granted & Filed & Granted & Filed & Granted & Filed & Granted & Filed & Granted \\
\hline 1950 & 1,987 & 2,278 & 1,422 & 1,156 & 246 & 215 & 0 & 0 & 3655 & 3649 \\
\hline 1951 & 2,047 & 943 & 1,439 & 1,303 & 165 & 118 & 0 & 0 & 3651 & 2364 \\
\hline 1952 & 1,952 & 1,187 & 1,390 & 1,484 & 177 & 149 & 요 & 0 & 3519 & 2820 \\
\hline 1953 & 2,124 & 1,364 & 1,358 & 1,206 & 216 & 203 & 0 & 0 & 3698 & 2773 \\
\hline 1954 & 2.438 & 1,777 & 1,703 & 1.251 & 245 & 23.8 & 0 & 0 & 4386 & 3266 \\
\hline 1955 & 2,438 & 1,777 & 1,653 & 1,349 & 255 & 249 & 0 & 0 & 4346 & 3375 \\
\hline 1956 & 2,439 & 1,900 & 1,653 & 1,349 & 255 & 249 & 0 & 0 & 4347 & 3498 \\
\hline 1957 & 2,320 & 1,797 & 1,892 & 1,352 & 272 & 221 & 0 & 0 & 4434 & 3370 \\
\hline 1958 & 2,384 & 1,889 & 1,999 & 1,559 & 236 & 193 & 0 & 0 & 4619 & 3641 \\
\hline 1959 & 2,785 & 1,896 & 2,258 & 1,157 & 257 & 244 & 0 & 0 & 5300 & 3297 \\
\hline 1960 & 2,748 & 1,544 & 2,441 & 1,722 & 353 & 234 & 0 & 0 & 5542 & 3500 \\
\hline 1961 & 2,893 & 1,574 & 2,358 & 1,873 & 346 & 253 & 0 & 0 & 5597 & 3700 \\
\hline 1962 & 2,820 & 1,538 & 2,304 & 2,082 & 308 & 226 & 0 & 0 & 5432 & 3846 \\
\hline 1963 & 3,192 & 1,621 & 2,571 & 1,872 & 366 & 331 & 0 & 0 & 6129 & 3824 \\
\hline 1964 & 3,447 & 2,159 & 2,625 & 1,726 & 440 & 271 & 0 & 0 & 6512 & 4156 \\
\hline 1965 & 2,850 & 2,070 & 2,658 & 1,686 & 342 & 163 & 0 & 0 & 5850 & 3919 \\
\hline 1966 & 3,665 & 2,824 & 2,858 & 2,247 & 383 & 519 & 0 & 0 & 6906 & 5590 \\
\hline 1967 & 3,718 & 2.824 & 2,866 & 2,027 & 386 & 365 & 0 & 0 & 6970 & 5216 \\
\hline 1968 & 3,953 & 2,824 & 3,058 & 2,877 & 430 & 319 & 0 & 0 & 7441 & 6020 \\
\hline 1969 & 3,701 & 2,312 & 3,339 & 2,384 & 319 & 358 & 0 & 0 & 7359 & 5054 \\
\hline 1970 & 3,573 & 3,396 & 3,449 & 3,330 & 311 & 376 & 0 & 0 & 7333 & 7102 \\
\hline 1971 & 3,510 & 2,500 & 3,492 & 2,480 & 412 & 213 & 0 & 0 & 7414 & 5193 \\
\hline 1972 & 3,497 & 2,500 & 3,511 & 2,924 & 377 & 447 & 0 & 0 & 7385 & 5871 \\
\hline 1973 & 3,563 & 2,500 & 4,019 & 1,667 & 384 & 195 & 0 & 0 & 7966 & 4362 \\
\hline 1974 & 3,326 & 2,500 & 3,779 & 2,343 & 344 & 396 & 0 & 0 & 7449 & 5239 \\
\hline 1975 & 3,332 & 2,290 & 3,654 & 2,860 & 413 & 324 & 7 & 0 & 7406 & 5474 \\
\hline 1976 & 3,329 & 1,340 & 3,750 & 2,476 & 508 & 312 & 40 & 2 & 7627 & 4130 \\
\hline 1977 & 3,135 & 2,452 & 3,848 & 2,571 & 432 & 564 & 37 & 17 & 7452 & 5604 \\
\hline 1978 & 3,165 & 1,581 & 3,905 & 1,665 & 544 & 434 & 31 & 5 & 7645 & 3685 \\
\hline 1979 & 3,211 & 1,535 & 4,509 & 2,440 & 535 & 537 & 37 & 41 & 8292 & 4553 \\
\hline 1980 & 3.438 & 1.259 & 4,671 & 1.842 & 529 & 343 & 31 & 43 & 8669 & 3487 \\
\hline 1981 & 3,457 & 1,634 & 4,629 & 2,542 & 579 & 398 & 61 & 24 & 8726 & 4598 \\
\hline 1982 & 3,533 & 1,377 & 4,800 & 2,692 & 696 & 510 & 45 & 40 & 9074 & 4619 \\
\hline 1983 & 3,793 & 1,934 & 5,104 & 2,869 & 640 & 1,080 & 61 & 25 & 9598 & 5908 \\
\hline 1984 & 4,012 & 1,914 & 5,855 & 2,451 & 588 & 555 & 48 & 46 & 10503 & 4966 \\
\hline 1985 & 3,975 & 1,732 & 6,332 & 2,410 & 677 & 634 & 75 & 43 & 11059 & 4819 \\
\hline 1986 & 4,085 & 3,035 & 6,332 & 2,410 & 677 & 634 & 88 & 54 & 11182 & 6133 \\
\hline 1987 & 4,280 & 2,510 & 7,080 & 2,629 & 725 & 499 & 71 & 51 & 12156 & 5689 \\
\hline 1988 & 4,425 & 2,705 & 12,325 & 2,085 & 673 & 795 & 72 & 55 & 17495 & 5640 \\
\hline 1989 & 4,467 & 2,841 & 8,329 & 4,524 & 656 & 691 & 96 & 47 & 13548 & 8103 \\
\hline 1990 & 4,671 & 3,481 & 10,072 & 5,525 & 637 & 566 & 128 & 60 & 15508 & 9632 \\
\hline 1991 & 4,533 & 3,598 & 7,907 & 4,141 & 587 & 533 & 71 & 91 & 13098 & 8363 \\
\hline 1992 & 4,421 & 2,988 & 8,671 & 4,580 & 668 & 590 & 71 & 91 & 13831 & 8249 \\
\hline 1993 & 3,102 & 2.886 & 9.162 & 3,992 & 728 & 708 & 139 & 72 & 13131 & 7658 \\
\hline 1994 & 3,771 & 2,670 & 11,145 & 4,674 & 741 & 598 & 181 & 117 & 15838 & 8059 \\
\hline 1995 & 4,719 & 2,641 & 13,007 & 6,166 & 900 & 781 & 157 & 141 & 18783 & 9729 \\
\hline 1996 & 7,467 & 2,771 & 13,526 & 12,119 & 848 & 864 & 187 & 132 & 22028 & 15886 \\
\hline 1997 & 9,831 & 3,823 & 15,727 & 20,935 & 779 & 380 & 195 & 132 & 26532 & 25270 \\
\hline 1998 & 5,700 & 4,068 & 16,558 & 20,021 & 930 & 980 & 144 & 150 & 23332 & 25219 \\
\hline 1999 & 7,961 & 2,463 & 16,576 & 14,259 & 885 & 980 & 169 & 156 & 25591 & 17858 \\
\hline 2000 & 7,048 & 4,587 & 24,046 & 15,908 & 1,038 & 1,093 & 189 & 121 & 32321 & 21709 \\
\hline 2001 & 7,275 & 3,539 & 20,614 & 20,490 & 892 & 801 & 143 & 162 & 28924 & 24992 \\
\hline 2002 & 6,948 & 2,582 & 20,094 & 18,378 & 898 & 856 & 188 & 103 & 28128 & 21919 \\
\hline 2003 & 6,873 & 10,124 & 23,219 & 18,823 & 1,194 & 947 & 177 & 149 & 31463 & 30043 \\
\hline 2004 & 6,531 & 5,571 & 16,290 & 12,312 & 1,089 & 1,089 & 149 & 153 & 24059 & 19125 \\
\hline 2005 & 7,005 & 4,189 & 16,833 & 6,716 & 1,308 & 984 & 121 & 118 & 25267 & 12007 \\
\hline 2006 & 7,365 & 3.412 & 18,826 & 5,068 & 1.599 & 1318 & 114 & 74 & 27904 & 9872 \\
\hline 2007 & 7,844 & 3,592 & 19,610 & 5,262 & 1,545 & 1,411 & 157 & 120 & 29156 & 10385 \\
\hline 2008 & 5,724 & 3,203 & 17,582 & 12,448 & 1,334 & 1,533 & 157 & 102 & 24797 & 17286 \\
\hline
\end{tabular}

${ }^{4}$ The information in the table was derived from the website for World Intellectual Property Organisation. The number of applications

filed and granted was not included for some years, in which case the information from the previous year was used to represent volumes. PVR volumes prior to 1975 were not found, all missing data is shown the colour red. PVR volumes from 2001-2008 were 


\subsection{Charting Output Volume Variations}

2.1 Patent application and registration 1950-2008

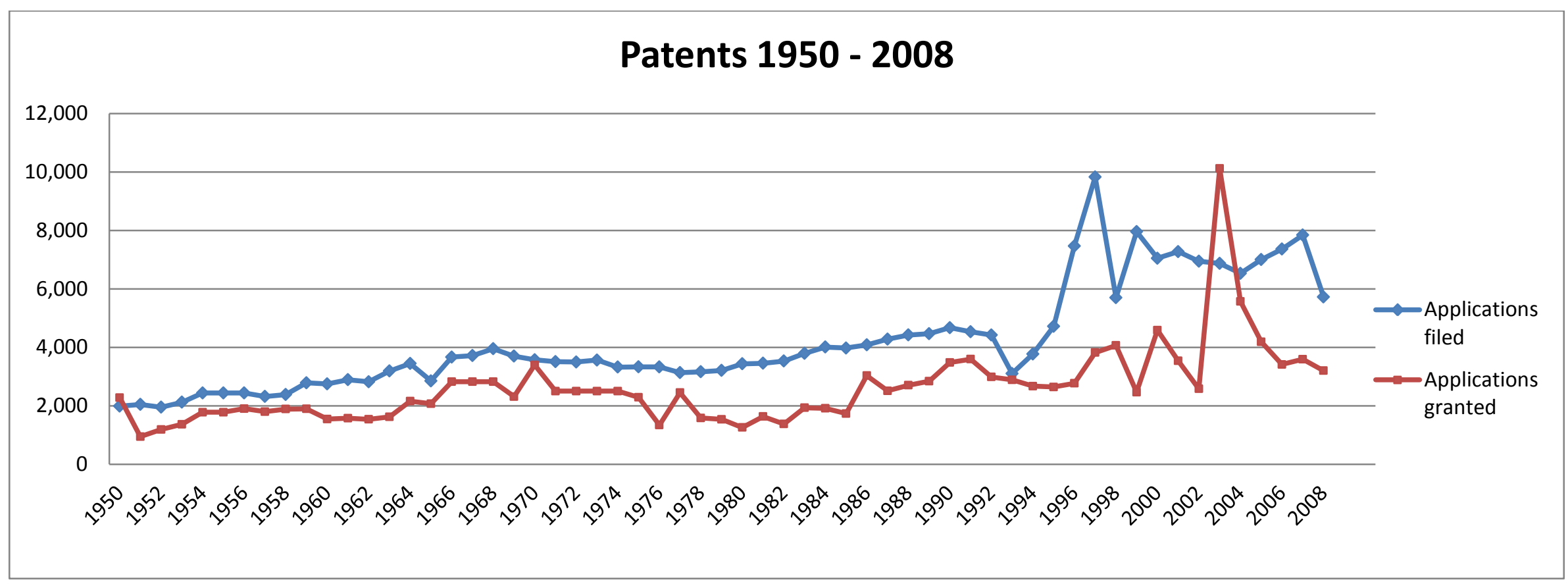


2.2 Trade Marks application and registration 1950-2008

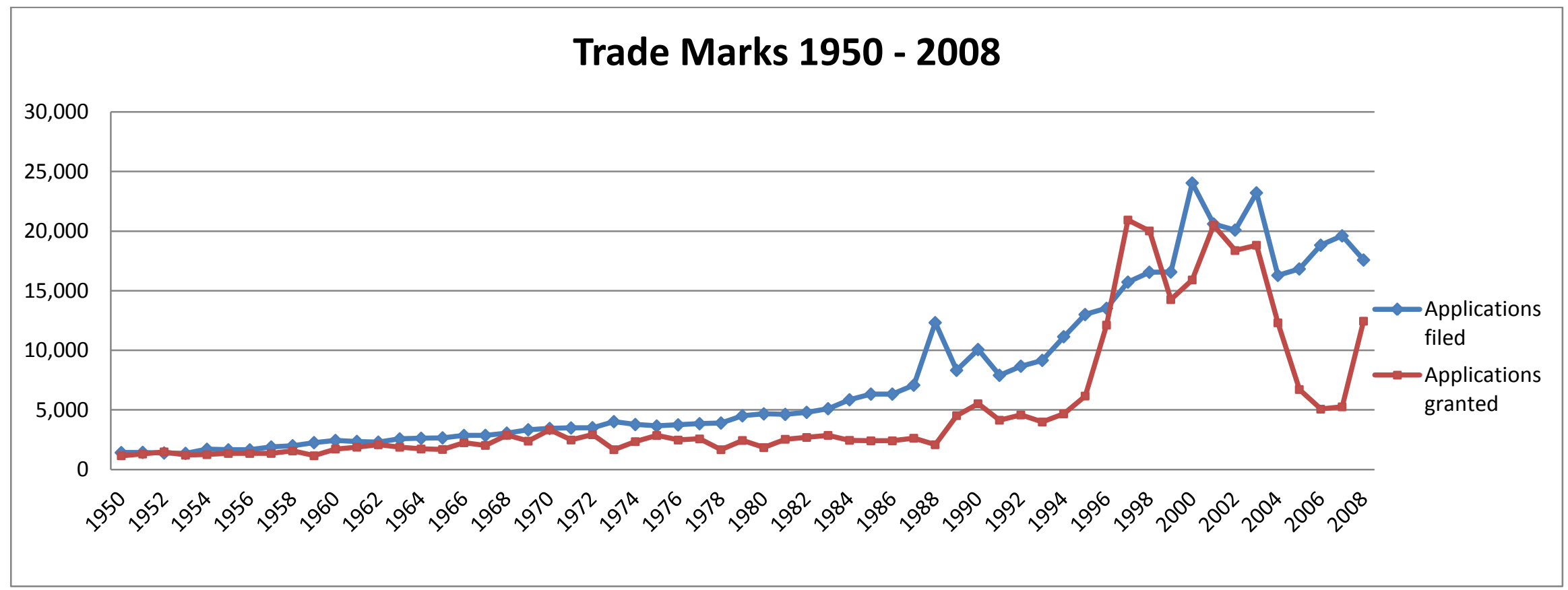


2.3 Design application and registration 1950-2008

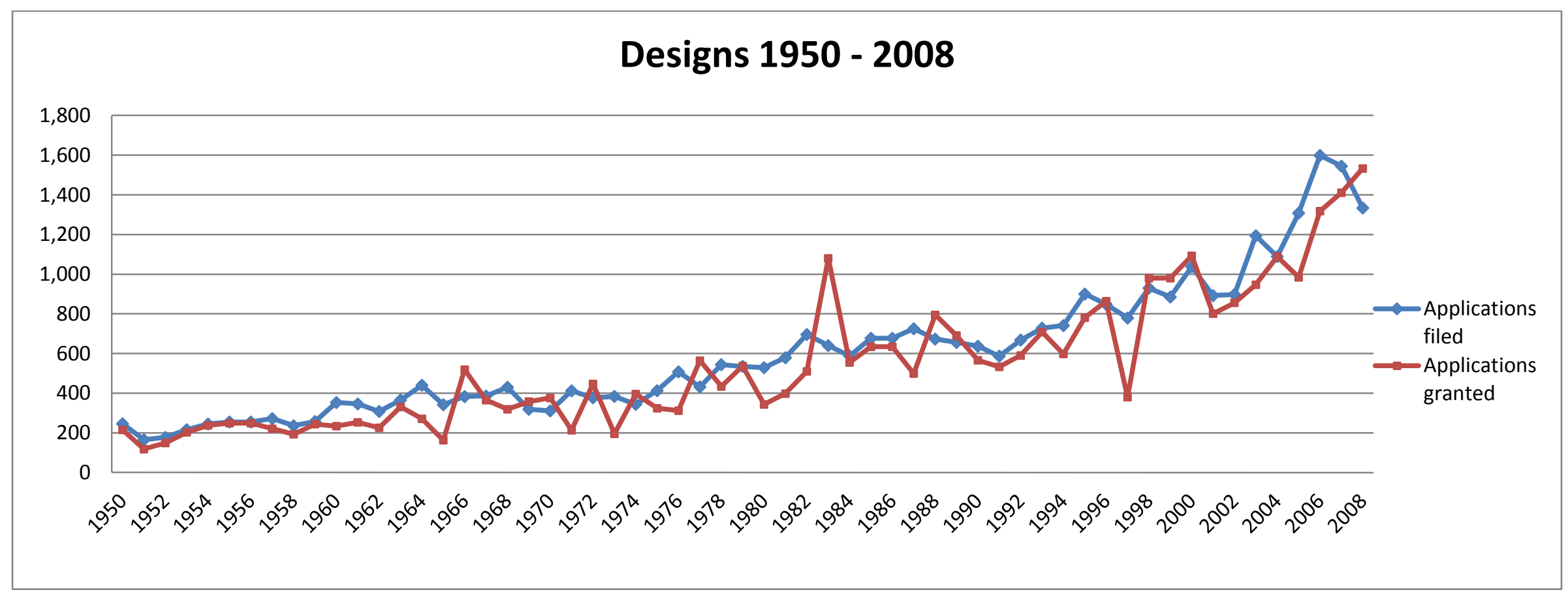


2.4 Plant Variety Rights (PVR) application and registration 1975-2008

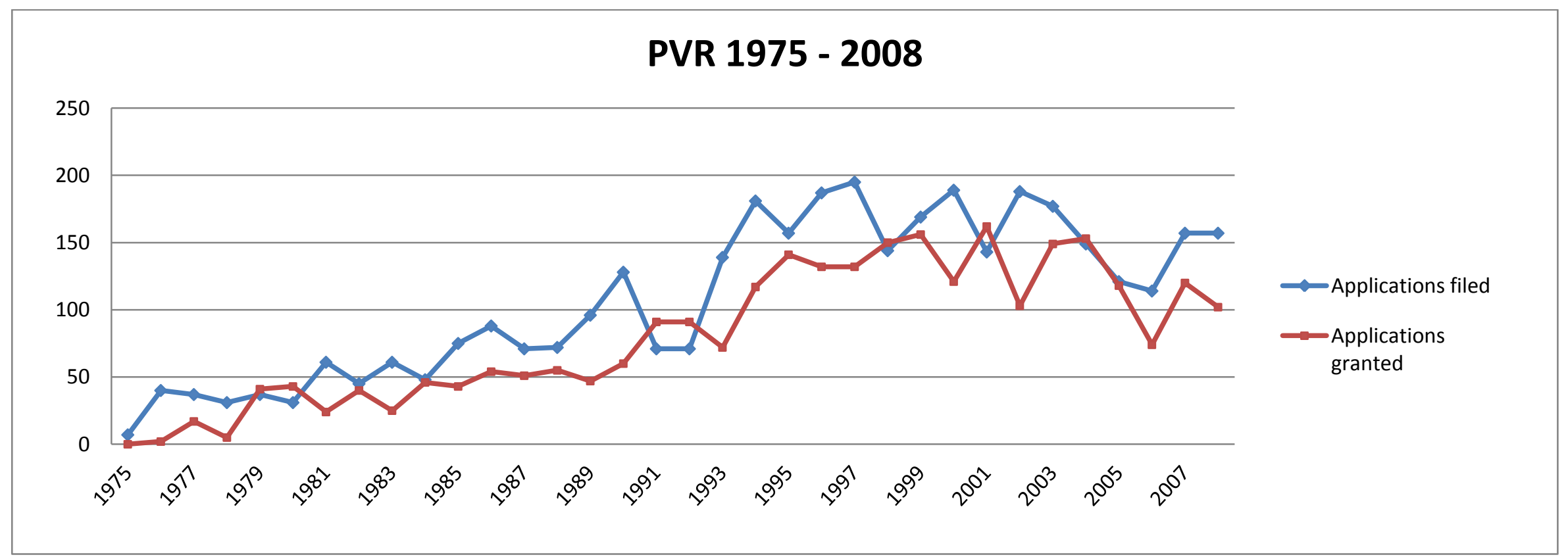


2.5 Combined IP application and registration 1950-2008

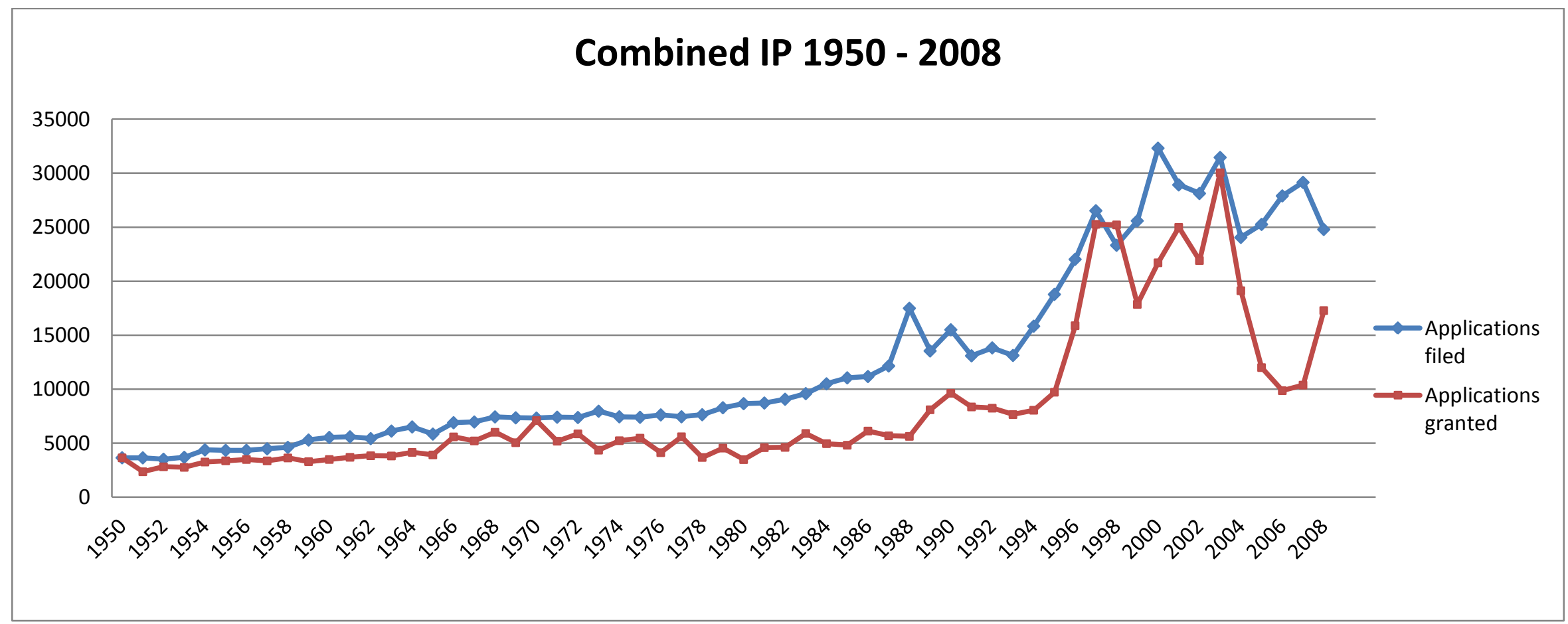




\subsection{Summary of IPONZ goal achievement}

\subsection{Year 2000-2010}

\begin{tabular}{|c|c|c|c|c|c|c|c|c|c|c|c|c|c|c|c|c|c|c|c|c|c|}
\hline & \multicolumn{10}{|c|}{ CAPABIUTYY } & \multicolumn{6}{|c|}{ CONFIDENCE } & \multirow{2}{*}{\multicolumn{2}{|c|}{$\begin{array}{r}\text { CAPACITY } \\
\text { Journal } \\
\end{array}$}} & \multirow{3}{*}{ 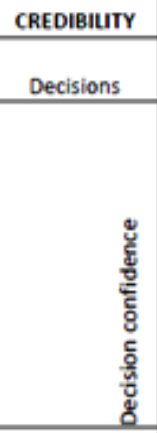 } & \multicolumn{2}{|c|}{ ACHIEVEMENT } \\
\hline Year & \multicolumn{2}{|c|}{ Patent } & \multicolumn{2}{|c|}{ Trade Marks } & \multicolumn{2}{|c|}{ Designs } & \multicolumn{2}{|c|}{$\begin{array}{l}\text { Plant Variety } \\
\text { Rights }\end{array}$} & \multicolumn{3}{|c|}{ Ministerial } & \multicolumn{5}{|c|}{ Notifications } & & & & Proportion & Percentage \\
\hline & 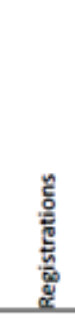 & 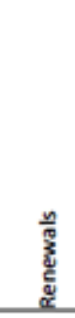 & 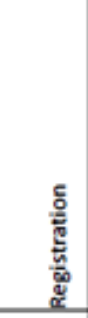 & 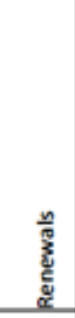 & 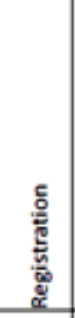 & 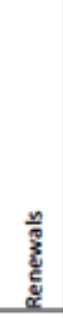 & 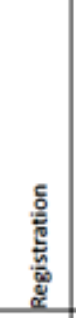 & 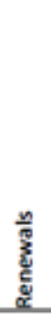 & 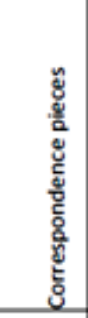 & 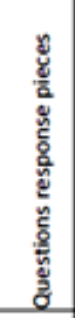 & 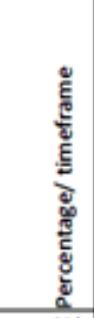 & 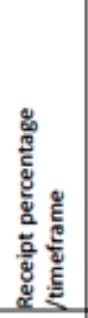 & 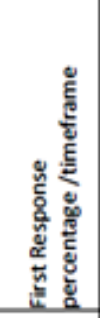 & 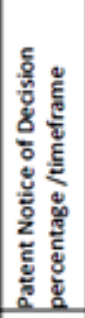 & 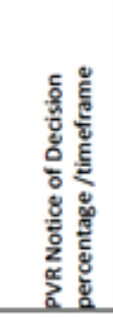 & 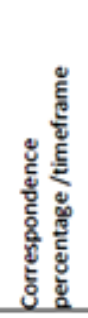 & 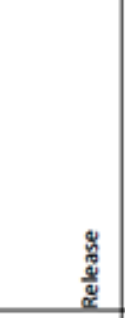 & 胥 & & 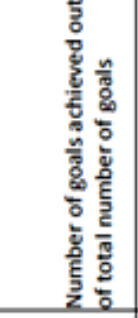 & 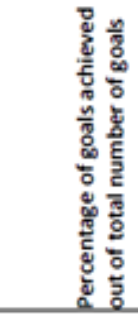 \\
\hline 2000 & 4500 & & 15000 & & 800 & & 155 & & $0-5$ & $5-10$ & $\begin{array}{r}100 \% / \\
10 \\
\text { days } \\
\end{array}$ & & $\begin{array}{r}95 \% / \\
5 \text { days } \\
\end{array}$ & & $\begin{array}{r}98 \% / \\
\text { 4months }\end{array}$ & & & & & $6 / 9$ & $67 \%$ \\
\hline & 6286 & & 22771 & & 976 & & 185 & & 14 & 1 & $\begin{array}{r}93 \% / \\
10 \text { days }\end{array}$ & & $\begin{array}{l}46 \% / \\
5 \text { days }\end{array}$ & & $\begin{array}{r}100 \% / \\
\text { 4months }\end{array}$ & & & & & & \\
\hline 2001 & 6200 & & 22000 & & 940 & & 155 & & $30-40$ & $0-10$ & & & $\begin{array}{r}95 \% / \\
\text { Sdays } \\
\end{array}$ & & $\begin{array}{r}98 \% / 7 \\
\text { 4months } \\
\end{array}$ & & Monthly & & & $6 / 9$ & $67 \%$ \\
\hline & 6609 & & 22620 & & 886 & & 160 & & & & & & $\begin{array}{r}95 \% / \\
5 \text { days } \\
\end{array}$ & & $\begin{array}{r}100 \% / \\
\text { 4months }\end{array}$ & & Monthly & & & & \\
\hline 2002 & 6700 & & 25000 & & 1150 & & 160 & & $10-20$ & $0-10$ & & & $\begin{array}{r}95 \% / \\
5 \text { days } \\
\end{array}$ & & $\begin{array}{r}96 \% / \\
\text { 4months } \\
\end{array}$ & & Monthly & & & $4 / 9$ & $44 \%$ \\
\hline & 6718 & & 19173 & & 937 & & 165 & & & & & & $\begin{array}{r}99.8 \% / \\
5 \text { ddays } \\
\end{array}$ & & $\begin{array}{r}100 \% / \\
\text { 4months }\end{array}$ & & & & & & \\
\hline 2003 & 7388 & & 20128 & & 995 & & 160 & & & & & & $\begin{array}{r}5 \% / \\
\text { 5days } \\
\end{array}$ & & $\begin{array}{r}96 \% / \\
\text { 4months }\end{array}$ & & Monthly & & & $5 / 7$ & $71 \%$ \\
\hline & 6632 & & 21560 & & 919 & & 192 & & & & & & $\begin{array}{r}99 \% / \\
\text { Sdays }\end{array}$ & & $\begin{array}{r}100 \% / \\
\text { 4months }\end{array}$ & & Monthly & & & & \\
\hline 2004 & 6630 & 8600 & 21000 & 9310 & 930 & 600 & 160 & & & & & \begin{tabular}{|l|}
$98 \% /$ \\
1 day \\
\end{tabular} & & & $\begin{array}{r}96 \% / \\
\text { 4months } \\
\end{array}$ & & Monthly & $98 \%$ & & $7 / 11$ & $64 \%$ \\
\hline & 6334 & 9283 & 25687 & 9430 & 1336 & 634 & 143 & & & & & $\begin{array}{l}98 \% / \\
1 \text { day } \\
\end{array}$ & & & $\begin{array}{r}92 \% / \\
\text { 4months } \\
\end{array}$ & & Monthly & & & & \\
\hline
\end{tabular}




\subsection{Year 2000-2010 (Continued)}

\begin{tabular}{|c|c|c|c|c|c|c|c|c|c|c|c|c|c|c|c|c|c|c|c|c|c|}
\hline \multirow{3}{*}{ Year } & \multicolumn{11}{|c|}{ CAPABIUTY } & \multicolumn{5}{|c|}{ CONFIDENCE } & \multirow{2}{*}{\multicolumn{2}{|c|}{\begin{tabular}{|c|} 
CAPACITY \\
Journal
\end{tabular}}} & \multirow{3}{*}{ 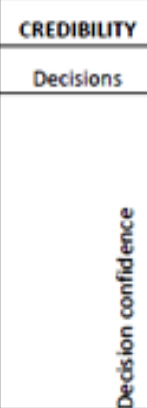 } & \multicolumn{2}{|c|}{ ACHIEVEMENT } \\
\hline & \multicolumn{2}{|c|}{ Patent } & \multicolumn{2}{|c|}{ Trade Marks } & \multicolumn{2}{|c|}{ Designs } & \multicolumn{3}{|c|}{ Plant Variety Rights } & \multicolumn{3}{|c|}{ Ministerial } & \multicolumn{4}{|c|}{ Notifications } & & & & \multirow[b]{2}{*}{ 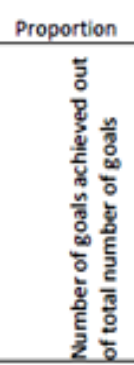 } & \multirow[b]{2}{*}{ 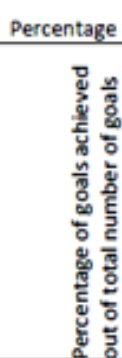 } \\
\hline & 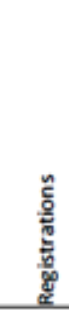 & 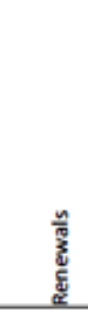 & 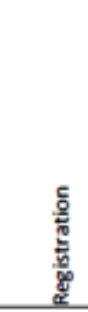 & 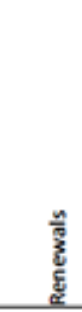 & 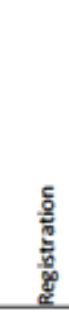 & 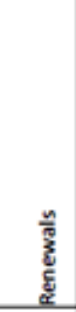 & 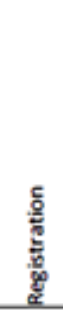 & 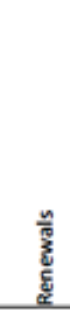 & 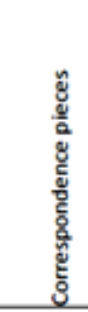 & 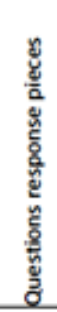 & 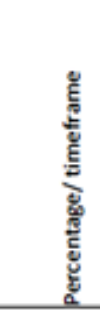 & 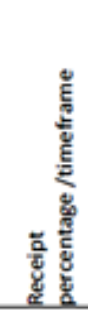 & 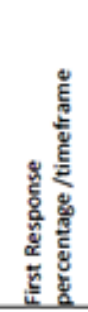 & 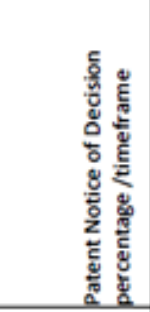 & 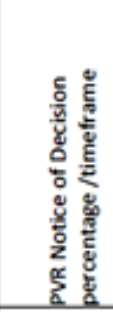 & 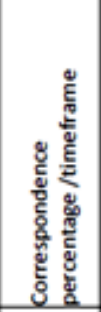 & 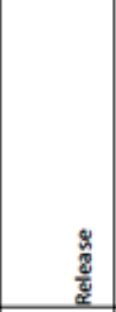 & 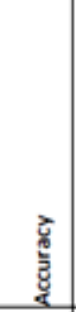 & & & \\
\hline 2005 & 5300 & 9300 & 23200 & 10700 & 1200 & 730 & 155 & 940 & & & & $\begin{array}{l}98 \% / / \\
1 \text { day }\end{array}$ & & & $\begin{array}{r}96 \% / \\
\text { 4months }\end{array}$ & & Monthly & $98 \%$ & & $8 / 12$ & $67 \%$ \\
\hline & 5585 & 9134 & 27937 & 10014 & 1321 & 775 & 148 & 1151 & & & & $\begin{array}{c}100 \% / \\
1 \text { day }\end{array}$ & & & & & Monthly & $98 \%$ & & & \\
\hline 2006 & 5500 & 8100 & 24000 & 10400 & 1200 & 610 & 155 & 1000 & & & & $\begin{array}{l}98 \% / / \\
1 d a y\end{array}$ & & & & & & & $99 \%$ & $9 / 10$ & $90 \%$ \\
\hline & 6232 & 9836 & 30691 & 11071 & 1448 & 752 & 99 & 1148 & & & & $\begin{array}{l}99 \% / \\
1 \text { day }\end{array}$ & & & & & & & $99 \%$ & & \\
\hline 2007 & 5500 & 9700 & 29100 & 10800 & 1200 & 670 & 155 & 1000 & & & & $\begin{array}{l}98 \% / \\
1 \text { day }\end{array}$ & & & & & & & $99 \%$ & $8 / 10$ & $80 \%$ \\
\hline & 6984 & 10040 & 35730 & 13229 & 1487 & 786 & 150 & 911 & & & & $\begin{array}{l}99 \% / \\
1 d a y \\
\end{array}$ & & & & & & & $99 \%$ & & \\
\hline 2008 & 5500 & 9700 & 29600 & 11200 & 1200 & 680 & 150 & 960 & & & & $\begin{array}{l}98 \% / \\
1 \text { day }\end{array}$ & $\begin{array}{l}95 \% / \\
5 \text { days }\end{array}$ & $\begin{array}{r}95 \% / \\
20 \text { days }(\mathrm{PCT}) \\
\end{array}$ & & \begin{tabular}{|r|}
$90 \% /$ \\
15 days \\
\end{tabular} & & & $99 \%$ & $10 / 13$ & $80 \%$ \\
\hline & 7403 & 10109 & 36509 & 13529 & 1372 & 719 & 145 & 1086 & & & & $\begin{array}{l}99 \% / \\
1 \text { day }\end{array}$ & $\begin{array}{l}\text { 96\%/ } \\
\text { 5days }\end{array}$ & $\begin{array}{r}41 \% / \\
20 \text { days }(\mathrm{PCT}) \\
\end{array}$ & & $\begin{array}{r}41 \% / \\
15 \text { days } \\
\end{array}$ & & & $99-100 \%$ & & \\
\hline 2009 & 5500 & 9700 & 29600 & 11200 & 1200 & 680 & 150 & 960 & & & & $\begin{array}{l}98 \% / \\
1 \text { day }\end{array}$ & $\begin{array}{l}95 \% / \\
5 \text { days }\end{array}$ & $\begin{array}{r}95 \% / \\
20 \text { days (St) } \\
\end{array}$ & & $\begin{array}{r}90 \% / \\
15 \text { days } \\
\end{array}$ & & & $99 \%$ & $11 / 13$ & $85 \%$ \\
\hline & 6001 & 9714 & 29720 & 13922 & 1273 & 1148 & 134 & 876 & 62788 & & & $\begin{array}{l}98 \% / \\
1 \text { day }\end{array}$ & $\begin{array}{l}95 \% / \\
\text { 5days }\end{array}$ & $\begin{array}{r}95 \% / \\
20 \text { days (st) } \\
\end{array}$ & & $\begin{array}{r}90 \% / \\
15 \text { days } \\
\end{array}$ & & & $99 \%$ & & \\
\hline 2010 & 5500 & 9100 & 29600 & 11200 & 1200 & 680 & 130 & 900 & & & $\begin{array}{r}100 \% / \\
10 \text { days }\end{array}$ & $\begin{array}{l}98 \% / \\
1 \text { day }\end{array}$ & $\begin{array}{l}95 \% / \\
5 \text { days }\end{array}$ & $\begin{array}{r}95 \% / \\
20 \text { days (St) } \\
\end{array}$ & & $\begin{array}{r}90 \% / \\
15 \text { days } \\
\end{array}$ & & & $99 \%$ & $14 / 14$ & $100 \%$ \\
\hline & 6084 & 9789 & 30848 & 12024 & 1208 & 948 & 154 & 988 & 62043 & & $\begin{array}{r}100 \% / \\
10 \text { days }\end{array}$ & $\begin{array}{r}99.8 \% / \\
1 \text { day }\end{array}$ & $\begin{array}{l}99 \% / \\
5 \text { days }\end{array}$ & $\begin{array}{r}99 \% / \\
20 \text { days (St) }\end{array}$ & & $\begin{array}{r}95 \% / \\
15 \text { days }\end{array}$ & & & $99.90 \%$ & & \\
\hline
\end{tabular}




\subsection{Summary of IPONZ Business Plan 2009-2013}

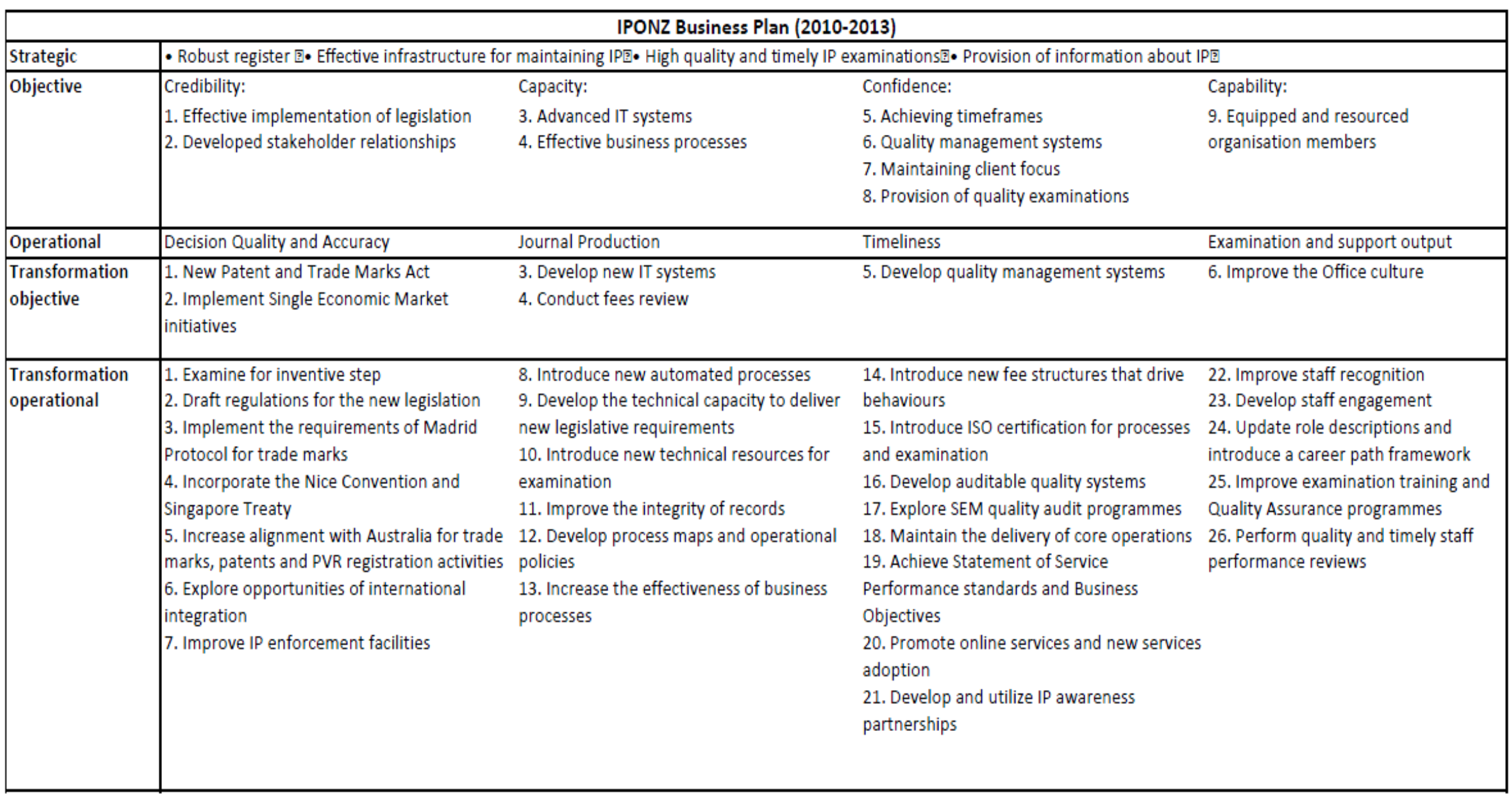


3.3 IPONZ Business Plan goal achievement 2009-2010

\begin{tabular}{|c|c|c|c|c|c|c|c|}
\hline \multicolumn{5}{|c|}{ GOALS } & \multicolumn{3}{|c|}{ GOAL ACHIEVEMENT } \\
\hline & Objectives & Operational & Transformation Objectives & Transformation Operational & Operational Goals Achievement & $\begin{array}{l}\text { Achievement } \\
\text { Proportion }\end{array}$ & $\begin{array}{l}\text { Achievemen } \\
\text { Percentage }\end{array}$ \\
\hline Credibility: & \begin{tabular}{|l|} 
1. Effective \\
implementation of \\
legislation \\
2. Developed stakeholder \\
relationships
\end{tabular} & $\begin{array}{l}\text { Decision } \\
\text { Quality and } \\
\text { Accuracy }\end{array}$ & $\begin{array}{l}\text { 1. New Patent and Trade } \\
\text { Marks Act } \\
\text { 2. Implement Single } \\
\text { Economic Market initiatives }\end{array}$ & $\begin{array}{l}\text { 1. Examine for inventive step } \\
\text { 2. Draft regulations for the new legislation } \\
\text { 3. Implement the requirements of Madrid Protocol for } \\
\text { trade marks } \\
\text { 4. Incorporate the Nice Convention and Singapore Treaty } \\
\text { 5. Increase alignment with Australia for trade marks, } \\
\text { patents and PVR registration activities } \\
\text { 6. Explore further opportunities of international } \\
\text { integration } \\
\text { 7. Improve IP enforcement facilities }\end{array}$ & $\begin{array}{l}\text { 3. Requirements for Madrid Protocol } \\
\text { introduced } \\
\text { 4. Nice Convention and Singapore } \\
\text { Treaty Introduced } \\
\text { 5. SEM alignment for trade marks and } \\
\text { patent attorney registration introduced }\end{array}$ & $3 / 7$ & $43 \%$ \\
\hline Capacity: & $\begin{array}{l}\text { 3. Advanced IT systems } \\
\text { 4. Effective business } \\
\text { processes }\end{array}$ & $\begin{array}{l}\text { Journal } \\
\text { Production }\end{array}$ & $\begin{array}{l}\text { 3. Develop new IT systems } \\
\text { 4. Conduct fees review }\end{array}$ & $\begin{array}{l}\text { 8. Introduce new automated processes } \\
\text { 9. Develop the technical capacity to deliver new } \\
\text { legislative requirements } \\
\text { 10. Introduce new technical resources for examination } \\
\text { 11. Improve the integrity of records } \\
\text { 12. Develop process maps and operational policies } \\
\text { 13. Increase the effectiveness of business processes }\end{array}$ & $\begin{array}{l}\text { 8. New automated searches introduced } \\
\text { 9. New database being built for } \\
\text { introduction in } 2012 \\
\text { 10. New search tool (Acsepto) } \\
\text { introduced } \\
\text { 12. Process maps developed }\end{array}$ & $4 / 6$ & $67 \%$ \\
\hline Confidence: & $\begin{array}{l}\text { 5. Achieving timeframes } \\
\text { 6. Quality management } \\
\text { systems } \\
\text { 7. Maintaining cllent } \\
\text { focus } \\
\text { 8. Provision of quality } \\
\text { examinations }\end{array}$ & Timeliness & $\begin{array}{l}\text { 5. Develop quality } \\
\text { management systems }\end{array}$ & $\begin{array}{l}\text { 14. Introduce new fee structures that drive behaviours } \\
\text { 15. Introduce ISO certification for processes and } \\
\text { examination } \\
\text { 16. Develop auditable quality systems } \\
\text { 17. Explore SEM quality audit programmes } \\
\text { 18. Maintain the delivery of core operations } \\
\text { 19. Achleve Statement of Service Performance (SSP) } \\
\text { standards and Business Objectives } \\
\text { 20. Promote online services and new services adoption } \\
\text { 21. Develop and utilize IP awareness partnerships }\end{array}$ & $\begin{array}{l}\text { 15. ISO certification introduced } \\
\text { 16. Quality management systems } \\
\text { introduced } \\
\text { 18. Maintained "business as usual" } \\
\text { 19. Exceeded SSPs in } 2009 \text { and } 2010 \\
\text { 20. Online service adoption promoted } \\
\text { 21. IP awareness partnerships built } \\
\text { within the education system, and with } \\
\text { prominent New Zealand inventors } \\
\text { (IPONZ, 2010). }\end{array}$ & $6 / 8$ & $75 \%$ \\
\hline Capabality: & $\begin{array}{l}\text { 9. Equipped and } \\
\text { resourced organisation } \\
\text { members }\end{array}$ & $\begin{array}{l}\text { Examination } \\
\text { and Support } \\
\text { output }\end{array}$ & $\begin{array}{l}\text { 6. Improve the Office } \\
\text { culture }\end{array}$ & $\begin{array}{l}\text { 22. Improve staff recognition } \\
\text { 23. Develop staff engagement } \\
\text { 24. Update role descriptions and introduce a career path } \\
\text { framework } \\
\text { 25. Improve examination training and Quality Assurance } \\
\text { programmes } \\
\text { 26. Perform quality and timely staff performance reviews }\end{array}$ & $\begin{array}{l}\text { 22. New compensation structures } \\
\text { 23. Social participation initiatives } \\
\text { introduced } \\
\text { 24. Revised work structures include } \\
\text { new roles } \\
\text { 26. Staff performance reviews } \\
\text { periodically conducted }\end{array}$ & $4 / 5$ & $80 \%$ \\
\hline
\end{tabular}




\subsection{Goal Achievement Percentages}

\begin{tabular}{|r|r|r|}
\hline \multicolumn{1}{|l|}{ Year } & $\begin{array}{l}\text { Achievement } \\
\text { Proportion }\end{array}$ & $\begin{array}{l}\text { Percentage } \\
\text { Achievement }\end{array}$ \\
\hline $\mathbf{2 0 0 0}$ & $6 / 9$ & $67 \%$ \\
\hline $\mathbf{2 0 0 1}$ & $6 / 9$ & $67 \%$ \\
\hline $\mathbf{2 0 0 2}$ & $\mathbf{4} 9$ & $44 \%$ \\
\hline $\mathbf{2 0 0 3}$ & $5 / 7$ & $71 \%$ \\
\hline $\mathbf{2 0 0 4}$ & $7 / 11$ & $64 \%$ \\
\hline $\mathbf{2 0 0 5}$ & $8 / 12$ & $67 \%$ \\
\hline $\mathbf{2 0 0 6}$ & $9 / 10$ & $90 \%$ \\
\hline $\mathbf{2 0 0 7}$ & $8 / 10$ & $80 \%$ \\
\hline $\mathbf{2 0 0 8}$ & $10 / 13$ & $80 \%$ \\
\hline $\mathbf{2 0 0 9}$ & $11 / 13$ & $85 \%$ \\
\hline $\mathbf{2 0 1 0}$ & $14 / 14$ & $100 \%$ \\
\hline
\end{tabular}

- Achievement proportion is the number of goals that were achieved, out of the total number of quantitative goals in that year

- Achievement percentage is the calculated percentage of the number of goals achieved, out of the total number of quantitative goals in that year 


\subsection{Summary of analysis}

\subsection{Ranking of data within categories}

\begin{tabular}{|c|c|c|c|c|c|c|}
\hline Theme Category & Codes & Code definitions & $\begin{array}{l}\text { No. of } \\
\text { sources }\end{array}$ & $\begin{array}{l}\text { No. of } \\
\text { units } \\
\text { coded }\end{array}$ & $\begin{array}{l}\text { Category } \\
\text { Ranking by } \\
\text { sources }\end{array}$ & \begin{tabular}{|l} 
Category \\
Ranking by \\
units
\end{tabular} \\
\hline \multirow[t]{8}{*}{$\begin{array}{l}\text { Aspects of the } \\
\text { organisation }\end{array}$} & DT.A.1 & $\begin{array}{l}\text { Issues related to governance, carried out by the managers, } \\
\text { commissioners and MED officials }\end{array}$ & 8 & 16 & 7 & 7 \\
\hline & DT.A.2 & Clients of the organisation & 12 & 38 & 4 & 4 \\
\hline & DT.A.3 & Issues related to client services & 14 & 56 & 1 & $2=$ \\
\hline & DT.A.4 & Identified operational processes & 13 & 83 & $2=$ & 1 \\
\hline & DT.A.5 & Employee and employment related issues & 13 & 56 & $2=$ & $2=$ \\
\hline & DT.A.6 & Issues related to IPONZ reputation and image & 5 & 10 & 8 & 8 \\
\hline & DT.A.7 & Legislation and legislative developments & 11 & 34 & 5 & 5 \\
\hline & DT.A.8 & IT systems and technical facilities & 9 & 21 & 6 & 6 \\
\hline \multirow[t]{10}{*}{ Goal focus } & DT.B.1 & Development of Information Technology and Communication & 17 & 35 & 2 & 5 \\
\hline & DT.B.2 & Clearing backlog files & 5 & 14 & 10 & 9 \\
\hline & DT.B.3 & Improving processes & 15 & 59 & $4=$ & 3 \\
\hline & DT.B.4 & $\begin{array}{l}\text { Improving the structure of teams and the arrangement of } \\
\text { work }\end{array}$ & 12 & 32 & 6 & 6 \\
\hline & DT.B.5 & Improving resources available to staff & 19 & 73 & 1 & 2 \\
\hline & DT.B.6 & Establishing formal systems of management & 5 & 11 & 9 & 10 \\
\hline & DT.B.7 & Improving organisational culture & 10 & 24 & 7 & 7 \\
\hline & DT.B.8 & Improving legislation and the legal jurisdiction of the Office & 9 & 15 & 8 & 8 \\
\hline & DT.B.9 & Timely processing of work & 15 & 51 & $4=$ & 4 \\
\hline & DT.B.10 & Increase service quality & 16 & 84 & 3 & 1 \\
\hline \multirow{3}{*}{$\begin{array}{l}\text { Perceptions of } \\
\text { innovation }\end{array}$} & DT.C.1 & Descriptions of what innovation is & 20 & 90 & $1=$ & 2 \\
\hline & DT.C.2 & List of innovations implemented at IPONZ & 20 & 108 & $1=$ & 1 \\
\hline & DT.C.3 & Perceptions of the most significant innovations & 11 & 14 & 3 & 3 \\
\hline \multirow{2}{*}{$\begin{array}{l}\text { Perceptions of } \\
\text { goals }\end{array}$} & DT.D.1 & Descriptions of what goals are & 21 & 169 & $1=$ & 1 \\
\hline & DT.D.2 & Descriptions of how goals are used & 21 & 154 & $1=$ & 2 \\
\hline \multirow{6}{*}{$\begin{array}{l}\text { Descriptions of } \\
\text { change }\end{array}$} & DT.E.1 & List of changes implemented & 22 & 187 & $1=$ & 3 \\
\hline & DT.E.2 & Description of how changes were implemented & 21 & 199 & $3=$ & 2 \\
\hline & DT.E.3+ & Description of the positive effects of implementing changes & 22 & 235 & $1=$ & 1 \\
\hline & DT.E.3- & Description of the negative effects of implementing changes & 17 & 69 & 5 & 5 \\
\hline & DT.E.4+ & Description of positive effects of NOT implementing changes & 7 & 19 & 6 & 6 \\
\hline & DT.E.4- & Description of negative effects of NOT implementing changes & 21 & 143 & $3=$ & 4 \\
\hline \multirow{3}{*}{$\begin{array}{l}\text { Descriptions of } \\
\text { Ideal Final Result } \\
\text { (IFR) }\end{array}$} & LC.D.1 & List of IFR & 19 & 56 & 1 & 1 \\
\hline & LC.D.2 & Percieved benefits of IFR & 12 & 24 & 2 & 2 \\
\hline & LC.D.3 & Percieved set-backs in reaching IFR & 11 & 17 & 3 & 3 \\
\hline
\end{tabular}




\subsection{Overall ranking of data by number of sources}

\begin{tabular}{|c|c|c|c|}
\hline Code & Code Description & $\begin{array}{l}\text { Number of } \\
\text { sources }\end{array}$ & $\begin{array}{l}\text { Overall } \\
\text { Ranking by } \\
\text { sources }\end{array}$ \\
\hline DT.E.1 & List of changes implemented & 22 & $1=$ \\
\hline DT.E.3+ & Description of the positive effects of implementing changes & 22 & $1=$ \\
\hline DT.D.1 & Descriptions of what goals are & 21 & $3=$ \\
\hline DT.D.2 & Descriptions of how goals are used & 21 & $3=$ \\
\hline DT.E.2 & Description of how changes were implemented & 21 & $3=$ \\
\hline DT.E.4- & $\begin{array}{l}\text { Description of negative effects of NOT implementing } \\
\text { changes }\end{array}$ & 21 & $3=$ \\
\hline DT.C.1 & Descriptions of what innovation is & 20 & $7=$ \\
\hline DT.C.2 & List of innovations implemented at IPONZ & 20 & $7=$ \\
\hline DT.B.5 & Improving resources available to staff & 19 & $9=$ \\
\hline LC.D.1 & List of IFR & 19 & $9=$ \\
\hline DT.B.1 & $\begin{array}{l}\text { Development of Information Technology and } \\
\text { Communication }\end{array}$ & 17 & $11=$ \\
\hline DT.E.3- & $\begin{array}{l}\text { Description of the negative effects of implementing } \\
\text { changes }\end{array}$ & 17 & $11=$ \\
\hline DT.B.10 & Increase service quality & 16 & 13 \\
\hline DT.B.3 & Improving processes & 15 & $14=$ \\
\hline DT.B.9 & Timely processing of work & 15 & $14=$ \\
\hline DT.A.3 & Issues related to client services & 14 & 16 \\
\hline DT.A.4 & Identified operational processes & 13 & $17=$ \\
\hline DT.A.5 & Employee and employment related issues & 13 & $17=$ \\
\hline DT.A.2 & Clients of the organisation & 12 & $19=$ \\
\hline DT.B.4 & $\begin{array}{l}\text { Improving the structure of teams and the arrangement of } \\
\text { work }\end{array}$ & 12 & $19=$ \\
\hline LC.D.2 & Percieved benefits of IFR & 12 & $19=$ \\
\hline DT.A.7 & Legislation and legislative developments & 11 & $22=$ \\
\hline DT.C.3 & Perceptions of the most significant innovations & 11 & $22=$ \\
\hline LC.D.3 & Percieved set-backs in reaching IFR & 11 & $22=$ \\
\hline DT.B.7 & Improving organisational culture & 10 & 25 \\
\hline DT.A.8 & IT systems and technical facilities & 9 & $26=$ \\
\hline DT.B.8 & Improving legislation and the legal jurisdiction of the Office & 9 & $26=$ \\
\hline DT.A.1 & $\begin{array}{l}\text { Issues related to governance, carried out by the managers, } \\
\text { commissioners and MED officials }\end{array}$ & 8 & 28 \\
\hline DT.E.4+ & $\begin{array}{l}\text { Description of positive effects of NOT implementing } \\
\text { changes }\end{array}$ & 7 & 29 \\
\hline DT.A.6 & Issues related to IPONZ reputation and image & 5 & $30=$ \\
\hline DT.B.2 & Clients of the organisation & 5 & $30=$ \\
\hline DT.B.6 & Issues related to IPONZ reputation and image & 5 & $30=$ \\
\hline
\end{tabular}




\subsection{Overall ranking of data by number of units coded}

\begin{tabular}{|c|c|c|c|}
\hline Code & Code Description & $\begin{array}{l}\text { Number of } \\
\text { units }\end{array}$ & $\begin{array}{l}\text { Overall } \\
\text { Ranking by } \\
\text { units }\end{array}$ \\
\hline DT.E.3+ & Description of the positive effects of implementing changes & 235 & 1 \\
\hline DT.E.2 & Description of how changes were implemented & 199 & 2 \\
\hline DT.E.1 & List of changes implemented & 187 & 3 \\
\hline DT.D.1 & Descriptions of what goals are & 169 & 4 \\
\hline DT.D.2 & Descriptions of how goals are used & 154 & 5 \\
\hline DT.E.4- & $\begin{array}{l}\text { Description of negative effects of NOT implementing } \\
\text { changes }\end{array}$ & 143 & 6 \\
\hline DT.C.2 & List of innovations implemented at IPONZ & 108 & 7 \\
\hline DT.C.1 & Descriptions of what innovation is & 90 & 8 \\
\hline DT.B.10 & Increase service quality & 84 & 9 \\
\hline DT.A.4 & Identified operational processes & 83 & 10 \\
\hline DT.B.5 & Improving resources available to staff & 73 & 11 \\
\hline DT.E.3- & $\begin{array}{l}\text { Description of the negative effects of implementing } \\
\text { changes }\end{array}$ & 69 & 12 \\
\hline DT.B.3 & Improving processes & 59 & 13 \\
\hline DT.A.3 & Issues related to client services & 56 & $14=$ \\
\hline DT.A.5 & Employee and employment related issues & 56 & $14=$ \\
\hline LC.D.1 & List of IFR & 56 & $14=$ \\
\hline DT.B.9 & Timely processing of work & 51 & 17 \\
\hline DT.A.2 & Clients of the organisation & 38 & 18 \\
\hline DT.B.1 & $\begin{array}{l}\text { Development of Information Technology and } \\
\text { Communication }\end{array}$ & 35 & 20 \\
\hline DT.A.7 & Improving organisational culture & 34 & 21 \\
\hline DT.B.4 & $\begin{array}{l}\text { Improving the structure of teams and the arrangement of } \\
\text { work }\end{array}$ & 32 & 22 \\
\hline DT.B.7 & Improving organisational culture & 24 & $23=$ \\
\hline LC.D.2 & Percieved benefits of IFR & 24 & $23=$ \\
\hline DT.A.8 & IT systems and technical facilities & 21 & 25 \\
\hline DT.E.4+ & $\begin{array}{l}\text { Description of positive effects of NOT implementing } \\
\text { changes }\end{array}$ & 19 & 26 \\
\hline LC.D.3 & Percieved set-backs in reaching IFR & 17 & 27 \\
\hline DT.A.1 & $\begin{array}{l}\text { Issues related to governance, carried out by the managers, } \\
\text { commissioners and MED officials }\end{array}$ & 16 & 28 \\
\hline DT.B.8 & Improving legislation and the legal jurisdiction of the Office & 15 & 29 \\
\hline DT.B.2 & Clearing backlog files & 14 & $30=$ \\
\hline DT.C.3 & Perceptions of the most significant innovations & 14 & $30=$ \\
\hline DT.B.6 & Establishing formal systems of management & 11 & 31 \\
\hline DT.A.6 & Issues related to IPONZ reputation and image & 10 & 32 \\
\hline
\end{tabular}




\subsection{Summarizing IPONZ processes of management innovation}

\begin{tabular}{|c|c|c|c|c|}
\hline Management Innovation & Stimulation/Motivation & Conception and proposal/invention & Adoption/Implementation & Theorization and feedback \\
\hline Work and wage revision & High staff turnover & $\begin{array}{l}\text { Management exercise } \\
\text { Structural redrafting } \\
\text { New roles and pay system }\end{array}$ & $\begin{array}{l}\text { Gradual implementation } \\
\text { Incorporate changes into one team at a } \\
\text { time }\end{array}$ & $\begin{array}{l}\text { Employee satisfaction with career } \\
\text { progression and higher wage } \\
\text { opportunities } \\
\text { Expectations of lower turnover and } \\
\text { more positive employee attitudes }\end{array}$ \\
\hline $\begin{array}{l}\text { ISO accreditation with } \\
\text { process mapping }\end{array}$ & $\begin{array}{l}\text { Increasing the effectiveness of } \\
\text { management systems and knowledge } \\
\text { sharing } \\
\text { Improving the organsation's image }\end{array}$ & $\begin{array}{l}\text { Process mapping exercise } \\
\text { Developing quality management } \\
\text { systems }\end{array}$ & $\begin{array}{l}\text { Gradual implementation } \\
\text { Undergoing audits } \\
\text { Obtaining ISO certification }\end{array}$ & $\begin{array}{l}\text { Endorsing the use of quality } \\
\text { management systems throughout the } \\
\text { organisation } \\
\text { Promoting updates to the process map } \\
\text { to reflect improvement }\end{array}$ \\
\hline Change control system & $\begin{array}{l}\text { Improving the coordination of change } \\
\text { Providing systems for systematicaly } \\
\text { monitoring and evaluating changes }\end{array}$ & Remodelling an existing tool & $\begin{array}{l}\text { Extensive use by management } \\
\text { Extensive adoption throughout the } \\
\text { organisation }\end{array}$ & $\begin{array}{l}\text { Organisation-wide acceptance, inspite } \\
\text { of slight resistance }\end{array}$ \\
\hline $\begin{array}{l}\text { Articulating a formal business } \\
\text { plan/document }\end{array}$ & $\begin{array}{l}\text { Building unity across teams and team } \\
\text { managers } \\
\text { Increasing coordination of operations } \\
\text { Driving change initiatives }\end{array}$ & $\begin{array}{l}\text { Combined management effort to draft } \\
\text { document }\end{array}$ & $\begin{array}{l}\text { Organisation-wide distribution of } \\
\text { document and promotion by } \\
\text { management }\end{array}$ & $\begin{array}{l}\text { Little discussion among non- } \\
\text { management organisation members } \\
2 \text { out of } 6 \text { managers discuss } \\
\text { implications of the document }\end{array}$ \\
\hline $\begin{array}{l}\text { Patent Bill (novel changes in } \\
\text { examination process and fee } \\
\text { structure) }\end{array}$ & $\begin{array}{l}\text { Improving patentability } \\
\text { Higher international alignment }\end{array}$ & $\begin{array}{l}\text { Bill undergoing processes for } \\
\text { enactment }\end{array}$ & $\begin{array}{l}\text { Preparation to implement new } \\
\text { examination processes and fees } \\
\text { structure }\end{array}$ & Implementation not yet significant \\
\hline $\begin{array}{l}\text { Establishment of Business } \\
\text { Systems and Development } \\
\text { team }\end{array}$ & $\begin{array}{l}\text { Introduction of Project COMPASS } \\
\text { The need to drive continuous change } \\
\text { implementation }\end{array}$ & $\begin{array}{l}\text { Appointment of team members from } \\
\text { within IPONZ, and contracted } \\
\text { employees }\end{array}$ & $\begin{array}{l}\text { Defining team members roles and } \\
\text { project expectations } \\
\text { Managing performance }\end{array}$ & $\begin{array}{l}\text { Positive feedback from manager } \\
\text { Acceptance by other IPONZ divisions }\end{array}$ \\
\hline $\begin{array}{l}\text { SEM Trans-Tasman } \\
\text { Harmonization }\end{array}$ & $\begin{array}{l}\text { Integrating IP systems for higher } \\
\text { efficiency and legislative development }\end{array}$ & $\begin{array}{l}\text { Government introduction for } \\
\text { regulatory systems }\end{array}$ & $\begin{array}{l}\text { Gradual harmonization of trademarks, } \\
\text { then patents and designs, and patent } \\
\text { attorney registratoin services }\end{array}$ & $\begin{array}{l}\text { Positive client feedback if } \\
\text { implementation is successful } \\
\text { Negative client feedback if } \\
\text { implementation is not successful }\end{array}$ \\
\hline Call Centre & $\begin{array}{l}\text { Providing more accesible client } \\
\text { services }\end{array}$ & $\begin{array}{l}\text { Using a toll-free number to support } \\
\text { clients }\end{array}$ & $\begin{array}{l}\text { Employment of client services officers, } \\
\text { now managed externally }\end{array}$ & $\begin{array}{l}\text { Positive feedback from clients } \\
\text { Supports IPONZ by detracting work }\end{array}$ \\
\hline
\end{tabular}




\title{
6.0 Data collection information \\ 6.1 IPONZ letter of request to participate in research
}

\author{
Addressee \\ Intellectual Property Office of New Zealand \\ 205 Victoria Street \\ Wellington
}

\section{REQUEST FOR THE PARTICIPATION OF IPONZ IN A RESEARCH ENDEAVOUR}

Dear

My name is Ama Momoh from Victoria University of Wellington. Currently undergoing a Master of Commerce and Administration in Management, I have chosen to carry out a case study on goal setting and management innovation at the Intellectual Property Office of New Zealand (IPONZ). Approval has been granted by a Human Ethics Committee to conduct this research study, as it will make up the course requirements for completing a Master's Thesis program.

From 2009 to 2010 I was employed at IPONZ as a temporary staff member in the Business Support team, and have come to understand the workings of the agency. New Zealand is recognized as a country full of innovative entrepreneurs, some of whose ideas have been turned into products that are used worldwide. As the agency in charge of registering the intellectual property rights for these ideas and helping to promote innovative business, it is useful to examine the past and present innovativeness of business practices within IPONZ itself.

The research will aim at exploring the operational history of IPONZ, in the context of its legislative and regulatory framework. The report compiled at the end of the study will contribute significantly to existing research on the management of public sector organizations, particularly within New Zealand. With your permission, interviews can be conducted with you, the managers and some staff members at IPONZ. The information from these interviews will serve as primary data for the study. 
Accompanying this letter is an information sheet that will be given to all interviewees after your approval, explaining some important aspects of the research study. In addition they will also be given the attached consent form that provides information about the rights of the interviewees. Please confirm your approval for members of IPONZ to be interviewed by signing the agreement section at the end of this letter.

The participation of IPONZ will be of immeasurable value to this research endeavour, as well as to the management body of knowledge in IP and the public sector. Thank you in advance for your assistance and look forward to seeing you in the near future.

Please do not hesitate to contact me or my supervisor with any inquiries:

Researcher: Ama Momoh

Postgraduate Student

Victoria Management School

Mobile: 0274080666

Email: ama.momoh@vuw.ac.nz

Supervisor: Vicky Mabin

Associate Professor

Victoria Management School

DDI : 044635140

Email : vicky.mabin@vuw.ac.nz

I have read this letter requesting for the participation of IPONZ in this research endeavour, and approve the participation of IPONZ for the case study. I also agree to allow members of IPONZ to be interviewed in order for the primary researcher to collect information that will be used to make up a report for this research.

Name 


\subsection{Information Sheet}

\section{Information Sheet for Interview Participants}

\section{Preaching and Practising: A retrospective look at innovative developments in the administration of inventive property rights}

In preparation to complete a Master of Commerce and Administration (MCA) program, I have embarked on a year-long research project that explores the previous organisational developments of the Intellectual Property Office (IPONZ). Ethics approval has been granted to proceed with the project and I would like to conduct some interviews to collect primary data for the research study. The participation of members of IPONZ is entirely voluntary and there are no obligations for involvement.

New Zealand is recognized as a country full of innovative entrepreneurs, some of whose ideas have been turned into products that are used worldwide. The Government has established infrastructure to promote the development of successfully commercialized innovative ideas, and to encourage the innovativeness of businesses in New Zealand. As the agency in charge of registering the intellectual property rights for these ideas and helping to promote innovative business, it is useful to examine the innovativeness of business practices within the Intellectual Property Office of New Zealand itself.

The research is essentially a case study of IPONZ, and will aim at exploring the operational history of IPONZ, in the context of the regulatory framework within which it functions. This research will contribute significantly to existing research on the management of public sector organisations, particularly within New Zealand.

The past innovative developments of IPONZ will be examined using the management concept of goal setting, where previously set goals will be considered for any association with innovative practices implemented over the years.

The primary information used to conduct this research will be obtained through oneon-one interviews with managers and staff members of the Intellectual Property Office of New Zealand. I have been granted permission by the Group Manager, to conduct these interviews and they are expected to take between 45 minutes to 
1 hour to complete. The information collected from these interviews will be used by the researcher, who will be supervised by an academic staff member of Victoria University of Wellington, and records of it will be destroyed 3 years after the completion of the project.

The process and findings of this research will be written up in the form of a thesis report and/or used for possible publication in an academic journal. The report will be made available to the Intellectual Property Office of New Zealand, for the free viewing of all participants. In addition, a summary of sections of this report can be made available to the Office at the request of the Managers.

Because this is a case study of a unique organisation, it will be impossible for the organisation to remain anonymous in the final report. However if individual participants would prefer their identities to be confidential, it will not be disclosed in the final report. Specific information that is provided can also be kept confidential upon request, and the details of such information will not be disclosed. In addition, after the interviews have been conducted, participants will be allowed to withdraw themselves and the information they provided, in which case the information will be excluded from the data and records of it will be destroyed. The researcher should be informed of any requests to be withdrawn by the $10^{\text {th }}$ of May 2011 .

Thank you very much for your time and efforts in making this study possible. If you have any further inquiries please phone or email:

Researcher: Ama Momoh

Postgraduate Student

Victoria Management School

Mobile: 0274080666

Email: ama.momoh@vuw.ac.nz

Supervisor: Vicky Mabin

Associate Professor

Victoria Management School

Email : vicky.mabin@vuw.ac.nz

DDI : 044635140 


\subsection{Consent Form}

\section{Research Interviewees}

\section{Consent Form}

- I have read the Information Sheet about the research project and have had the details of the study explained to me. My questions about the study have been answered to my satisfaction, and I understand that I may ask further questions at any time.

- I also understand that I am free to withdraw from the interview or to decline to answer any particular questions in the study.

- I will inform the researcher of my desire to withdraw by the $10^{\text {th }}$ of May 2011 , and understand that in this case records of the information I provided will be destroyed.

- I also understand that a final report of the research project will be given to my organisation, and I am free to access this report when it is available.

I accept to be a participant in the interview for the research project specified in the information sheet, subject to the following preferences:

- I agree to the interview being digitally recorded. Yes No

- I would like my identity to be confidential in both the data collection and final reporting. However my position or role description will be used to refer to me in the report where necessary to place my comments into context.

Yes No

- I wish to be given a copy of the transcripts of the interview with me before the final report is released.

Yes No

- I agree to the use of the interview information in the publication or presentation of this research project.

Yes No 


\section{Participant:}

Signed:

Name:

Organisation:

Date:

\section{Researcher/s}

Signed:

Name:

Date: 


\subsection{Interview Questions}

\section{SEMI-STRUCTURED INTERVIEWS}

\section{Questions for staff members:}

1. What is your role at IPONZ?

2. How long have you worked for IPONZ?

3. What is innovation to you?

4. Do you think innovation is important for the way things get done at IPONZ?

5. Do you think goals have helped to get things done at IPONZ over the years?

6. Can you think of any goals that that have been used in the past, either for your team or for other teams or for the whole of IPONZ?

7. Have goals affected the way you did your own work in the past? Are there any specific circumstances you can recall to use as an example?

8. Do you think that IPONZ has innovative ways of providing services to clients?

9. Can you think of some innovative things you know that IPONZ has done and when were they introduced?

10. If there was innovation, do you think goals have helped IPONZ to get the innovation and use them in a way that actually made things better for both IPONZ and clients?

11. What do you think is the best thing for IPONZ to achieve with IP and clients?

12. Complete the following statement and please explain your answer:

"In a perfect world IPONZ would be able to. ." 
${ }^{5}$ For example:

"In a perfect world IPONZ would be able to grant all applications without objections or opposition. This will be because every prospective applicant will have perfect understanding of what they need to get intellectual property rights, and those who apply will be able to provide it"

13. Other than the fact that we are not in a perfect world, can you give me some specific reasons why that statement (from question 12) cannot happen?

14. Would you like to add anything else?

${ }^{5}$ The example statement in question 12 will only be used if the answer to the question is not conclusively given or the interviewee is unsure of what to answer. This example statement may also change during the interview depending on the answer provided for question 11. 


\section{UNSTRUCTURED INTERVIEWS}

\section{Questions for Managers:}

1. What is your role in the organisation?

2. How long have you worked for IPONZ?

3. What is innovation and is it used at IPONZ?

4. How have goals been used for managing performance?

5. Would you associate any previously set goals with any applied innovative methods at IPONZ?

6. What do you think is the best thing for IPONZ to achieve with IP and clients?

7. Complete the following statement and please explain your answer:

"In a perfect world IPONZ would be able to............"

${ }^{6}$ For example:

"In a perfect world IPONZ would be able to grant all applications without objections or opposition. This will be because every prospective applicant will have perfect understanding of what they need to get intellectual property rights, and those who apply will be able to provide it"

8. Other than the fact that we are not in a perfect world, can you give me some specific reasons why the statement (above) cannot be realized?

9. Would you like to add anything else?

\footnotetext{
${ }^{6}$ The example statement in question 7 will only be used if the answer to the question is not conclusively given or the interviewee is unsure of what to answer. This example statement may also change during the interview depending on the answer provided for question 6.
} 